Linköping Studies in Science and Technology

Dissertation, No. 1750

\title{
Grinding effects on surface integrity, flexural strength and contact damage resistance of coated hardmetals
}

\author{
Jing Yang
}

\author{
I..U U. \\ Nanostrutured Materials \\ Department of Physics, Chemistry and Biology (IFM) \\ Linköping University, Sweden
}

Part of

The Joint European Doctoral Programme in Materials Science and Engineering (DocMASE) in collaboration with

Structural Integrity and Reliability of Materials (CIEFMA)

Department of Materials Science and Metallurgical Engineering

Universitat Politècnica de Catalunya, Spain 
ISBN: 978-91-7685-809-7

ISSN: 0345-7524

Printed by LiU-Tryck

Linköping, Sweden 


\section{Abstract}

The tribological and mechanical behavior of coated tools depends not only on intrinsic properties of the deposited film but also on substrate surface and subsurface properties - such as topography and residual stress state - as well as on interface adhesion strength. It is particularly true in the case of coated tools based on WC-Co cemented carbides (backbone materials of the tool manufacturing industry, and simply referred to as hardmetals in practice) as substrates. Manufacturing of hardmetals often involves grinding, and in the case of cutting tools also edge preparation, etching and coating. The quality of the shaped components is influenced by how the surface integrity evolves through the different process steps. In this regard, substrate grinding and coating deposition represent key steps, as they are critical for defining the final performance and relative tool manufacturing cost. Within this framework, it is the main objective of this thesis to assess the influence of substrate surface integrity on different mechanical (flexural strength and contact damage resistance under spherical indentation) and tribological (scratch resistance as well as cracking and delamination response under Brale indentation) properties for a TiN-coated finegrained hardmetal grade (WC-13 wt.\%Co). In doing so, three different surface finish conditions are studied: as-sintered (AS), ground (G), and mirror-like polished (P). Moreover, aiming for an in-depth analysis of surface integrity evolution from grinding to coating, a relevant part of the work is devoted to document and understand changes induced by grinding in nude hardmetal substrates. The study is also extended to a fourth surface finish variant (GTT), corresponding to a ground substrate which is thermal annealed before being ion etched and coated. Because residual stress induced by grinding are effectively relieved after this high temperature thermal treatment, GTT condition allows to separate grinding-induced effects associated with surface texture and surface/subsurface damage changes (inherited from the G surface finish) from those related to the referred residual stresses.

Surface integrity was characterized in terms of roughness, residual stresses (prior and after coating deposition), and damage at the subsurface level. It was found that grinding induces significant alterations in the surface integrity of cemented carbides. Main changes included relevant roughness variations; emergence of a topographic texture; anisotropic distribution of microcracks within a subsurface layer of about 1 micron in depth; severe deformation, microstructure refinement and 
phase transformation of binder regions, down to 5 microns in depth; and large compressive residual stresses, gradually decreasing from the surface to baseline values at depths of about 10-12 microns.

Additional changes in surface integrity are induced during subsequent ion etching and coating deposition. In general, removal of material from the surface during sputter cleaning and extended low-temperature (during film deposition) treatment resulted in a significant residual stresses decrease (about half its original value). However, damage induced by grinding was not completely removed, and some microcracks were still left on the substrate surface (close to the interface). On the other hand, and as expected, high temperature annealing (GTT condition) resulted in a complete relief of the referred residual stresses, but without inducing any additional change in terms of existing microcracks and depth of damaged layer. This was not the case for the metallic binder phase where thermal treatment induced an unexpected microporosity, development of a recrystallized subgrain structure, and reversion of grinding-induced phase transformation.

Flexural strength was measured on both uncoated and coated hardmetals, and complemented with extensive fractographic analysis. It was found that grinding significantly enhances the strength of hardmetals, as compared to AS and P conditions. However, such beneficial effect was partly lost in the corresponding coated specimens. On the other hand, film deposition increases strength measured for GTT surface variant. These findings were analyzed on the basis of the changes on nature and location of critical flaws, induced by the effective residual stress field resulting at the surface and subsurface after each manufacturing stage.

The influence of substrate surface finish on scratch resistance of coated hardmetals and associated failure mechanisms was investigated. It was found that coated AS, G and P samples exhibit similar critical load for initial substrate exposure and the same brittle adhesive failure mode. However, damage scenario was discerned to be different. Substrate exposure was discrete and localized to the scratch tracks for $\mathrm{G}$ samples, while a more pronounced and continuous decohesion was seen for AS and P ones. Relieving of the substrate compressive residual stresses (GTT condition) yielded lower critical loads and changes in the mechanisms for the scratch-related failure, the latter depending on the relative orientation between scratching and grinding directions. 
The cracking and delamination of TiN-coated hardmetals when subjected to Brale indentation was studied while varying the microstructure and surface finish of the substrate. In this case, another fine-grained WC-Co cemented carbide with lower binder content (6 wt.\%Co) was included in the investigation. It was found that polished and coated hardmetals exhibit more brittleness (radial cracking) and lower adhesion strength (coating delamination) with decreasing binder content. Such a response is postulated on the basis of the influence of intrinsic hardness/brittleness of the hardmetal substrate on both cracking at the subsurface level and effective stress state, particularly regarding changes in shear stress component. On the other hand, grinding was discerned to promote delamination, compared to the polished condition, but strongly inhibits radial cracking. This was the result of the interaction between elastic-plastic deformation imposed during indentation and several grinding-induced effects: remnant compressive stress field, pronounced surface texture, and microcracking within a thin microcracked subsurface layer. It is then concluded that coating spallation prevails over radial cracking as the main mechanism for energy dissipation in ground and coated hardmetals.

Contact damage resistance of coated hardmetals with different substrate surface finish conditions was investigated by means of spherical indentation under increasing monotonic loads. It was found that grinding enhanced resistance against both crack nucleation at the coating surface and subsequent propagation into the hardmetal substrate. Hence, crack emergence and damage evolution was effectively delayed for the coated G condition, as compared to the reference P one. The observed system response was discussed on the basis of the beneficial effects associated with compressive residual stresses remnant at the subsurface level after grinding, ion-etching and coating. The influence of the stress state was further corroborated by the lower contact damage resistance exhibited by the coated GTT specimens. Finally, differences observed on the interaction between indentation-induced damage and failure mode under flexural testing pointed in the direction that substrate grinding also enhances damage tolerance of the coated system when exposed to contact loads. 



\section{Populärvenskaplig Sammanfattning}

I strävan att optimera valet av material för specifika applikationer, har intensiv forskning lagts på att studera sambandet mellan kemi, mikrostruktur och materials egenskaper. Utöver materialets bulkegenskaper har även ytans specifika egenskaper stor betydelse för materialets prestanda under användning.

Under tillverkningen av strukturella komponenter formas materialet till önskad geometri och dimension genom flera processsteg, vilket innebär att även materialets yta ändras under processens gång. Som en följd har konceptet ytintegritet introducerats som ett mått och definition av ytans egenskaper under tillverkningen. Genom kunskap om ytintegriteten kan metoder för att tillgodose ökade krav på prestanda och säkerhet förbättras, och även ge kunskap till att utveckla nya tillverkningsprocesser. Utöver detta, skapas en stor databank med tillgängliga ytintegritetsdata.

Hårdmetall, vilket utgör en grundpelare för verktygsindustrin, representerar en grupp av kerammetallkompositer, där de hårda karbidpartiklarna ligger inbäddade i en mjukare och segare bindemetall. Kompositer bestående av wolframkarbid (WC) och kobolt (Co) kallas generellt för hårdmetall. Den slutliga kvaliteten på hårdmetallkomponenten beror i hög grad på hur ytintegriteten utvecklas i varje steg i tillverkningsprocessen. I detta sammanhang utgör slipning och ytbeläggning nyckelsteg. Utöver kvalitet påverkas även produktionskostnaderna. Diamantslipning är den vanligaste metoden när man slipar hårdmetall till önskad form och dimension, varefter man ofta belägger hårdmetallen med ett skyddande skikt för att ytterligare öka nötningsmotståndet och därmed livslängden på verktyget.

Målet med denna avhandling att studera substratets ytbeskaffenhet med avseende på flera mekaniska egenskaper för en belagd hårdmetall. Olika yttillstånd har studerats där man har använt substrat direkt från sintring (AS), slipad (G), spegelblankt polerad (P) och slipad plus värmebehandlad (GTT).

Ytintegritet analyserades sedan i termer av ytråhet, restspänningar (före och efter ytbeläggning) och deformation under ytan. Det visade sig att slipning signifikant påverkar hårdmetallens 
ytintegritet. De största förändringarna var bildandet av mikrosprickor i en zon $1 \mu \mathrm{m}$ under ytan och stora kompressiva restspänningar som gradvis klingar av till ett djup på 10-12 $\mu \mathrm{m}$. Efterföljande beläggning av ett hårt skikt resulterade i minskade restspänningar, emedan andra deformationer kvarstod. $\AA$ andra sidan, en högtemperaturvärmebehandling (GTT tillståndet) resulterade i en fullständig utläkning av restspänningarna utan att tillföra ytterligare mikrosprickor i deformationszonen.

Interaktionen mellan bulkmaterialets deformation under yttre tryck och deformation som härrör till ytintegritet (kompressiva spänningar, yttextur, mikrosprickor) definierar det mekaniska utfallet. Fraktografi, dvs den systematiska beskrivningen av brottytors utseende, är en central parameter i utvecklingen av material. Det visade sig att slipning höjer hållfastheten signifikant i jämförelse med AS och P tillstånden. Denna positiva effekt är dock delvis förlorad för motsvarande ytbelagda prov. Däremot ökar hållfastheten efter ytbeläggning för GTT tillståndet.

Adhesion eller vidhäftning av ytbeläggningen är även det en viktig parameter för att bestämma funktionalitet och livslängd av ytbelagda material. I denna studie undersöktes därför inverkan av substratens ytfinish på repmotstånd av ytbelagd hårdmetall samt tillhörande brottmekanismer. De belagda yttillstånden AS, G och P uppvisar liknande kritisk last för substratexponering och samma spröda adhesiva brott. Dock skiljer sig brottscenariot mellan tillstånden. Substratexponering var icke kontinuerlig och lokal i repspåret för prov G medan AS och P uppvisar en mer omfattande och kontinuerlig substratexponering. Ytbelagda hårdmetaller med två olika Co-halter undersöktes. En ökning av sprickor och lägre vidhäftning av ytbeläggningen där substratet hade en lägre Cohalt kunde konstateras. Slipning bedömdes minska vidhäftningen jämfört med en polerad substratyta, men också hämma sprickbildning.

Belastning i form av tryck är alltid närvarande under användningen av hårdmetallverktyg. Kraftig belastning åstadkommer deformation och sprickor i materialet med försämrad prestanda som följd. Att studera materialets kontaktdeformationsmotstånd är därför en viktig parameter. Det visade sig att slipning ökar motståndet mot kontaktdeformation, både initiering av sprickor i den belagda ytan men också efterföljande sprickpropagering in i hårdmetallsubstratet minskade. Det kvardröjande restspänningstillståndet under ytan efter slipning antogs förklara det ökade motståndet mot 
kontaktdeformation. Det ståndpunkten av spänningstillståndet var vidare underbyggt via det lägre kontaktdeformationsmotstånd som uppvisades i GTT-proven. 



\section{Preface}

This thesis is a result of my doctoral studies in the Centre d'Integritat Estructural i Fiabilitat dels Materials group at Universitat Politècnica de Catalunya as well as in the Nanostrutured Materials group at Linköping University between 2012 and 2016. This work is carried out within the framework of the European Joint Doctoral Program in Materials Science and Engineering (DocMASE), in close collaboration with SECO Tools AB. The content of the thesis is the product of original work, except as specified in acknowledgments or in footnotes or in detailed references. 



\section{Included Papers and Author's Contribution}

\section{Paper 1}

Grinding effects on surface integrity and mechanical strength of WC-Co cemented carbides

J.Yang, M.Odén, M.P. Johansson-Jõesaar, L.Llanes

Procedia CIRP 13 (2014) 257-263

\section{Paper 2}

Substrate surface finish effects on scratch resistance and failure mechanisms of TiN-coated hardmetals

J. Yang, J.J. Roa, M. Odén, M.P. Johansson-Jõesaar, J. Esteve, L. Llanes, Surf Coat Tech. 265 (2015) 174-184

\section{Paper 3}

Contact damage resistance of TiN-coated hardmetals: Beneficial effects associated with substrate grinding

J. Yang, F. García Marro, T. Trifonov, M. Odén, M.P. Johansson-Jõesaar, L. Llanes

Surf Coat Tech. 275 (2015) 133-141

\section{Paper 4}

Influence of substrate microstructure and surface finish on cracking and delamination response of TiN-coated cemented carbides

J.Yang, M.Odén, M.P. Johansson-Jõesaar, L.Llanes

Wear 352-353 (2016) 102-111

\section{Paper 5}

Thermally induced surface integrity changes of ground WC-Co hardmetals

J. Yang, J.J Roa, M. Schwind, M. Odén, M.P. Johansson-Jõesaar, J. Esteve and L. Llanes Procedia CIRP (accepted) 


\section{Author's contribution:}

In all the paper listed above, I was involved in planning and design of experimental activities, performed all the mechanical tests, conducted most of the characterization activities, led and coordinated analysis and discussions of the results; and finally, wrote all the manuscripts. 


\section{Annexes}

\section{Annex 1}

Influence of coating deposition on surface integrity and flexural strength of ground WC-Co cemented carbides

\section{Annex 2}

3D FIB/FESEM tomography of grinding-induced damage in WC-Co composites

\section{Annex 3}

Grinding-induced metallurgical alterations within the binder phase of WC-Co cemented carbides: Assessment by means of EBSD and TEM 



\section{Related, not Included Publications}

\section{Paper 6}

Mechanical response under contact loads of AlCrN-coated tool materials

J. Yang, C. A. Botero, N. Cornu, G. Ramírez, A. Mestra, L. Llanes

IOP Conf. Series: Materials Science and Engineering 48 (2013). doi:10.1088/1757899X/48/1/012003

\section{Paper 7}

Fracture toughness of cemented carbides: Testing method and microstructural effects

S. Sheikh, R. M'Saoubi, P. Flasar, M. Schwind, T. Persson, J. Yang, L. Llanes

Int J Refract Met Hard Mater. 49 (2015)153-160 



\section{Acknowledgements}

I am sincerely grateful for all the people who have helped me in this thesis work during these four years. Especially my sincere gratitude is expressed to:

Luis Llanes, my supervisor in UPC, who has guided me through the research work with his continuous support, patience and immense knowledge during these years;

Magnus Odén, my supervisor in LIU, for always being open for discussions, and for all the support and encouragement in many aspects;

Mats P. Johansson-Jöesaar, for help in performing all experimental activities at SECO Tools and good advices and discussions about my work;

Joan Esteve, for allowing me to use the equipment in Universitat de Barcelona and for his collaboration;

Martin Schwind, for happily helping me in carrying out the EBSD characterization at SECO Tools; Fernando García, Joan Josep Roa and Rémi Weber, for their contribution in obtaining good results; Each single member from the group CIEFMA- Structural Integrity and Reliability of Materials, and Department of Materials Science and Metallurgical engineering in UPC, who helped me in giving constructive advices and performing my experiment more smoothly;

Trifon Trifnov, for teaching me valuable knowledge in focused ion beam;

All the nice and helpful people from Nanostructured materials group in LIU, who offered significant help generously and have made my Swedish times there being very joyful;

Lina Rogström and Phani Kumar Yalamanchili, for sharing their experience in stress analysis;

Arni Sigurdur Ingason, for training me as a qualified x-ray diffractometer manipulator;

All the friends, with whom I share the interesting lunch times during working days and part of my leisure time: Jose, Miquel, Ina, Quentin, Erica, Latifa, Erik, Romain, Mireia, Roberta, Yass, Giuseppe etc.;

Family members, especially my parents and Chaoren Liu, for their continuous support and love. 



\section{Contents}

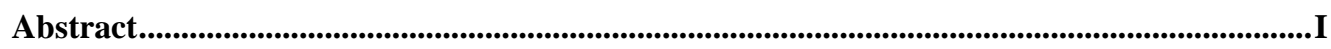

Populärvenskaplig Sammanfattning................................................................................................... V

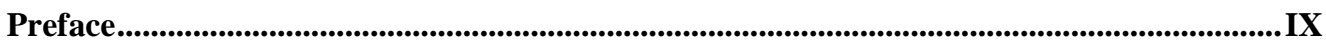

Included Papers and Author's Contribution .....................................................................................XI

Annexes .....................................................................................................................................................XIII

Related, not Included Publications............................................................................................XV

Acknowledgements ............................................................................................................................. XVII

Symbols and Abbreviations ...........................................................................................................XIX

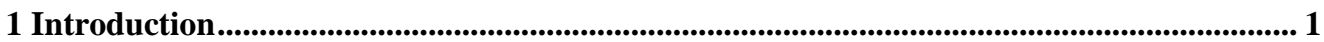

2 Cemented Carbides....................................................................................................................... 7

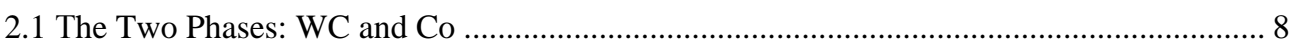

2.2 Microstructural Aspects ……………………………………………………………... 9

2.3 Mechanical Properties .................................................................................................. 10

2.4 Tooling Applications ........................................................................................................ 11

2.5 Manufacturing Process ................................................................................................. 13

3 Surface Integrity ………………………...................................................................................... 19

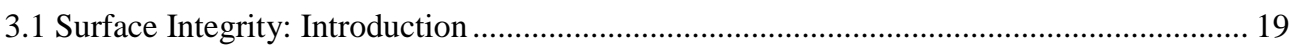

3.2 Surface Integrity in Hardmetals ................................................................................. 23

3.2.1 Grinding.................................................................................................... 24

3.2.2 From Grinding to Coating Deposition........................................................................... 31

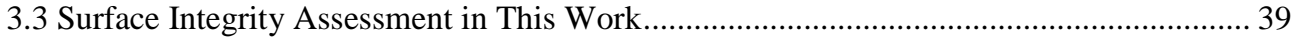

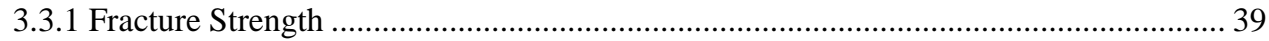

3.3.2 Adhesion Behavior ............................................................................................... 42

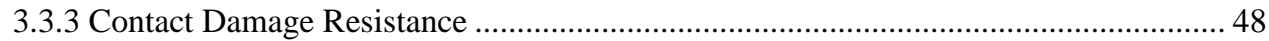


4 Materials and Characterization Techniques ............................................................................. 59

4.1 Materials in This Study and Surface Finish Conditions.................................................... 59

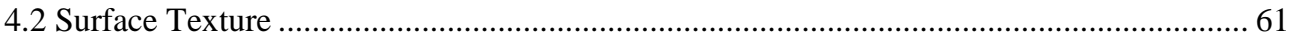

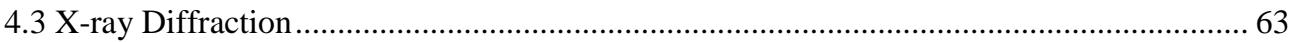

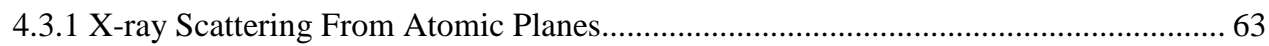

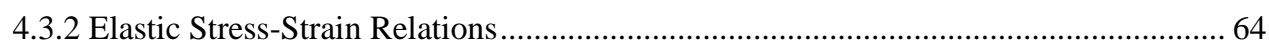

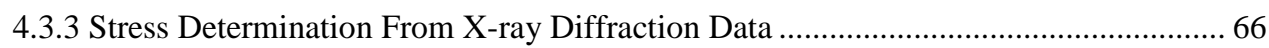

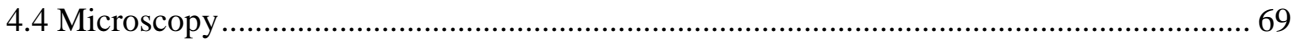

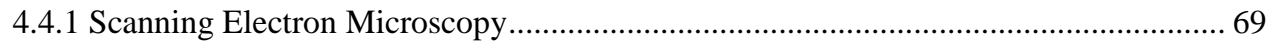

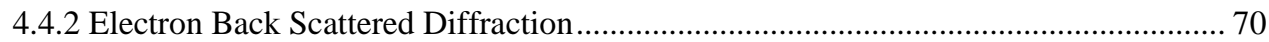

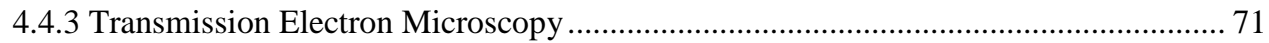

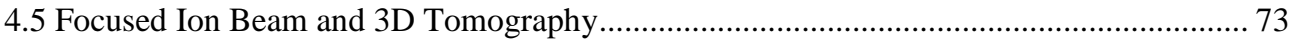

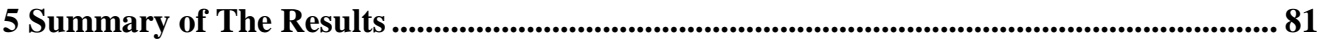

5.1 Surface Integrity Resulting From Grinding and Subsequent Coating................................ 81

5.2 Grinding and Coating Effects on Fracture Strength............................................................. 83

5.3 Influence of Grinding on Cracking and Delamination Response....................................... 84

5.4 Beneficial Grinding Effects on Contact Damage Resistance............................................. 86

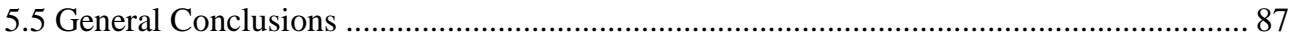

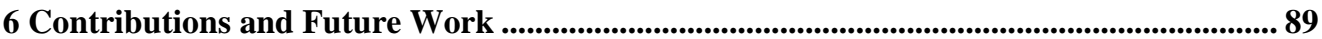

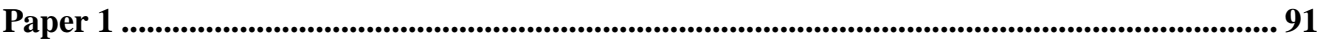

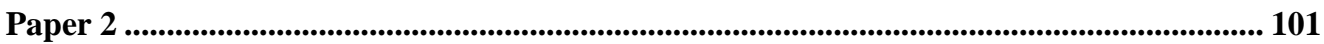

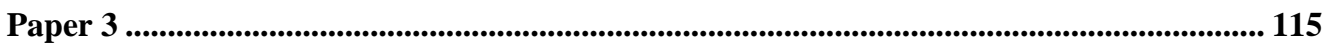

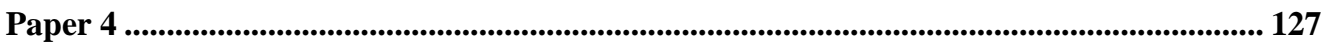

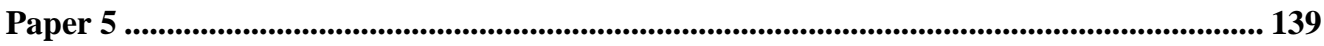

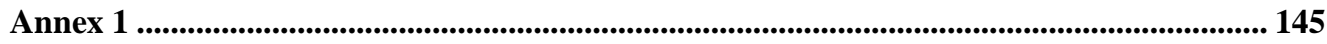

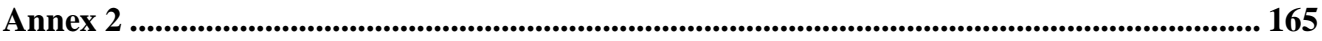

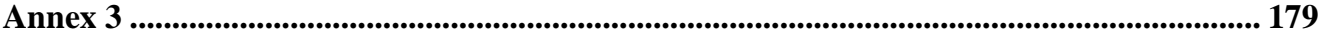




\section{Symbols and Abbreviations}

\begin{tabular}{|c|c|}
\hline WC & Tungsten carbide \\
\hline Co & Cobalt \\
\hline $\mathrm{TiN}$ & Titanium nitride \\
\hline wt.\% & Weight percentage \\
\hline As & As-sintered \\
\hline G & Ground \\
\hline $\mathrm{P}$ & Polished \\
\hline GTT & Ground plus thermal treatment \\
\hline XRD & $\mathrm{X}$-ray diffraction \\
\hline FIB & Focused ion beam \\
\hline FESEM & Field-emission scanning electron microscopy \\
\hline EBSD & Electron back scattered diffraction \\
\hline TEM & Transmission electron microscopy \\
\hline hср & Hexagonal close-packed \\
\hline fcc & Face centered cubic \\
\hline$d_{w c}$ & Mean carbide grain size \\
\hline$\lambda_{C o}$ & Binder mean free path \\
\hline$C_{w c}$ & Carbide contiguity \\
\hline$K_{I C}$ & Fracture toughness \\
\hline PM & Powder metallurgy \\
\hline EDM & Electrical discharge machining \\
\hline CVD & Chemical vapour deposition \\
\hline PVD & Physical vapour deposition \\
\hline$v_{w}$ & Workpiece speed \\
\hline C & Number of cutting edges per unit area \\
\hline$v_{g}$ & Grinding wheel speed \\
\hline$h_{g}$ & Depth of cut \\
\hline$D_{g}$ & Wheel diameter \\
\hline$B$ & Grinding width \\
\hline SEM & Scanning electron microscopy \\
\hline $\mathrm{E}^{*}$ & Normalized energy flux \\
\hline $\mathrm{T}^{*}$ & Generalized temperature \\
\hline $\mathrm{Ar}$ & Argon \\
\hline TRS & Transverse rupture strength \\
\hline$\sigma_{f}$ & Fracture strength \\
\hline$F$ & Break force \\
\hline$L_{2}$ & Outer span \\
\hline$L_{1}$ & Inner span \\
\hline
\end{tabular}


$b$

$h$

$K_{\text {app }}$

$Y$

$a_{c}$

$K_{t}$

$K_{\text {res }}$

$\mathrm{L}_{\mathrm{c}}$

HSS

CC

PCBN

$6 \mathrm{~F}$

$13 \mathrm{~F}$

$\mathrm{HV}$

$R_{a}$

$R_{y}$

SP

$\Delta \theta$

$\Delta d$

$\varepsilon$

$\sigma$

$\lambda$

$n$

$d_{h k l}$

$\theta$

E

$v$

$S_{i}$

$L_{i}$

$\varphi$

$\psi$

$d_{\varphi \psi}$

$d_{0}$

$\mathrm{BC}$

DPs

PED

3D

2D

$+\mathrm{I}-\mathrm{E}$

$+\mathrm{C}$

SAED
Width of test-piece

Thickness of test-piece

Applied stress intensity factor

Geometry factor

Critical flaw size

Total stress intensity factor

Residual stress intensity factor

Critical loads defined in scratch test

High speed steel

Cemented carbides

Polycrystalline cubic boron nitride

Hardmetal grade with 6 wt.\% binder content

Hardmetal grade with 13 wt.\% binder content

Vickers hardness

Average roughness

Maximum peak to valley height value

Stylus profiler

Diffraction angle variation

Plane spacing change

Strain

Stress

Wave length of the x-ray beam

An integral multiple

Plane spacing

The angle of incidence and reflection

Young's modulus of elasticity

Poisson's ratio

Specimen orthogonal coordinate system

Laboratory orthogonal coordinate system

Azimuth angle

Tilting angle

Lattice spacing in the diffracted plane

Lattice spacing in the unstressed plane

Band contrast

Diffraction patterns

Precession electron diffraction

3-dimensional

2-dimensional

Ion-etched

Coated

Selected area electron diffraction 


\section{Introduction}

Aiming to achieve an optimized selection of materials for specific applications, extensive research has been dedicated to study the relation between chemistry, microstructure and the resultant properties. In addition to those bulk-related features, surface characteristics are also crucial in determining the functional response of a given material. Generally, materials used for structural components are shaped into final dimensions and geometry by a variety of manufacturing processes. In this regard, surface nature is continuously changed as the material goes throughout the manufacturing chain: mechanical working operations, material removal methods, heat treatment, intended surface modification processes, and other finishing practices [1]. Surface alterations become critical in controlling the properties and performance of final products, particularly if service conditions involve contact loading (e.g. wear, impact, fatigue, etc.) and/or environmental (e.g. corrosion, oxidation, etc.) interaction.

In the case of manufacturing stages involving material removal, such as grinding, lapping and other non-conventional process, a complex surface interaction exists between the tool and workpiece. A large amount of heat can be generated which could produce microstructural changes, including possible local melting at the surface. Plastic deformation, tearing and fracture may also occur. Moreover, fluctuating mechanical and thermal states may induce relevant residual stresses [2]. Mechanical properties of the final tool or component, particularly those that could be described as surface-sensitive, are considerably affected by all above changes.

The existence of a pronounced influence of manufacturing methods on mechanical properties and service performance, as a result of the type of surface produced, is well-established. Within this framework, the concept of surface integrity has been introduced as a holistic parameter to study this issue in depth. Surface integrity is defined as the inherent or enhanced condition of a surface produced by machining or other generating operation. It contains not only the geometry consideration, including surface roughness and accuracy, but also other surface/subsurface microstructure aspects. The broadness and complexity of this topic demand synergic interdisciplinary expertise of different fields: materials science, machining and shaping 
technology, as well as mechanical and tribological testing, among others [3,4]. The corresponding outcome is extremely useful as figure of merit to satisfy the increased requirements for reliability and safety, unusual service needs, development of and need for understanding of new manufacturing processes, and the availability of extensive sets of surface integrity data [3].

WC-Co Cemented carbides, also simply termed as hardmetals, are the backbone materials for tooling industry, owning to its excellent combination properties of hardness, strength, and fracture toughness together with unique wear and abrasion resistance [5]. Hardmetal tools are produced through a powder metallurgical method where mixed WC and Co powders are sintered at high temperature to consolidate the composite material. Manufacturing of cemented carbide components often involves grinding, and in the case of cutting tools also edge preparation, etching and coating. The quality of the shaped components is influenced by how the surface integrity evolves through the different process steps. In this regard, substrate grinding and coating deposition represent key steps, as they are critical for defining the final performance and relative tool manufacturing cost [6].

Diamond wheel grinding is the most common method to machine hardmetals. As a result of the nature of this hard material and the grinding process, surface integrity is altered and then affects mechanical properties, tribological response and reliability of the ground tools [7]. Meanwhile, structural coatings are usually applied to the tools to improve its lifetime by offering a better resistance to mechanical and thermal loads, diminishing friction and wear, chemical attack, etc. [8]. Thermal effect during the film deposition process and the presence of an external coating by itself give the surface a new state compared to the one resulting from ground.

Compared to the extensive knowledge existing in open literature on bulk-related issues for hardmetals (e.g. Refs. [9-12]), reports addressing surface integrity - manufacturing property/performance relationships for these materials are rather scarce. Accordingly, it is the objective of this thesis to assess the influence of substrate surface integrity on different mechanical (flexural strength and contact damage resistance under spherical indentation) and tribological (scratch resistance as well as cracking and delamination response under Brale indentation) properties for a TiN-coated fine-grained hardmetal grade (WC-13 wt.\%Co). In doing so, three 
different surface finish conditions are studied: as-sintered (AS), ground (G), and mirror-like polished (P). Moreover, aiming for an in-depth analysis of surface integrity evolution from grinding to coating, a relevant part of the work is devoted to document and understand changes induced by grinding in nude hardmetal substrates. The study is also extended to a fourth surface finish variant (GTT), corresponding to a ground substrate which is thermal annealed before being ion etched and coated. Because residual stress induced by grinding are effectively relieved after this high temperature thermal treatment, GTT condition allows to separate grinding-induced effects associated with surface texture and surface/subsurface damage changes (inherited from the G surface finish) from those related to the referred residual stresses.

A scheme illustrating the thesis layout is presented in Fig. 1.1. Following this introductory chapter, a brief description of cemented carbides is given in Chapter 2. It includes information about constitution, microstructure, basic mechanical properties, applications and manufacturing process of hardmetals. Chapter 3 provides a background on the concept of surface integrity. Moreover, in this chapter studies reported in the literature on ground or/and coated hardmetals as well as on evaluation approaches implemented in this investigation are critically reviewed. Experimental details, including studied materials, surface conditions and characterization techniques, are detailed in Chapter 4. In Chapter 5 a summary of the main results of the investigation conducted is given. Finally, Chapter 6 depicts the contribution and future work. 

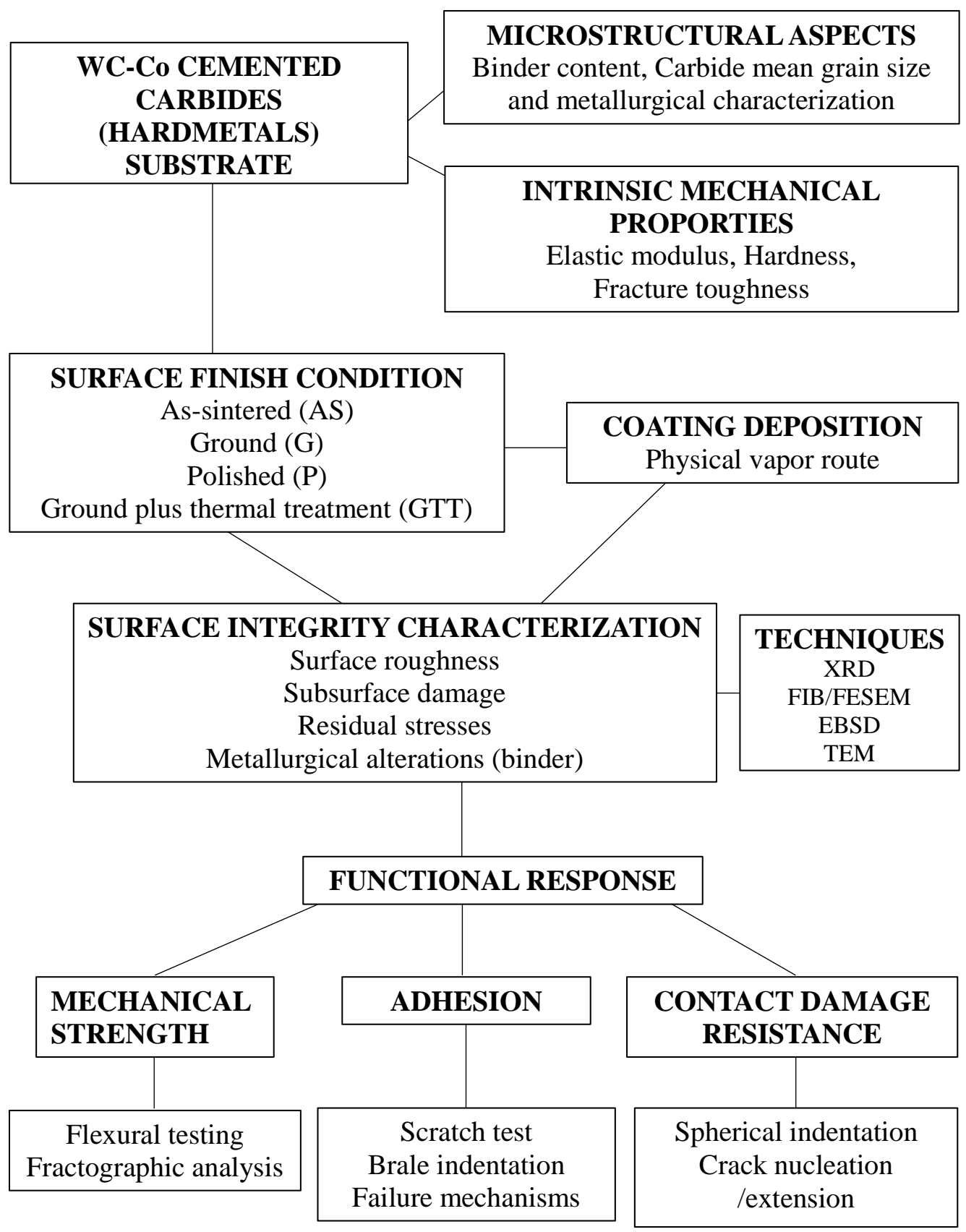

Fig. 1.1 Scheme illustrating the thesis layout. 


\section{References}

[1] Kahles JF, Field M. Surface integrity - a new requirement for surfaces generated by materialremoval methods. Proc. I. Mech. E., 1967;182:31-45.

[2] Astakhov VP. Surface integrity - Definition and importance in functional performance. In: Paulo Davim J (Eds.) Surface Integrity in Machining. London: Springer; 2010, p. 1-35.

[3] Field M, Kahles JF, Cammett JT. A Review of measuring methods for surface integrity. CIRP Ann. 1972;21:219-38.

[4] Jawahir IS, Brinksmeier E, M'Saoubi R, Aspinwall DK, Outeiro JC, Meyer D, Umbrello D, Jayal AD. Surface integrity in material removal processes: Recent advances. CIRP AnnManuf Techn. 2011;60:603-26.

[5] Prakash L. 1.02 - Fundamentals and General Applications of Hardmetals. In: Sarin VK, Mari D, Llanes L (Eds.) Comprehensive Hard Materials. Oxford: Elsevier; 2014. Vol. 1, p. 29-90.

[6] Byrne G, Dornfeld D, Denkena B. Advancing cutting technology. CIRP Ann-Manuf Techn. 2003;52:483-507.

[7] Takeyama H, Iijima N, Uno K. Surface integrity of cemented carbide tool and its brittle fracture. CIRP Ann-Manuf Techn. 1982;31:59-63.

[8] Bouzakis KD, Michailidis N, Skordaris G, Bouzakis E, Biermann D, M'Saoubi R. Cutting with coated tools: coating technologies, characterization methods and performance optimization. CIRP Ann-Manuf Techn. 2012;61:703-23.

[9] Exner HE. Physical and chemical nature of cemented carbides. Int Met Rev. 1979;24:149-73.

[10] Roebuck B, Almond EA, Cottenden AM. The influence of composition, phase transformation and varying the relative F.C.C. and H.C.P. phase contents on the properties of dilute Co-W-C alloys. Mater Sci Eng. 1984;66:179-94.

[11] Roebuck B, Almond EA. Deformation and fracture processes and the physical metallurgy of WC-Co hardmetals. Int Mat Rev. 1988;33:90-112.

[12] Roebuck B. Extrapolating hardness-structure property maps in WC/Co hardmetals. Int J Refract Met Hard Mater. 2006;24:101-8. 



\section{Cemented Carbides}

Cemented carbides are, from a technical viewpoint, one of the most successful cases of "tailormade” (ceramic-metal) composites ever produced. This is mainly due to their outstanding combination of high hardness and strength together with excellent wear and abrasion resistance. As a result, they are positioned as well-established materials for highly demanding applications: from tools in the manufacturing industry to wear-resistant and structural components in a variety of other industrial sectors. Cemented carbides represent a group of sintered materials where brittle refractory carbides of the transition metals are combined with a tough binder metal. The composites based on tungsten carbide (WC) and cobalt (Co) alloy (the most commonly used combination) are often referred as hardmetals ${ }^{1}$ and/or straight grades. Fig. 2.1 shows a typical hardmetal microstructure. Addition of other hard carbides and carbonitrides or use of alternative binder materials have widened the application range of cemented carbides. However, the twophase (WC-Co) straight grades still demonstrate their predominance in numerous applications [1].

The history of cemented carbides began in Germany during the First World War, as toughness improvement of tungsten carbide tools was required. At that time, hardness of WC was found to be comparable to that of diamond, but its brittleness limited the commercial use of these ceramic tools. In the early 1920s, a significant breakthrough was made by Schröter [2]. He was able to manufacture cemented carbides by compacting and sintering a mixture of cobalt and tungsten carbide powders. Further development of cemented carbides involved use of other combinations, including partial or total replacement of WC with other carbides, e.g. titanium carbide (TiC), tantalum carbide $(\mathrm{TaC})$, and/or niobium carbide $(\mathrm{NbC})$, as well as use of other metallic alloys as alternative binders (e.g. Ni, NiCr or FeNiCo).

\footnotetext{
${ }^{1}$ The German word "hartmetall” was initially coined when this new product was invented. It was then translated into English as "hardmetal”, a nomenclature recognized internationally. Later, the term "cemented carbide” was first used in the United States, a concept which describes the composite nature of these materials.
} 


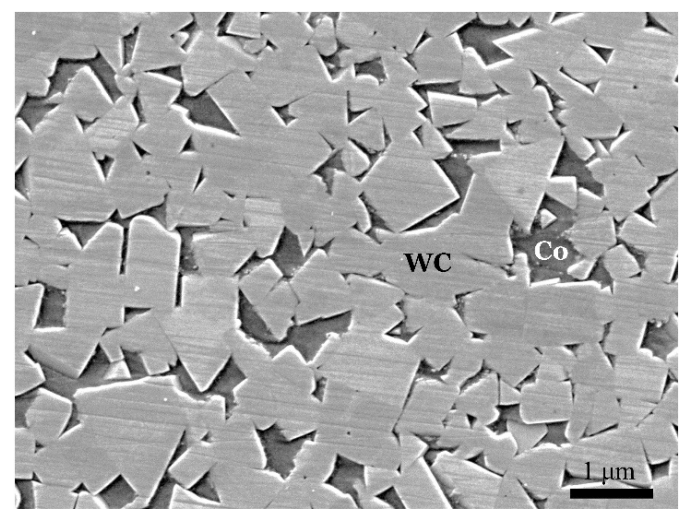

Fig. 2.1 Typical microstructure of two-phase (WC-Co) straight grade.

\subsection{The Two Phases: WC and Co}

According to the W-C phase diagram, tungsten monocarbide WC holds a very small range of homogeneity. The crystal structure is simple hexagonal with two atoms per unit cell. Due to the different spacing of [1010] directions in tungsten and carbon, there are two sets of three equivalent (1010) planes. The microhardness of WC is highly anisotropic, in agreement with the noncentrosymmetric crystal structure. Elasticity modulus of WC is extremely high (well above 700 $\mathrm{GPa}$ ), only exceeded by that of diamond. Very interesting, thermal conductivity of WC is also quite elevated $\left(1.2 \mathrm{~J} \mathrm{~cm}^{-1} \mathrm{~S}^{-1} \mathrm{~K}^{-1}\right)$ [3].

Cobalt has been a superior and exclusive material choice as binder phase in cemented carbide production. It should be highlighted that cobalt exhibits two allotropic modifications: a closepacked hexagonal (hcp) form, stable at temperatures below approximately $400{ }^{\circ} \mathrm{C}$; and a face centered cubic (fcc) form, stable at higher temperature. The existence of one or another may affect the mechanical properties of the whole composite material [3]. For example, WC-Co alloys show higher transverse rupture strength and toughness as cobalt binder phase has a relatively higher proportion of the more ductile $\alpha$-Co (fcc) phase. Phase transformation temperature depends critically on purity and heating/cooling rate. Higher tungsten and carbon contents, dissolved within 
the cobalt matrix, result in an increase of phase transformation temperature; and thus, stabilization of the fcc phase [4]. Moreover, other factors like cobalt content and binder mean free path also influences the transformation temperature. Thus, cobalt powders may partly keep a cubic structure at room temperature. Even in conventional solid cobalt subjected to either hot or cold deformation, and subsequently annealed and slowly cooled to room temperature, crystal structure will not be entirely hexagonal. A proportion of the metastable cubic phase will always be present [5].

\subsection{Microstructural Aspects}

The microstructure of two-phase (WC-Co) straight grades may be quantitatively described on the basis of several parameters [2,6]: carbide grain size distribution and mean carbide size $\left(d_{w c}\right)$, volume fraction of the individual phases, binder mean free path $\left(\lambda_{C o}\right)$, and carbide contiguity $\left(C_{w c}\right)$. Mean carbide size and binder volume fraction are the principal parameters used to characterize the microstructure of hardmetals. However, they are frequently varied simultaneously, and correlation between property and microstructure requires of additional two-phase normalizing parameters, such as binder mean free path and carbide contiguity. The distribution of the binder phase is related to the spacing between the carbide crystals. In this regard, $\lambda_{C o}$ is determined from the mean linear intercept (at carbide/binder interfaces) in the binder, and refers to the mean size of the metallic phase. On the other hand, $C_{w c}$ is determined as the ratio of grain boundary surface (WC/WC interface) to total surface (WC/WC+WC/Co interface); and thus, describes the interface area fraction of WC carbides that is shared by them. It is indeed a quantitative measurement of the continuity of the carbide phase skeleton 


\subsection{Mechanical Properties}

Basic mechanical parameters and response of hardmetals include hardness, elastic moduli, wear resistance, deformation behavior, fracture mode, fracture toughness and strength. These properties are usually measured at room temperature and serve as quantitative basis for comparison of the materials and their production technologies [7]. Fig. 2.2 is a scheme comparing hardness and transverse rupture strength (with fracture toughness values also indicated) of cemented carbides, as compared to those of other tool materials. They own an extremely high hardness which is only surpassed by diamond, cubic boron nitride and some structural ceramics. However, rupture strength (and fracture toughness) of hardmetals is usually higher than that measured for the referred harder materials. In this regard, it is interesting to underline that fracture toughness of cemented carbides exhibits similar value range as that of high speed steel.

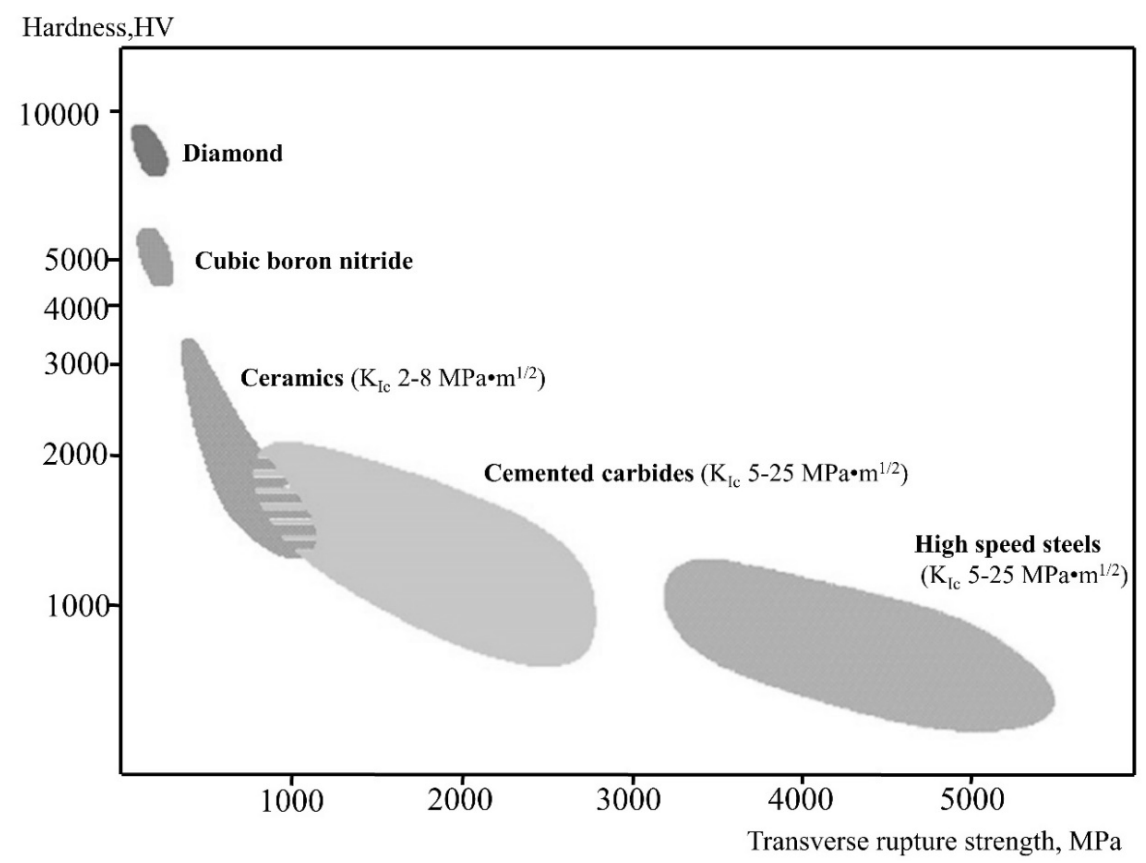

Fig.2.2 Scheme showing the hardness and strength of cemented carbides compared to other materials. Note that fracture toughness values are also labeled. (Adapted from Sandvik's “Understanding Cemented Carbide” [8]) 
Deformation and fracture behavior of hardmetals are dictated by the individual and combined properties of their two constituents [6]. As the binder phase exhibits large ductility and deformation compatibility, compared to the relative hard and brittle carbides, it commonly consumes most of the deformation and fracture energy, despite its relatively small fraction in the composite [7]. The metallic binder phase is known to enhance crack propagation resistance by means of toughening associated with formation of ductile ligaments behind the crack tip [9,10]. As a result, mechanical properties of cemented carbides, such as fracture and fatigue resistance, are strongly dependent on the binder phase. However, specific literature information about the intrinsic mechanical properties of the binder phase, and how they affect the mechanical and tribological response of cemented carbides is rather scarce. This is directly related to the facts that binder usually occupies small regions within the composite and material removal rates for ceramic and metallic phases are different. As a consequence, mechanical characterization of the metallic phase is not an easy task, in terms of either metallurgical sample preparation or measurement of properties at small length scale.

\subsection{Tooling Applications}

Cemented carbides hold a wide range of unique properties on the basis of different combinations of microstructure and composition. It enables them to meet different sets of requirements in general engineering applications. A sound example of this statement is the role that hardmetals play as backbone tool materials for the metal cutting industry. Other examples are their application as forming or mining tools, as well as wear resistance components [11]. Fig. 2.3 shows the application range of hardmetals, as a function of carbide grain size and binder content. Generally, hardness increases with decreasing grain size and binder content. Unfortunately, this will always be at the expense of reduced toughness. In truly abrasive applications, hardness is a good measure of wear resistance. 


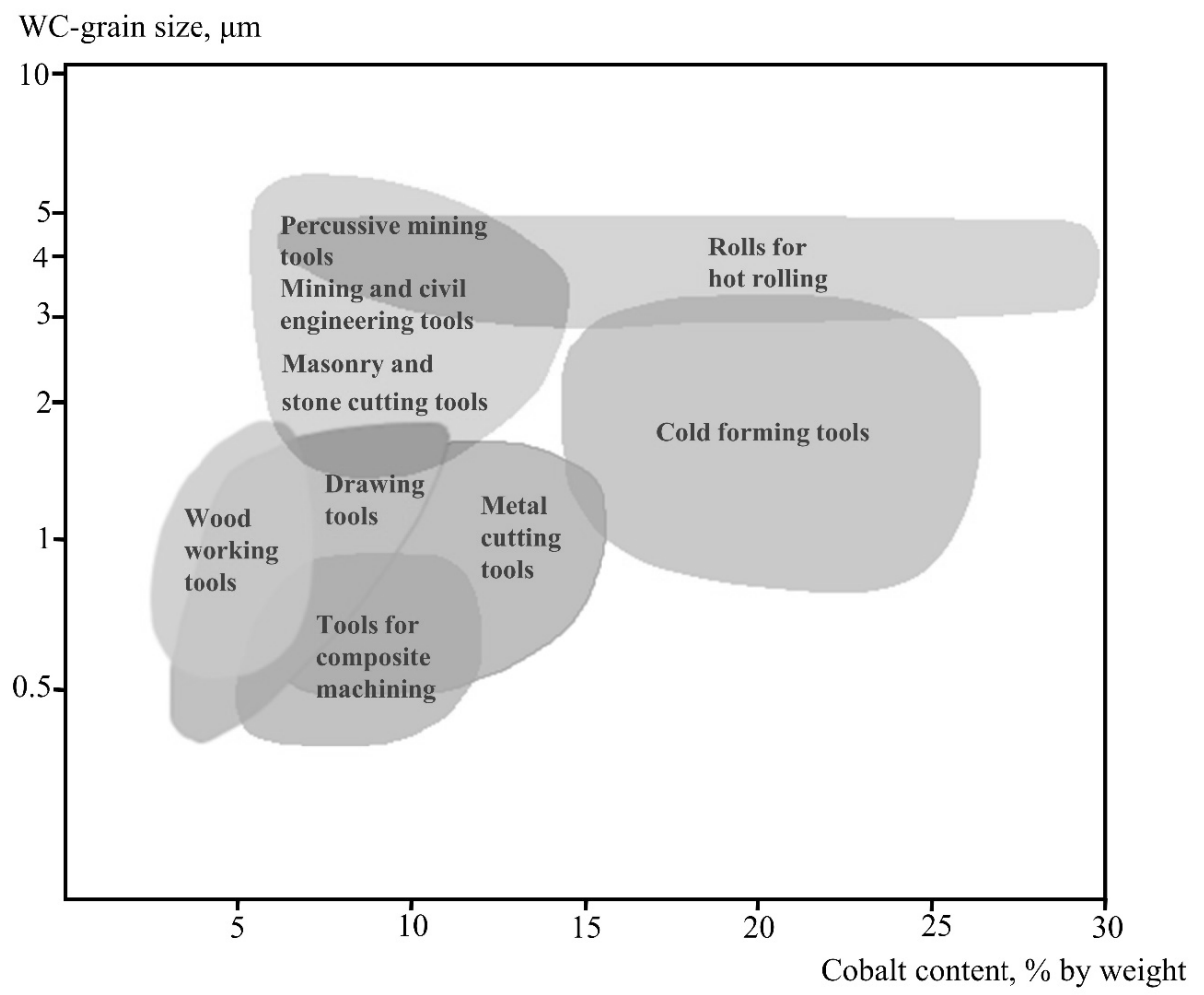

Fig. 2.3 Application range of straight cemented carbides grades. (Adapted from Sandvik's “Understanding Cemented Carbide” [8])

Straight WC-Co grades are classified according to their cobalt content and WC grain size. The proportion of carbide phase is generally between $70-97 \%$ of the total weight of the composite and its grain size averages between 0.4 and $10 \mu \mathrm{m}$. This range of cemented carbides can be subdivided into its major application areas as follows [12]:

Nano, Ultrafine and Submicron grades: Grades with binder content in the range of 3-10 wt.\% and carbide grain size below $1 \mu \mathrm{m}$. They have the highest hardness and compressive strength values, combined with exceptionally elevated wear resistance and reliability against breakage. These 
grades are used in a wide range of wear part applications as well as cutting tools designed for metallic and non-metallic machining, where a combination of high strength, wear resistance and sharp cutting edges are essential.

Fine and Medium grades: Grades with binder content between 6-30 wt.\% and carbide grain size of 1-3 $\mu \mathrm{m}$. They are also used in wear parts and cutting tools, but within applications where improved strength and shock resistance is required.

Medium Coarse, Coarse and Extra Coarse grades: Grades with binder content between 6-15 wt.\% and carbide grain size above $3 \mu \mathrm{m}$. They are used in oil and gas, and mining applications, where resistance to high impact stresses and abrasive wear are required.

\subsection{Manufacturing Process}

Cemented carbides are produced by means of a Powder Metallurgy (PM) process. The starting materials for manufacturing cemented carbides are hard refractory carbides and a metal alloy, both in the form of powders. A flow chart of how the cemented carbides is produced is shown in Fig.2.4 $[2,13]$.
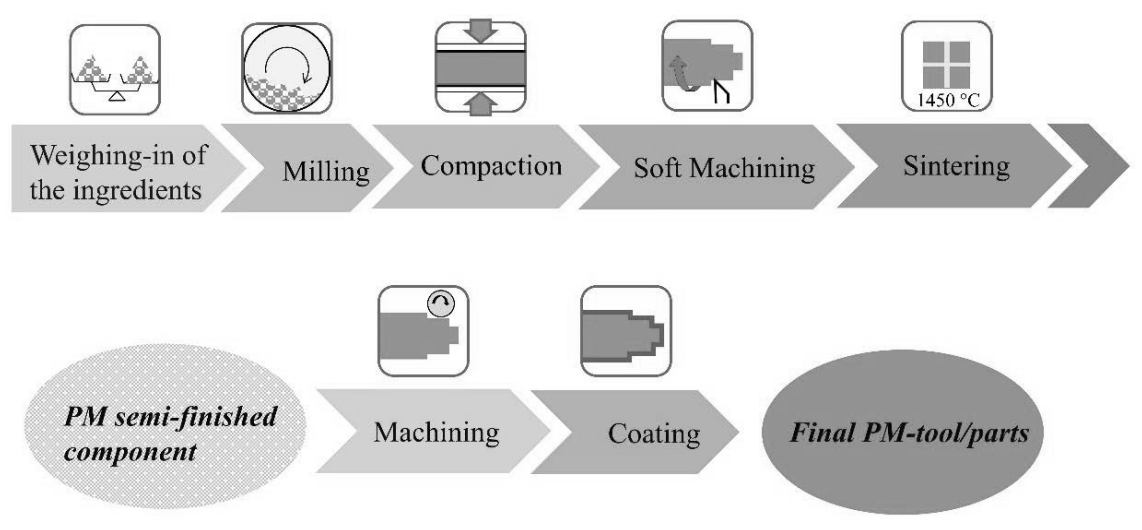

Fig. 2.4 Flow chart of the production process of the cemented carbides. 
Weighing the ingredients and milling: After weighing the carbide and metal (WC and Co in straight grades) powders as well as other additives, to prescribed composition and cemented carbide grade, the mixture is wet milled. The primary object of ball milling, apart from particle size reduction, is to ensure that every particle is coated with the metal alloy. In addition, it creates new active surfaces and an increased defect structure for both carbide and metal binder phases.

Compaction: Green compacts are prepared by pressing loose powder mass using an external pressure. This gives shape to the compacts as well as dimensional control. Following green compaction of cemented carbides, uniaxial die pressing, cold-isostatic pressing and extrusion are applied, depending on the application requirements of the final product.

Soft-machining: In the production of cemented carbide components, it is occasionally necessary to carry out a number of shaping operations before final sintering. Green compacts can then be produced in simple shapes, such as rectangular and round blanks, by means of conventional methods such as turning, drilling, and grinding.

Sintering: The sintering is the final step in which cemented carbides achieve their full density and hardness as a high strength engineering material. The practical sintering temperature of technical WC-Co hardmetals is over $1350^{\circ} \mathrm{C}$, which is above the melting points of W-Co-C and Co-C eutectics. In this case, molten cobalt is combined with WC phase. As a result, part of WC dissolves into Co during sintering, and precipitate after cooling. Diffusion rates, wetting of WC by cobalt, solubility of WC in cobalt, and volume percent of the liquid phase increase above the liquids temperature, whereas the liquid viscosity decreases. All these factors contribute to strong temperature sensitivity in sintering, as all of them favour rapid densification.

Machining: During the sintering process, the cemented carbide piece may shrink as much as $20 \%$ linearly (or nearly $48 \%$ by volume), as a result of pore elimination, but retaining its shape. After sintering, the corresponding blank has achieved its full density and hardness, and it is ready to be dispatched. Most blanks need to be further finished to the desired shape, size, flatness, and surface finish by either diamond wheel grinding or diamond lapping and polishing. Grinding will be discussed in detail later (Chapter 3). Moreover, electrical discharge machining (EDM) is 
increasingly used by cemented carbide suppliers. This is a thermal process where a workpiece electrode is shaped through the action of a succession of discrete electrical discharges which locally erode (melt or vaporize) the material surface. It is usually implemented for the fabrication of tools with intricate outline shapes and/or close tolerances prescribed by design [14].

Coating: After the machining stage (i.e. from grinding to polishing), cemented carbide pieces have a precise dimension and shape that fulfill requirements in real application. However, in the case of cutting tools, most of them are finally coated in order to enhance their lifetime and reliability. Coating became one of the most significant developments in the history of cemented carbides, starting in the early 1960s (TiC, TiN), and still evolving today. Coated tools have a composite-like structure, consisting of a substrate covered with a hard, anti-friction, chemically inert and thermal isolating layer, approximately one to a few micrometers thick. Coated tools, as compared to uncoated ones, offer better protection against mechanical and thermal loads, diminish friction and interaction between tool and chip, and improve wear resistance in a wide cutting temperature range $[15,16]$. In practical applications, the design of the coated tools must always take into account the coating-substrate assemblage as a composite system. The substrate determines geometry and toughness of the tool, whereas the tribological properties depend on the coating characteristics. The intermediate zone between coating and substrate, called interface, determines the film adhesion. In modern industry, several coating technologies offer the possibility to deposit different coating compositions as well as film structures. Nowadays, chemical vapour (CVD) and physical vapour deposition (PVD) are the main surface modification routes used for deposition of coatings in tools and components. PVD-process involves low substrate temperatures during deposition $\left(300{ }^{\circ} \mathrm{C}<\mathrm{T}<500{ }^{\circ} \mathrm{C}\right.$ ) as well as a great flexibility of possible target materials. This is different from CVD ones where high temperatures $\left(\mathrm{T}>800^{\circ} \mathrm{C}\right)$ are required. As a consequence, thermal loads are imparted to the substrate and thermal stresses develop at the interface. Accordingly, PVD-processes have gained market and popularity for coating of cutting tools in the last 15 years [17]. PVD-process applied within this work will be described in more detail in Chapter 3. 


\section{References}

[1] Schubert W-D, Lassner E, Böhlke W. Cemented Carbide-a Success Story. ITIA Newsletter June 2010.

[2] Upadhyaya GS. Cemented tungsten carbides: production, properties and testing, Noyes Publications New Jersey, USA 1998.

[3] Exner HE. Physical and chemical nature of cemented carbides. Int Met Rev. 1979;24:149-73.

[4] Roebuck B, Almond EA, Cottenden AM. The influence of composition, phase transformation and varying the relative F.C.C. and H.C.P. phase contents on the properties of dilute Co-W-C alloys. Mater Sci Eng. 1984;66:179-94.

[5] Upadhyaya GS. Materials science of cemented carbides - an overview. Mater Des. 2001;22:483-9.

[6] Roebuck B, Almond EA. Deformation and fracture processes and the physical metallurgy of WC-Co hardmetals. Int Mat Rev. 1988;33:90-112.

[7] Shatov AV, Ponomarev SS, Firstov SA. 1.10 - Fracture and Strength of Hardmetals at Room Temperature. In: Sarin VK, Mari D, Llanes L (Eds.) Comprehensive Hard Materials. Oxford: Elsevier; 2014. Vol. 1, p. 301-43.

[8] Sandvik Hard Materials, " Understanding cemented carbide", http://www2.sandvik.com/sandvik/0130/HI/SE03411.nsf/a0de78d35676d88d412567d90029 4747/4c7827530abfa4e1c1256b0a0034cc36/\$FILE/ATTYN87R/9100\%20eng.pdf (accessed 03/29 2016).

[9] Sigl LS, Exner HE. Experimental-study of the mechanics of fracture in WC-Co alloys. Metall Trans A. 1987;18:1299-308.

[10] Llanes L, Torres Y, Anglada M. On the fatigue crack growth behavior of WC-Co cemented carbides: kinetics description, microstructural effects and fatigue sensitivity. Acta Meter. 2002;50:2381-93.

[11] Van den Berg H. Hardmetals: trends in development and application. Powder Metall. 2007;50:7-10.

[12] Sandvik Hard Materials, "Cemented carbide, new developments and applications," http://www2.sandvik.com/sandvik/0130/HI/SE03411.nsf/7a5364adb7735b05412568c70034 
ea1b/651f6e334db04c46c125707600562c88/\$FILE/Cemented+Carbide.pdf～(accessed 12/15 2015).

[13] Sandvik Hard Materials, "All about cemented carbide," http://www.allaboutcementedcarbide.com/cn/03.html (accessed 12/15 2015).

[14] General Carbide, "The designer's guide to tungsten carbide," http://igor.chudov.com/manuals/Carbide-Design-Handbook.pdf (accessed 03/21 2016).

[15] Bouzakis KD, Michailidis N, Skordaris G, Bouzakis E, Biermann D, M'Saoubi R. Cutting with coated tools: coating technologies, characterization methods and performance optimization. CIRP Ann-Manuf Techn. 2012;61:703-23.

[16] Hogmark S, Jacobson S, Larsson M. Design and evaluation of tribological coatings. Wear. 2000;246:20-33.

[17] Byrne G, Dornfeld D, Denkena B. Advancing cutting technology. CIRP Ann-Manuf Techn. 2003;52:483-507. 



\section{Surface Integrity}

\subsection{Surface Integrity: Introduction}

Manufacturing process is commonly applied in practical applications, to shape a workpiece fulfilling defined requirements. During this process, two aspects need to be taken into account: the functionality of the machined workpiece itself and the economic efficiency. According to different applications, the functionality that a workpiece has to achieve after the machining process, may be divided into different groups [1]:

- Mechanical functions (capability of carrying mechanical loads)

- Thermal functions (heat resistance or temperature conductivity)

- Tribological functions (surface interaction with other media)

- Optical functions (visible appearance, light reflection behavior)

- Flow functions (influence on the flow of fluids)

Each step in a manufacturing chain influences the workpiece properties, which directly link to its functionality. The capability of the manufacturing processes related to the workpiece functionality can be described at four levels, from the geometry of the element to the atomic-scale/chemical interaction [1]:

- Macroscale: accuracy in shape and dimension

- Microscale: surface topography

- Mesoscale: material structure and properties (e.g. residual stresses)

- Nanoscale: tribochemical reaction layers

Aiming to develop high-performance manufacturing methods/tools as well as to reduce the production costs, research in this field is continuous and intensive. Henriksen [2] was among the first to investigate the characteristics of the residual stress state in machined surface in the 1950s. He pointed out that residual stresses remnant in the workpiece surface are one of the most crucial factors influencing the fatigue strength. Colwell and coworkers [3] developed some experimental 
methods for analyzing the residual stresses. In the 1960s, Field and Kahles [4] brought out the concept of surface integrity for the first time. They subsequently reviewed surface integrity issues of different machined components, and emphasized that both conventional and nonconventional machining process can induce changes (even metallurgical ones) in the workpiece at both surface and subsurface levels [5]. In a follow-up publication, Field and coworkers [6] developed an experimental procedure for approaching the surface integrity problem. Indeed, they did a significant pioneering work in this subject and enable future researchers to follow.

Over the last two decades, surface integrity and functional performance resulting from different manufacturing process have been studied in many publications: key review articles [7-10], book chapters [11-13] and numerous individual papers. Brinksmeier et al. [14] measured residual stress distributions generated by some relevant machining processes, and tried to explore the possible sources for them. Lucca et al. [7] reported progress in both, development of characterization tools for the assessment of surface integrity and experimental examination of surface alterations. Griffiths [15] did a significant contribution to the field by providing a comprehensive review of surface integrity in a monograph, serving as a superior reference to control enhanced functional performance of machined components. Withers [8] published a state of the art contribution on residual stress measurement methods related to structural integrity assessment. M'Saoubi et al. [9] and Guo et al. [16] presented sound reviews of surface integrity studies in the context of machined components for a range of work materials, including stainless steels, $\mathrm{Ni}$ and $\mathrm{Ti}$ alloys, and hardened steels. They also analyzed modeling and simulation actions to develop predictive models for residual stresses and means for enhancing product sustainability in terms of its functional performance. One CIRP keynote paper by Jawahir et al. [17] summarized outcomes from the Collective Working Group (CWG) on Surface Integrity and Functional Performance of Components. In such contribution, authors reported the results of a three-year study as well as recent progress in experimental and theoretical investigations on surface integrity in material removal processes. 
According to the information gathered in the above references, surface integrity may then be defined as the inherent or enhanced condition of a surface produced by machining or other surface generating operations, and it has been pointed out as a comprehensive criteria influencing the performance of the final product.

Typical surface alterations during surface generating processes may include plastic deformation, microcracks, residual stress distribution, metallurgical changes (phase transformation), surface morphology changes, etc. Field and coworkers [6] has specified three types or levels of data sets to study and evaluate the characteristic features of machined surfaces:

(1) the minimum surface integrity data set, containing essentially metallographic information supplemented with microhardness measurements and conventional surface finish measurements;

(2) the standard surface integrity data set, including the minimum data set and deeper properties data for more critical applications which are influenced by surface integrity, i.e. fatigue, stress corrosion, etc. ; and

(3) the extended surface integrity data set providing data suitable for detailed design, i.e. tensile, stress rupture and creep, among others.

Hence, to approach the surface integrity problem thoroughly, properties requiring investigation include surface topography, surface metallurgy, mechanical properties, surface chemistry, and other engineering properties. A brief summary of techniques and practices used to evaluate and control surface integrity are listed in Table 3.1. 
Table 3.1 Techniques for surface integrity measurements (Based on reference [6])

\begin{tabular}{ll}
\hline Property & Techniques \\
\hline $\begin{array}{l}\text { Surface Topography } \\
\text { Surface Metallurgy }\end{array}$ & Contact (tracer point or stylus measurement) \\
Microstructure & \\
Microhardness & Metallurgical sectioning - optical microscopy \\
Microcracks and crevice-like defects & Microharness testing - Knoop/Vickers indenter \\
& Nondestructive - Macroetching penetration \\
& inspection, etc.
\end{tabular}

Static Mechanical Properties

Tensile strength \& ductility

Tensile testing

Stress rupture \& creep

Creep testing

Residual stress

X-ray diffraction

Layer removal- curvature measurement

Dynamic Mechanical Properties

High \& low cycle fatigue

Bending fatigue testing

Surface Chemistry

Electron microscopy analysis, spectroscopy, spectrophotometry, etc.

Other Engineering Properties

Friction

A variety of techniques have been developed to

Wear evaluate these properties for specific applications

Corrosion

Electrical properties

etc. 


\subsection{Surface Integrity in Hardmetals}

As described in chapter 2, the manufacturing chain of hardmetals involves several sequential stages, from sintered state to the finished shape and dimensions. During this process, surface integrity of the tools correspondingly changes. As a consequence, manufacturing itself affects largely the performance and reliability of the finished tools, particularly if service conditions involve contact loading and/or environmental interaction. Under these considerations, failure usually comes from the surface/subsurface region in tools with appropriate bulk-like properties [7,9,17-20]. Therefore, attempting to enhance tool performance and lifetime, it is crucial to evaluate and understand the relation between each stage of the manufacturing process and the final properties, on the basis of the evolving surface integrity.

This information is also beneficial for achieving appropriate surface quality at minimum cost. Within the manufacturing chain of coated hardmetal tools, grinding is not only one of the most

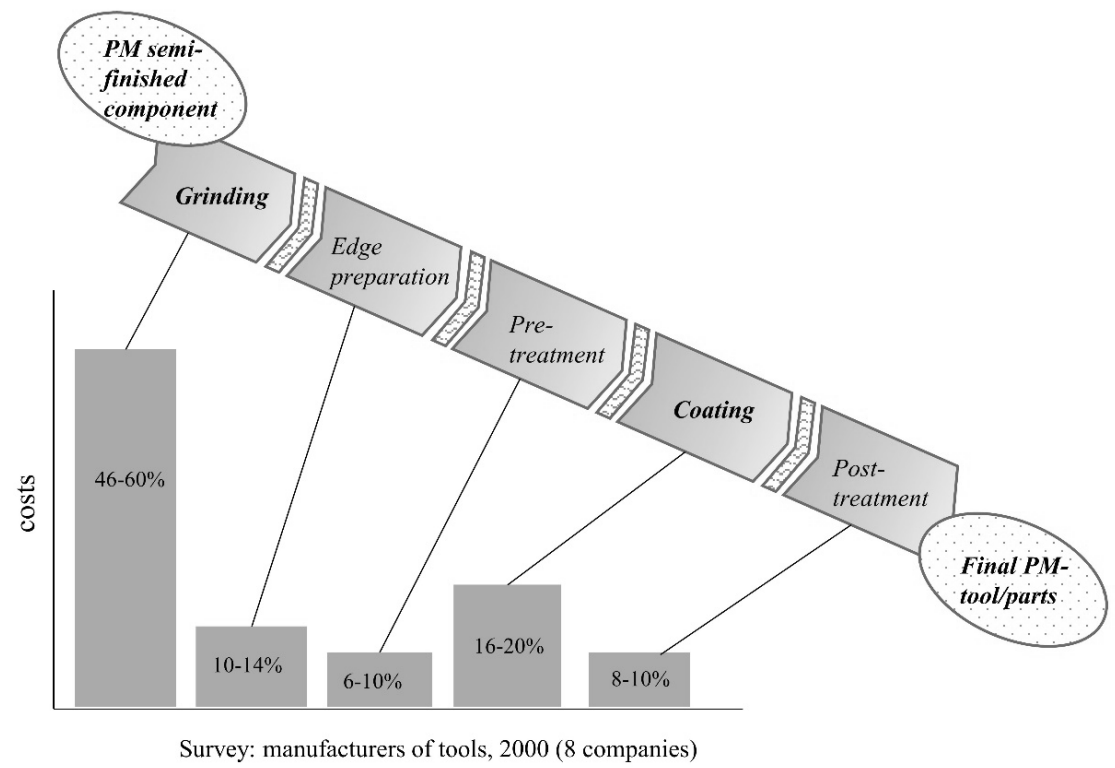

Fig. 3.1 Relative costs of each process stage involved in the manufacturing of coated powder metallurgical tools. Adapted from reference [21]. 
complex processes but also the stage that accounts for the highest relative cost $[20,21]$. The latter is clearly illustrated in Fig. 3.1. There it can also be observed that coating process is the second highest in terms of relative cost. Despite their importance, literature information on surface integrity evolution throughout the different stages of the hardmetal manufacturing process is quite scarce. Knowledge on how it may affect the functional response of the final coating-substrate system is even more limited. This is particularly true for studies dealing with both grinding and subsequent coating effects. Grinding and coating stages are described in more detail in the following sections.

\subsubsection{Grinding}

\subsubsection{Grinding Fundamentals}

Grinding is virtually unchallenged for machining of materials which, because of their extreme hardness or brittleness, cannot be efficiently shaped by other methods. In the case of cemented carbides, machining is almost exclusively dependent on this process [22].
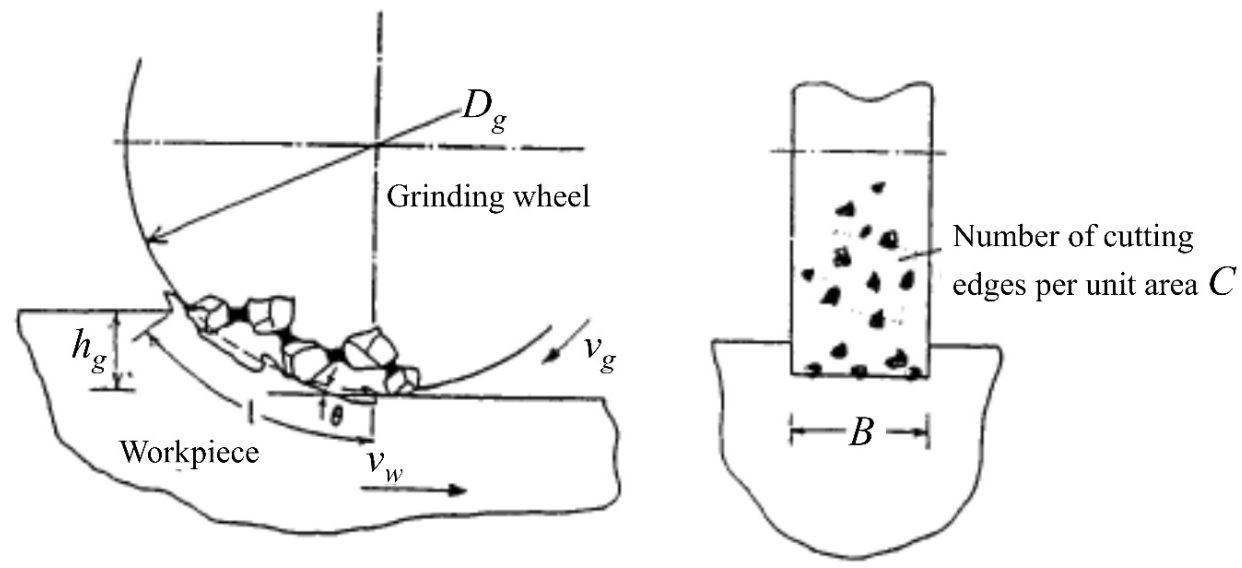

Fig. 3.2 Schematic drawing showing a workpiece being ground by a grinding wheel and the abrasive particles bonded on the wheel [23]. Note that some basic grinding parameters are also illustrated. Reprint is permitted by (C) 1999 Elsevier. 
Grinding is a representative abrasive process in which a grinding wheel is used. Fig. 3.2 illustrates a work piece being ground by the abrasive particles bonded on the wheel. Grinding wheels are generally composed of two materials: tiny abrasive particles called grains or grits, which do the cutting, and a softer bonding agent to hold the countless grits together in a solid mass. Each abrasive grain is a potential microscopic cutting tool. The grinding process uses thousands of abrasive cutting points simultaneously and millions continually [22]. The mechanism of material removal with abrasive cutting edges on the wheel surface is basically the same as that with cutting tools. However, the size of chips removed in grinding is much smaller than the case of cutting, providing better surface finish and machining accuracy. The length scale of chip thickness in grinding is far less than $0.1 \mathrm{~mm}$, whereas it is larger than $0.1 \mathrm{~mm}$ in cutting [23]. Basic grinding parameters involve the workpiece speed $v_{w}$, the number of cutting edges per unit area on the wheel surface $C$, the grinding wheel speed $v_{g}$, the depth of cut $h_{g}$, the wheel diameter $D_{g}$, and the grinding width $B$.

Efficient grinding of high performance workpiece requires selecting operating parameters to maximize removal rate while controlling surface integrity. Development of logical methodologies to optimize the grinding parameters requires a fundamental knowledge of the prevailing grinding mechanisms, and their influence on the resulting surface integrity and mechanical properties [22].

During grinding, each protruding abrasive grain interacts intensively with the workpiece surface. A local stress field upon each contact point causes irreversible material deformation in the form of dislocation, cracks and voids. The material removal mechanism can be commonly classified into two categories: brittle fracture and plastic deformation [24]. In brittle fracture, material is removed through void and crack nucleation and propagation, chipping or crushing. Plastic deformation involves scratching, plowing and chip formation. Material-removal is accomplished in the form of severely sheared machining chips. As a result of the interaction between the grinding grits and the workpiece material, grinding processes may cause changes of surface integrity containing a deformed layer, surface/subsurface microcracks, phase transformation, residual stress and other types of variations. The strength, hardness and fracture toughness of the work material are the governing factors that control the extent of surface variations. 


\subsubsection{Grinding - Surface Integrity Studies}

Before presenting the studies addressing grinding effects studies on cemented carbides, it is worthy to give a brief review of similar investigation on ceramics, since the major constituent of cemented carbides is the ceramic carbide phase. In terms of brittle and hard ceramics, the existence of machining-induced microcracks has been evidenced in many studies [25-31]. The crack pattern is analogous to that resulting from indentation of a brittle material by a harder indenter. However, it is more complex since pattern is asymmetric, with a strong tensile stress near the surface behind the contact point. In order to inspect the crack network inside ground ceramics, fractographic analysis has been the traditional approach followed in previous studies [30-34]. In addition to "lateral" cracks, running on planes closely parallel to the surface, a dual population of “median/radial”cracks, developed on symmetry median planes containing the load axis, were detected (Fig. 3.3). Stretched median cracks, made up of a series of smaller segments along, or very near the apex of the groove, develop as longitudinal damage features. Such cracking is the elongated version of the median cracks of a static indenter, emanating into the body from the base of the groove caused by the motion of the abrasive particle. Radial cracks are similar to the other

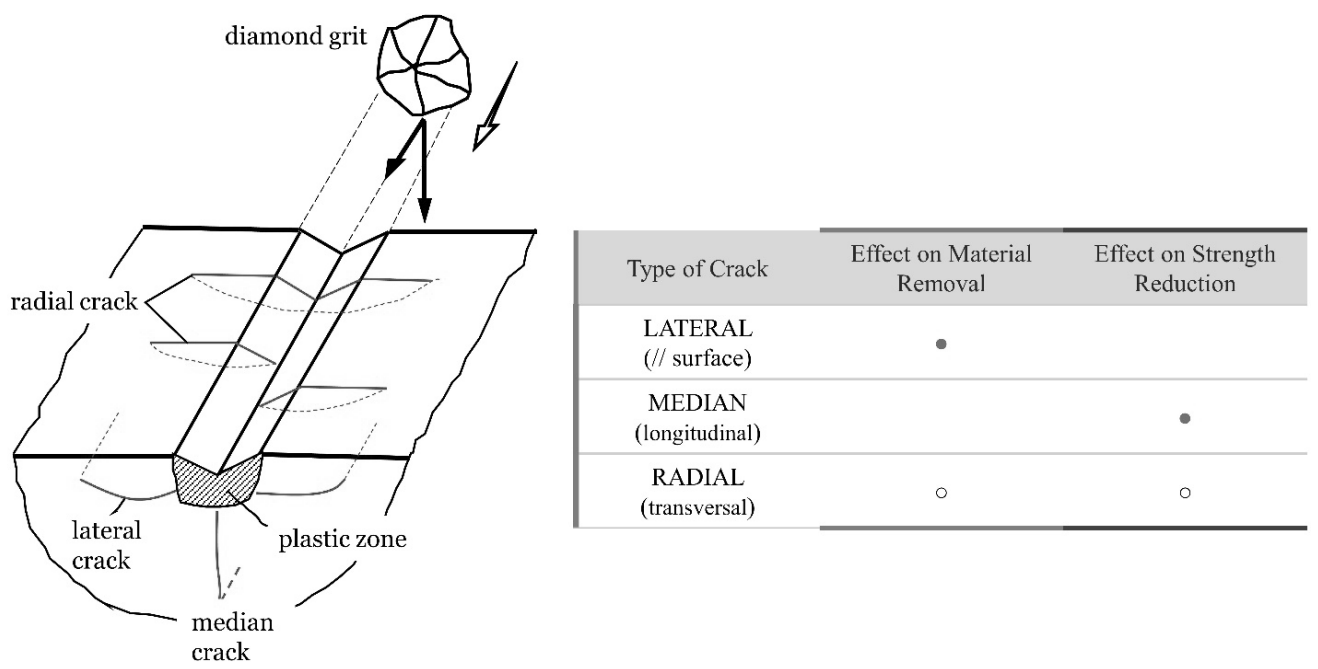

Fig. 3.3 Crack pattern identified in grinding of ceramics. Adapted from [33]. 
median crack of static indents, and emerge as transversal damage features, i.e. nominally normal to the abrasive particle motion and the machining grooves, with some variable curvature.

Lateral cracks may run to the surface, yielding then material removal. On the other hand, median/radial cracks may penetrate deeper into the bulk, inducing a potential strength reduction, and unexpected fracture. Subsurface anisotropic damage probably results in an anisotropic mechanical response behavior under external loading. Depth and relative elongation (shape) of introduced damage are the dominant factors in the strength anisotropy discerned in terms of relative orientation between machining direction and applied stress. Typically, median cracks are substantially more elongated and often larger than the radial ones. As a consequence, lower strength values are attained when the ground workpiece is stressed perpendicular to the grinding direction [31,32,34].

Experimental measurement and analysis of residual stresses induced by grinding are complex; and thus, studies dealing with it are rather limited. Nevertheless, it is well-established that grindinginduced residual stresses are compressive within a layer near the surface, and become tensile underneath [34]. The origin of these residual stresses may be understood by considering the machining damage as an accumulation of a large number of isolated sharp particle contact events [35]. An isolated elastic/plastic contact gives rise to a radially compressive residual field, with tangential tension outside the plastic zone which surrounds the contact site. The overlap of residual fields from neighboring damage sites in a machined surface gives rise to a layer of residual compressive stress. Underlying it, residual tension exists as a compensation effect.

The competing influence of surface flaws and the residual-stressed layer defines the strengthcontrolling damage. The depth of this layer, the relative amount of residual compression and tension implicit to it, and the geometry of the surface crack are important parameters which control the strength of the machined ceramic. Samuel et al. [36] studied nickel-zinc ferrite, tetragonal zirconia polycrystal, and two grades of silicon nitride ground by diamond wheel. They showed that compressive surface stresses from 400 grit diamond grinding (with a $200 \mathrm{~mm}$ depth of cut) extended over 10-20 $\mu \mathrm{m}$ below the surface. Underneath, the stresses rapidly became tensile and gradually fell off to zero at larger depth. Using fracture mechanics, grinding-induced crack sizes 
may be calculated. In most of the ceramics considered, these cracks are embedded in the compressive residual stress zone. Hence, the compressive residual stresses usually translates in a strength increase for ground ceramics.

Grinding is a very complex process with a large number of interacting characteristic parameters. Hence, in order to optimize it, i.e. to maximize productivity and minimize machining costs and induced damage, special attention has been paid to establish the quantitative relationships among grinding variables, machining damage and flexure strength of ground ceramics [32,34]. Because physical relationships are not accurately definable in grinding, pure physical modeling is seldom used. Contrarily, empirical models are commonly proposed on the basis of regression analysis of experimental data attained from direct grinding tests. Even in those cases, they accurate describe one machining application exclusively. Further research and knowledge on issues like nonuniformity of the grinding interface, crack measurement, thermal effects, microstructural features and interaction between machining flaws and residual stress state are clearly needed for better modeling and simulation of grinding operations of ceramics [32,34].

Similar to the case of ceramics, research on grinding-induced surface integrity and its relation with mechanical performance for cemented carbides is also quite limited [37-42]. Alike findings regarding surface integrity, in terms of induced damage and residual stresses, have been reported for ground hardmetals. However, cemented carbides have their own complexity since they are ceramic-metal composites, i.e. materials consisting of both brittle and ductile phases whose relative content may be varied.

Hegeman et al. studied the grinding behavior of WC-Co hardmetals [40]. They reported that WC grains are cracked and pulverized by the high-applied (tensile) stresses of the diamond abrasive grains. Moreover, it was evidenced that part of the carbide grains are pulled-out, leaving some pits, and others are plastically deformed by the compressive stresses in front of the abrasive grains. Analysis of fractured cross-sections indicated the presence of a deformed layer consisting of fragmented and pulverized grains, embedded in a matrix of cobalt which is smeared out on top of the ground surface (Fig. 3.4a). As grinding evolves, it is proposed that such layer is partly removed from the surface together with WC grains and fragments. However, this cross-section 
fractographic analysis did not enable direct inspection of some subsurface damage issues, like those associated with cracking. Hence, plastic deformation (in terms of slip traces) and cracking of WC grains were detected by removal of the deformed surface layer following a surface etching procedure (Fig. 3.4b and 3.4c). Nevertheless, detailed information about binder phase, depth and distribution of cracks, and microstructure-damage interactions cannot be captured from simple inspection of fracture surfaces or either by further etching step. In this thesis, FIB (focused ion beam) milling was applied to reveal grinding-induced damage in WC-Co. Although it was usually done for getting information on single cross-sections, FIB tomography, i.e. serial SEM (scanning electron microscopy) imaging and subsequent 3D reconstruction and visualization, was implemented for examination of specific issues such as distribution and orientation of grindinginduced cracks. Detail procedures are discussed in chapter 4 and results are shown within corresponding contributions, particularly in Annex 2.
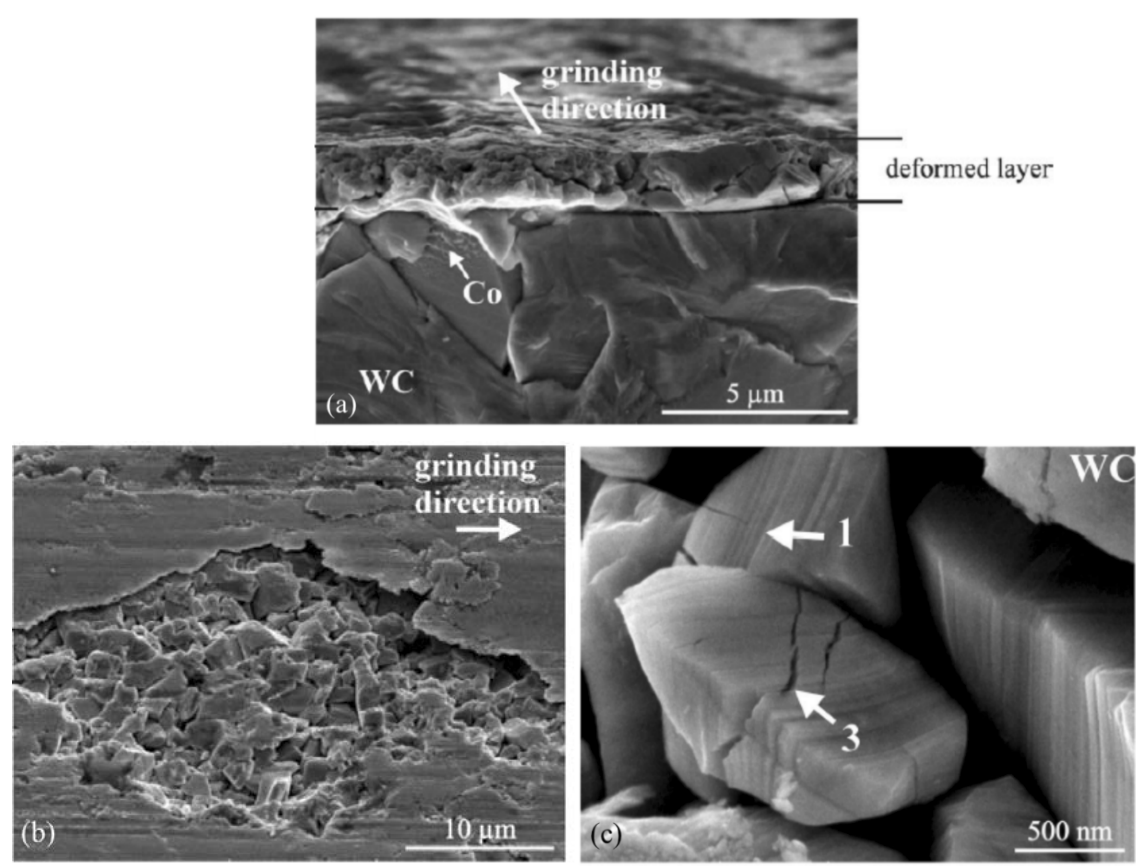

Fig.3.4 Grinding behavior of WC-Co hardmetals studied by Hegeman et al. [40]: (a) fractured cross-section showing the surface deformed layer, (b) this surface deformed layer was etched to reveal the subsurface region and (c) plastic deformation and crack of WC detected inside the etch pit. Reprint is permitted by (C) 2001 Elsevier. 
$\mathrm{X}$-ray diffraction technique is the most commonly used method for determining residual stresses for cemented carbides [37-42]. It is non-destructive, relatively fast, and easy to operate. Normally, residual stress induced by grinding are measured in the WC phase exclusively. Diffraction peaks from the cobalt-base binder phase are usually weak and broad, due to its relative low content, yielding then non-conclusive stress measurements. However, data taken from WC phase represent a good approximation of the deviatoric macrostresses in the surface, since the magnitude of the intrinsic microstresses in the carbide phase is relatively small compared to that of the macrostresses induced by grinding. Detailed principles about the $\mathrm{x}$-ray residual stresses measuring process are described in chapter 4 . In general, it has been reported that grinding generates compressive stresses within a surface layer of several microns in thickness. Distribution of residual stresses of WC grains at the subsurface of cemented carbides, ground using diamond wheel with different grits grain size, was studied by Takeyama et al [39]. They reported that compressive residual stresses existed and decrease gradually into the subsurface. Both magnitude and depth of induced residual stresses are more pronounced as grain size gets coarser. Stress-induced phase transformation of cobalt binder was also detected from identification of hcp phase at different depths beneath the surface. It was thus concluded that tool grinding gives rise to plastic flow and work hardening in the binder phase, these phenomena taken place within a layer of thickness close to $10 \mu \mathrm{m}$. Moreover, in this study the effect of the surface properties of ground cemented carbides regarding brittle fracture under cyclic impact test was investigated. A beneficial effect of grinding was found in terms of suppression of microcrack initiation associated with work hardening. Furthermore, deceleration of microcrack propagation was also evidenced, as related to the existing compressive residual stresses.

The relevance of machining-induced residual stresses on the mechanical response of cemented carbides is further supported by the work of Jiang et al. [41]. In this study, residual stresses and flexural strength of either ground or electrical discharge machined (EDMed) hardmetals were assessed. It was found that relative differences in strength values measured for ground and EDMed hardmetals was directly related to the significant compressive and tensile residual stresses induced, respectively, during implementation of both machining routes. However, a systematic analysis of relative strength changes from a fracture mechanics perspective (i.e. taking into consideration effective stress state, machining flaw, microstructure and fractographic data) was not conducted. 


\subsubsection{From Grinding to Coating Deposition}

As presented in chapter 2, following the machining stages (i.e. grinding and other less intensive operations such as lapping and polishing) that yield required geometry and dimensions of hardmetal tools for a given application, most cutting tools are coated to enhance their performance and lifetime. Deposition of ceramic films provide higher wear/oxidation resistance, thermal isolation and lower friction between the tool and the workpiece.

\subsubsection{Cathodic Arc Evaporation Principles}

Cathodic arc evaporation is the most common method employed to deposit coatings on cutting tools at industrial scale. This technology is able to produce dense compound coatings with high rates and good adhesion to the substrate.

The fundamentals of cathodic arc evaporation are based on the use of arc discharging between the cathode and the anode to induce evaporation of material from the target source (cathode), and its subsequent deposition on the substrate. A schematic figure (Fig. 3.5) shows the cathodic arc evaporation process. A high current, low voltage arc is ignited by the separation of a contact

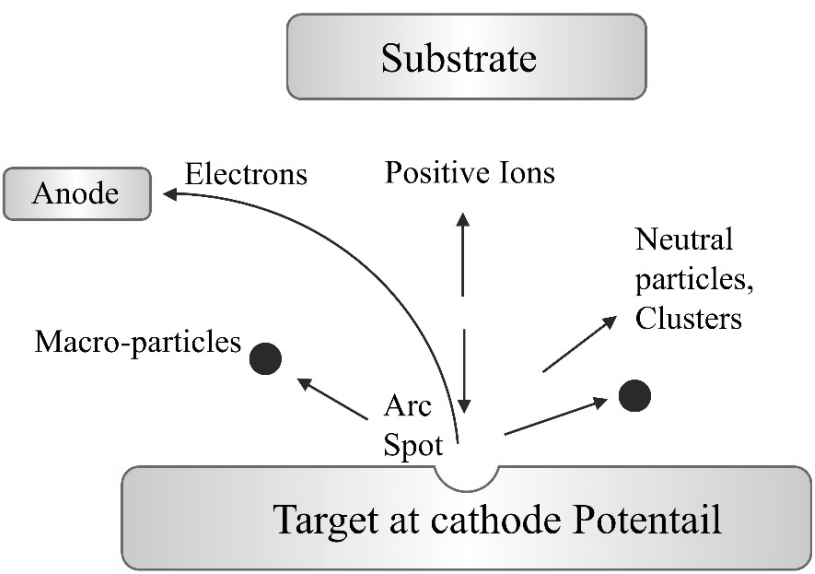

Fig.3.5 Schematic figure showing the cathodic arc evaporation process. 
between the two electrodes carrying an electric current. When the contact breaks, the current flowing between the electrodes melts and vaporizes the last small point of contact, named as arc spot. The arc possesses an extremely high power density resulting the formation of plasma (i.e. positively charged ions and electrons), neutral particles, clusters and macro-particles (droplets). Each cathode spot is active for a very short period. Electric current flowing through the electrodes, transported by the generated plasma, enables the arc to be self-sustained. Self-extinguish and reignition phenomena in a new area, close to the previous crater, cause the apparent motion of the arc. One disadvantage of the cathodic arc evaporation is the creation of macro-particles. These usually have an adverse effect on the mechanical and tribological performance of the coated system, since these heterogeneities are poorly attached to the coating and can extend downwards. Uniform erosion and fast movement of the arc can reduce the generation of macro-particles. Hence, in practice, a magnetic field is always applied to control the rapid motion of the arc over the entire surface of the cathode [43].

TiN is the first and still most commonly implemented arc coating, due to its decorative golden color with excellent wear and corrosion properties. It is widely deposited on cutting and forming tools as well as on wear parts, either as a single layer or combined with other types of films. In this thesis, a single layer of TiN was deposited on the studied hardmetals. The deposition of TiN film by cathodic arc evaporation is achieved by reactively evaporating a pure Ti cathode in the presence of a high partial pressure of nitrogen. A degree of control over the mechanical properties of the films is achievable by varying substrate temperature, substrate bias, and partial pressure of nitrogen [44].

An industrial reactive cathodic arc evaporation system MZR323 was employed in this work. Its configuration is schematically illustrated in Fig. 3.6. The cathodes are placed on the chamber walls, and samples are mounted on a rotating cylinder against the cathodes. A reactive gas, i.e. $\mathrm{N}_{2}$, is introduced into the system through the upper gas inlet for the reactive cathodic arc evaporation. During the arc evaporation process, the cathodes are water cooled through a Cu-plate back support. 


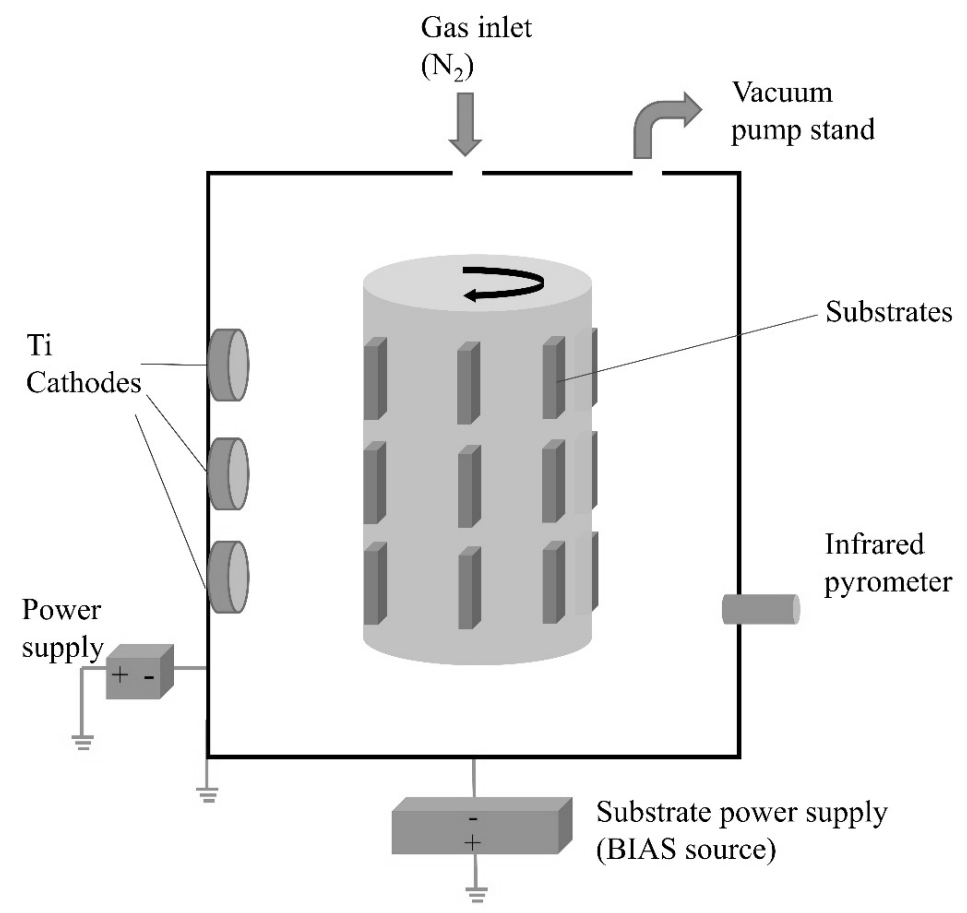

Fig. 3.6 Scheme of the deposition system used to synthesize the TiN coating in this thesis.

The microstructure and morphology of the deposited coating depends largely on the growth parameters, direct function of two main variables: ion energy and temperature. Four structure zones are defined to illustrate common features within films. Depending on the normalized energy flux $\mathrm{E}^{*}$ and the generalized temperature $\mathrm{T}^{*}$, the microstructure of the grown coating is controlled by shadowing effect (zone 1), surface diffusion (zone T and zone 2), and bulk diffusion (zone 3) [45]. In zone 1, the adatom mobility is low, leading to continued nucleation of grains. This results in a fine-grained structure of textured and fibrous grains. Zone $\mathrm{T}$ exhibits dense fiber grains, resulting from the improved diffusion of the adatoms. Zone 2 contains uniform columnar grains, led by surface diffusion. The grain size increases with temperature and may extend all the way throughout the film thickness. In zone 3, bulk diffusion and recrystallization generate dense films with large grains. 
Mechanical properties of thin films, such as cohesive strength and adhesion to the substrate, are critically affected by the intrinsic film stresses. The direct link between energetic issues during the deposition process and film microstructure determines the nature and magnitude of the stress. Tensile stress is generally observed in zone 1-type porous films, and is explained in terms of the grain boundary relaxation model. On the other hand, compressive stress discerned in zone T-type dense films, is associated with the atomic peening mechanism [46]. In general, dense films grown under energetic particle bombardment are typically in a compressive stress state, a finding that has been related to the defects created during the collision cascade [47].

In order to ensure adequate coating functionality, adhesion must be optimized. In this regard, substrate surface must be pretreated such to be vacuum- and coating-compatible. Pretreatment may involve several operations: surface cleaning, optimization of roughness profile, and removal of surface layers. For cathodic arc evaporation, intensive cleaning of the surfaces to be coated is generally needed, since unlike thermal CVD process, the coating temperature is not high enough to completely destroy organic pollution. Oil, grease and other coarse contaminations are removed by wet-chemical means in ultrasonic bath. Following the wet-chemical step, ion cleaning is applied inside the vacuum chamber to achieve extremely good adhesion through removal of reaction layers and surface activation. An extremely dense inert gas (generally Ar) plasma is generated and a negative bias voltage to the substrate is applied, resulting then in ion bombardment cleaning [48].

\subsubsection{Surface Integrity Issues on Coated Cemented Carbides}

It is well-established that successful functionality of a hard coating system depends not only on composition, microstructure and architecture of the layer itself [49-53], but also on the surface integrity of the supporting substrate as well as on the interface nature and strength. Within this context, existing literature concentrates on the influence of the former aspect. On the other hand, only a few investigations address the influence of surface topography or subsurface integrity resulting from changes induced at different manufacturing stages, particularly regarding those implemented prior to coating deposition, i.e., grinding, lapping, polishing, blasting and peening [54-62]. 
Operation of cutting tools under service conditions may involve, besides gradual abrasive wear, different failure phenomena which lead to an immediate halt of production. One type of failure is adhesive, given by coating delamination resulting from poor adhesion strength. The other one is rather cohesive, as it involves flaking of coating material with adhering substrate. In general, cohesive damage occurs at shorter service times; and thus, has great influence on productivity, reliability and safety. Furthermore, coating re-deposition on tools exhibiting adhesive-like failure is not only suitable but also commonly done. This is not clearly the case when cohesive failure takes place.

Surface integrity, mainly in terms of residual stress state, and its impact on performance of cutting tools has been addressed in the literature. In this regard, it has been proven that higher compressive stresses in both coating and substrate have a positive effect on tool life [61] (Fig. 3.7). Nevertheless, after PVD coating a tensile stresses may arise in the upper substrate surface just under the film. Then, in some cases, a superposition of the external stresses imposed during operation and those left after coating may yield cohesive failures. Accordingly, the existence of effective compressive residual stresses at the substrate subsurface after coating deposition, should be aimed if cohesive failure and cutting tool lifetime want to be prevented and improved, respectively.

The intrinsic properties of the substrate are also relevant for the final functional response of the coated system. Knotek et al. [55] investigated the influence of substrate properties on the performance of arc-PVD-coated cemented carbide indexable tips under interrupted-cut machining conditions. They found that higher substrate toughness, existence of compressive stress within the substrate subsurface, and substrate protective ionic etching reduce the risk of cutting-edge chipping.

After the coating deposition stage, the residual stresses on the substrate subsurface depends on the history of all the previous manufacturing steps. As a rule, mechanical loads cause compressive residual stresses, whereas thermal loads induce tensile ones. In some special cases, also mechanical issues can lead to a shift in direction to tensile stress. Denkena and Breidenstein [61,62] developed a model in order to explain the contributions of each single stage to the development of residual 


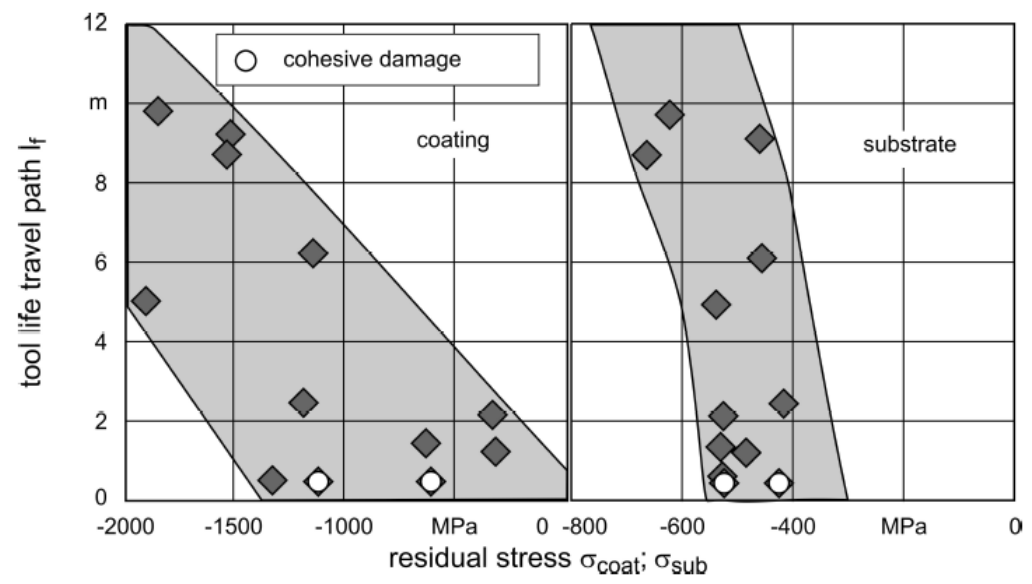

Fig. 3.7 Tool path depending on coating and substrate residual stresses. Taken from [61], reproduced under creative commons license.

stress (Fig. 3.8). A traditional manufacturing process: i) sintering $\rightarrow$ ii) grinding $\rightarrow$ iii) ionetching $\rightarrow$ iv) coating, was illustrated. A detailed description of the evolution of residual stresses during the manufacturing process of a coated tool is given as follows. First, in the sintering stage, both high mechanical and thermal loads exist and as a result, their effects concerning residual stress balance each other, so the surface has no or few residual stress. Second, during grinding, mechanical loads shift the residual stress to the compressive direction, whereas thermal effect is largely suppressed by the coolant. This stage generates penetrating cracks as described previously. Third, during the surface pretreatment before coating - etching, there are strong thermal effects, while mechanical loads relieve the WC grains by setting back the Co binder. Then, the residual stress would be more shifted to the tensile direction. Some surface damage within the shallow layer may be eliminated. Fourth, during the PVD-coating process, thermal effect dominates and leads the residual stress of the substrate surface into the tensile direction. To compensate the stronger compressive residual stress in the coating, the substrate surface generates an additional effect to tensile direction. However, here it is worthy to highlight that although this higher compressive stress in the coating itself may induce a region of the substrate surface shifting to a tensile direction; the coating still have a beneficial effect on the strength of the entire coated system. Casas et al. 


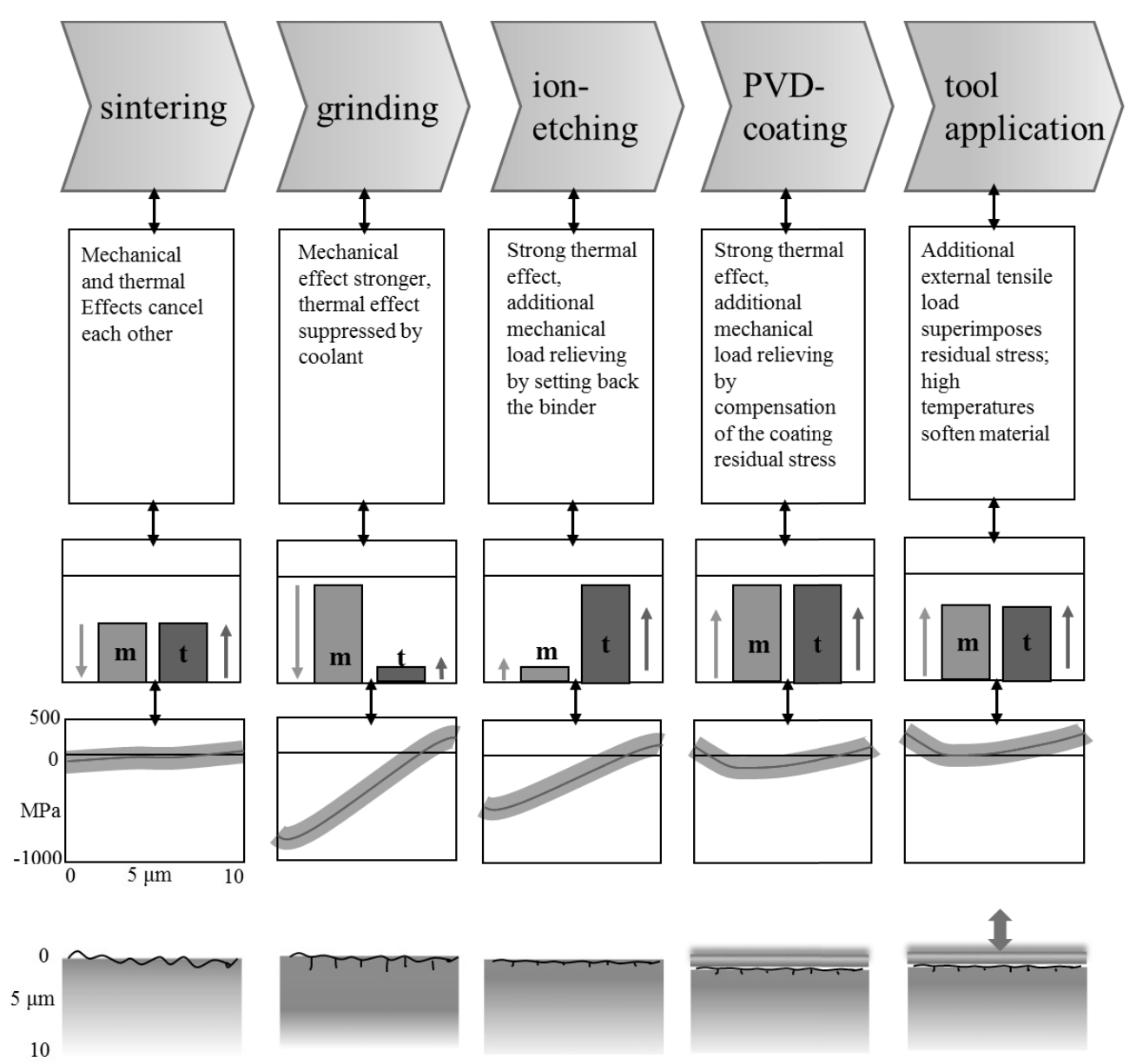

Fig. 3.8 Schematic model for the generation of residual stress in the substrate and subsurface damage evolution during the sequential process of tool manufacturing. Adapted from [61].

[63] reported a beneficial effect associated with coating on the flexural strength of EDMed cemented carbides. The advantageous influence of coating was discussed on the basis of less severe defects (compared to pit-like ones previously introduced by EDM) by recourse to the filler role played by the coating material and the high compressive stresses within the coating layer. 
Concerning manufacturing stages such as grinding or EDM, it must be pointed out that surface topography of coated hardmetals is usually inherited from previous steps. Hence, if surface texture and/or damage still exists, it will be kept after coating deposition and have an adverse influence on the adhesion strength of the coating [64]. Fifth and finally, during the tool use stage, external tensile loads superimpose the residual stresses, whereas the high application temperature may soften the material, then both effects may lead to earlier failure of the tool.

It should be noticed that some of these steps illustrated in Fig. 3.8 may be skipped or reduced in intensity, depending on tool geometry and specific application, i.e. some of the tools may not be coated and/or grinding intensity may vary as a function of material removal conditions as well as hardmetal composition and microstructure. Correspondingly, residual stresses and other surface integrity factors will follow different evolution routes. In this case, it is necessary to conduct a detail exploration of each stage effect. 


\subsection{Surface Integrity Assessment in This Work}

Assessment of the influence of grinding and coating stages on the performance of hardmetal tools requires the evaluation of surface integrity and micromechanical properties at different three coating/substrate levels: (1) substrate surface/subsurface; (2) coating/substrate interface; and (3) coating surface. In each case, attention was paid to different mechanical issues: fracture strength, adhesion behavior and contact damage response.

\subsubsection{Fracture Strength}

Fracture strength is a relevant mechanical parameter for quality control and validation of material production and design. At room temperature, hardmetals exhibit brittle fracture behavior at the macroscopic level, due to the large volume fraction of the carbide phase. However, at the microscopic one, ductile fracture features are evidenced within the metallic binder phase. In general, fracture of hardmetals takes place through catastrophic propagation of either preexisting (processing) or service-induced defects.

Strength is defined as the stress level at which unstable extension of a critical flaw occurs [65]. It is commonly measured as the transverse rupture strength (TRS) under bending test. In this thesis, four-point bending is applied on rectangular specimens, with inner and outer spans of 20 and 40 $\mathrm{mm}$, respectively. The typical test configuration is illustrated in Fig. 3.9. The bottom longitudinal section is the one subjected to the maximum tensile stress in bending. The fracture strength in the test-piece is calculated from the force applied at the moment of fracture and the dimensions of the test-jig and the test-piece, using a simple formula based on thin-beam bending:

$$
\sigma_{f}=\frac{3 F\left(L_{2}-L_{1}\right)}{2 b h^{2}}
$$

where $F$ is the break force, $L_{2}$ and $L_{1}$ are the outer and inner span respectively, $b$ is the width of test-piece, and $h$ is the thickness of test-piece in direction of bending. 

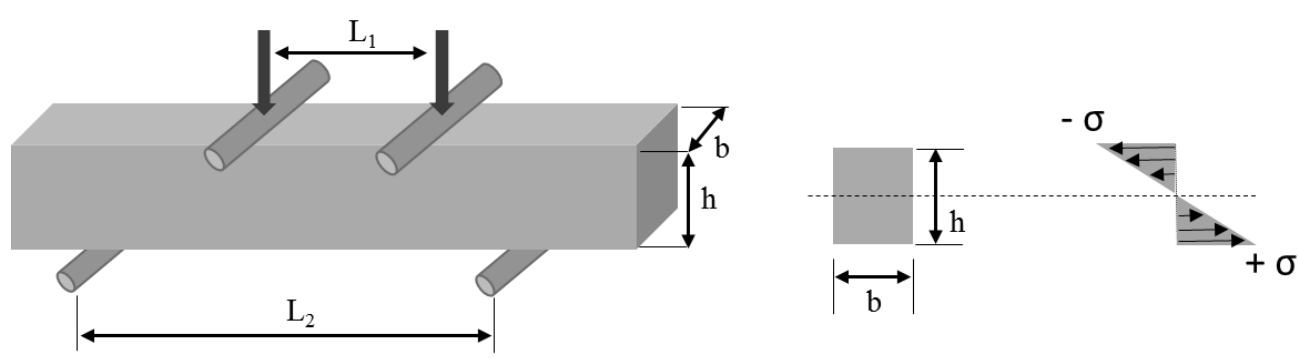

Fig. 3.9 Scheme illustrating typical four-point bending test configuration.

It is well established that strength of hardmetals is determined by microstructural parameters, which define fracture toughness as an intrinsic material property, as well as the nature, shape and dimensions of processing flaws (e.g. pores, inclusions, large carbides, phase clusters, etc.). It has been reported that, for WC-Co grades with binder content between 3 and 25 wt.\%, that TRS initially increases with binder mean free path $\lambda_{C o}$, until reaching a maximal value from which subsequently decreases for higher values of $\lambda_{C o}[66]$. Under external loading, stress concentration easily occurs at existing defects. The effective size, shape and distribution of these flaws influence largely the strength, resulting then in scatter strength values under certain loading mode. Quantitative description of this brittle fracture behavior is usually done on the basis of Weibull analysis. It is a form of extreme value statistics dealing with a weakest link situation, where the failure of a single element of a specimen causes failure of the whole specimen.

In addition to the above factors affecting strength of hardmetals, this parameter is particularly sensitive to surface integrity resulting from grinding and coating stages, especially in terms of subsurface damage layer and compressive stresses. Within this context, strength is effectively defined by the combined influence of depth and magnitude of residual stresses within the subsurface, geometry of the induced cracks, and the synergic interaction of these features with microstructure and processing defects. Such brittle-like fracture behavior of cemented carbides is commonly rationalized on the basis of linear elastic fracture mechanics. Within this framework, failure is defined when the applied stress intensity factor $K_{a p p}$ reaches a critical value $K_{I c}$ : 


$$
K_{a p p}=K_{I c}=Y \sigma_{f} \sqrt{\pi a_{c}}
$$

where $Y$ is a geometry factor, $\sigma_{f}$ is the fracture strength, and $a_{c}$ is the critical flaw size. In the case of existence of residual stress, the total stress intensity factor $K_{t}$ may be estimated as the superposition of the two stress intensity factors, $K_{a p p}$ and $K_{\text {res }}$, induced by the applied bending stress and the residual stress respectively:

$$
K_{t}=K_{a p p}+K_{r e s}=Y\left(\sigma_{a p p}+\sigma_{r e s}\right) \sqrt{\pi a}
$$

where $\sigma_{a p p}$ is the applied stress, $\sigma_{\text {res }}$ is the residual stress, $a$ is the size of the flaw where the above specific stresses localized. When fracture takes place, i.e. $K_{t}$ reaches the critical value $K_{I c}, \sigma_{a p p}$ becomes the fracture strength $\sigma_{f}$ acting on the critical flaw. From equation 3.3, the influence of grinding-induced surface integrity may be analyzed. On one hand, compressive residual stresses should result in enhanced facture strength. On the other hand, however, grinding-induced damage could also act as failure origin, besides any existing microstructural heterogeneity or processing defect. Furthermore, depending on the magnitude and distribution of the grinding-induced residual stresses, it is possible that nature/location of critical flaw may change too.

In this thesis, extensive fractography of all the broken samples is conducted to identify fracture origins as well as to characterize critical flaws. Such information is then used to correlate data collected on surface integrity, fracture strength and microstructure. 


\subsubsection{Adhesion Behavior}

Adhesion strength plays a significant role in determining the functionality and lifetime of a coated system [21,53]. It is well recognized that the intermediate zone between coating and substrate, usually referred to as interface, determines film adhesion. Under external shear and abrasive loading, "practical (extrinsic) adhesion” strength is a response not only of the film itself, but also of substrate surface and subsurface properties [54, 56, 59, 67, 68].

For well-adhered thin coatings, scratch is by far the most common method to assess adhesion, since it is easy to perform and yield comparatively quick results. Scratch test is based on ASTM standard [69]. There, a diamond stylus of defined geometry (normally Rockwell C, a conical diamond indenter with an included angle of $120^{\circ}$ and a spherical tip radius of $200 \mu \mathrm{m}$ ) is employed to slide across the coated surface under an increasing normal load mode. In doing so, the stylus produces progressive mechanical damage in the coating and the substrate (Fig. 3.10). Different critical loads, termed as $\mathrm{L}_{\mathrm{c}}$, are identified as related to well-defined failure events. Usually in-situ and post-failure inspection are employed to examine the failure mode evolution and involved mechanisms. Failure modes during scratch testing of hard coatings can broadly be split into three categories, depending on the properties of both substrate and coating (Fig. 3.11). A first category is given by through-thickness cracking - including tensile cracking behind the indenter, conformal cracking as the coating is bent into the scratch track, and Hertzian cracking. A second one includes spallation - including compressive spallation and/or buckling spallation ahead of the indenter, or elastic recovery induced spallation behind the indenter. Finally, a third category may be defined by chipping in the coating (alike to lateral cracking in bulk ceramics). In general, scratch testing is successfully implemented for hard coatings on substrates, where plastic deformation of the coating does not occur to any great extent $[70,71]$. 


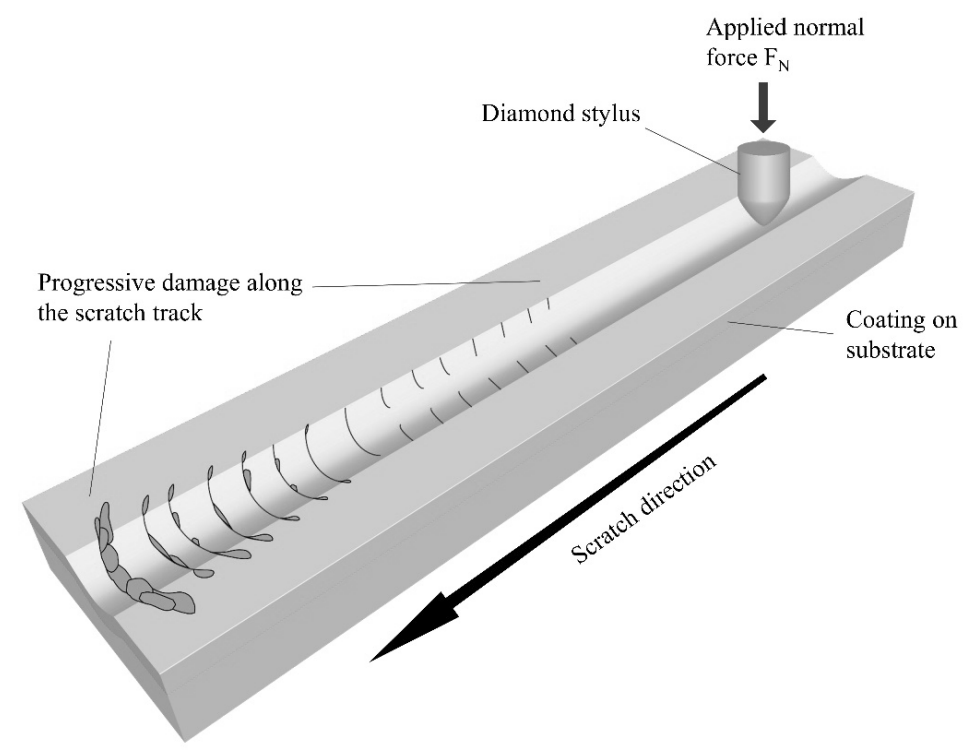

Fig. 3.10 Scheme of scratch test method.

Scratch response is directly influenced by diverse factors such as coating thickness and its roughness, the substrate hardness and its roughness prior to coating, friction force and friction coefficient [64]. The individual effect of each factor may be separated by fixing the other parameters. Here, the influence of substrate hardness is depicted as an example. The extent of the coating-substrate assembly deformation caused by the scratching point is mainly dictated by the substrate deformation. During the scratch test, the maximum of the von-Mises stress moves downwards to the substrate due to the increasing normal load. Once von Mises exceeds the yield strength of the substrate, plastic deformation in terms of yielding takes places. This initial failure of the system will lead to general failure of the coating later. The coating progressively loses its support, and is more and more stretched at the surface. At a given point, cracks occur from the surface straight downward to the coating-substrate interface. Therefore, as substrate hardness increases, higher load is needed to cause the same plastic deformation, and then crack initiation could be delayed. 


\section{$\underline{\text { Scratch Test Failure Regimes }}$}

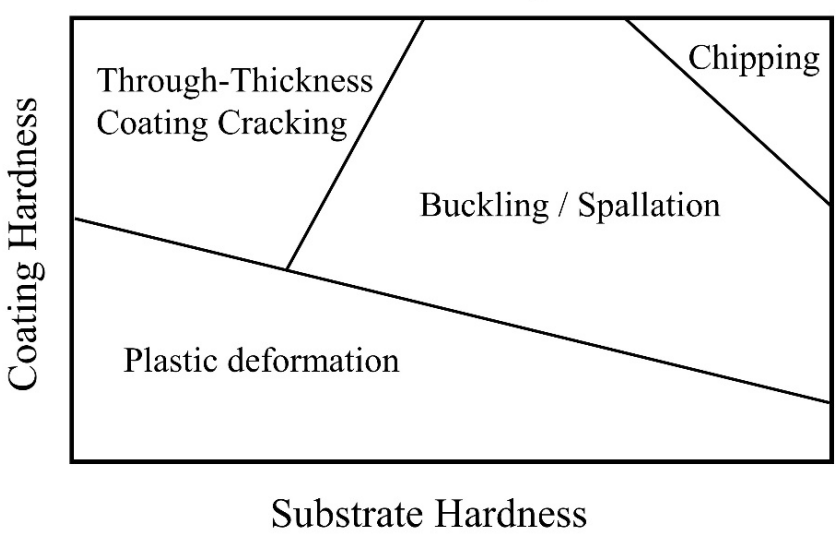

Fig. 3.11 Scratch test failure map depending on coating and substrate hardness. Adapted from [71].

Sveen et al. [68] used scratch testing for studying coating failure mechanisms on different substrate hard materials: high speed steel (HSS), cemented carbides (CC) and polycrystalline cubic boron nitride (PCBN). The practical adhesion of the TiAlN coatings to the underlying substrate material, as determined from the critical normal load corresponding to substrate exposure, was found to increase in the following order: PCBN - HSS - CC. They reported that coating failure does not necessarily correspond to interfacial cracking leading to adhesive failure. On coated PCBN sample, presence of subsurface microcracks at the interface serves as stress concentrators and promotes high local stresses. It deteriorates the cohesive strength of the substrate surface and subsurface region, promoting bulk fracture in connection to the interface. This finding illustrates the significance of substrate surface finish prior to coating, i.e. grinding/lapping process and the amount of damage they can induce. Both substrate load carrying capacity (hardness) and cohesive strength of the substrate surface and subsurface region affect the critical normal load. While the former becomes critical for metallic substrates, e.g. HSS, the latter results to be relevant for significantly harder substrates, e.g. PCBN. 


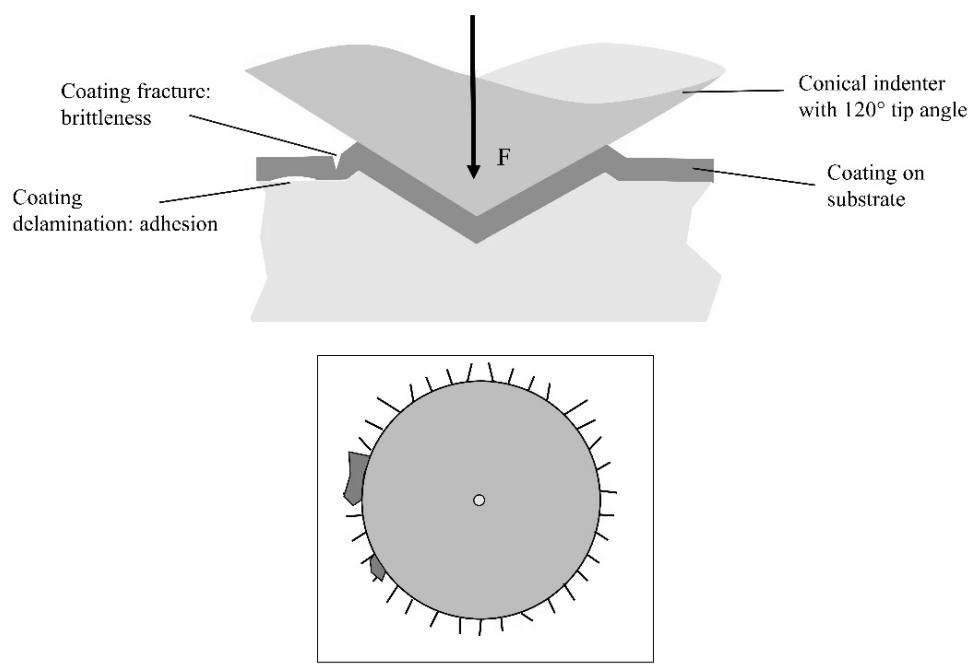

Fig. 3.12 Scheme of indentation technique using Brale conical indenter (top) and a corresponding indentation imprint from surface view point (bottom).

Indentation technique is another simple and practical technique widely used for assessing adhesion of hard coated systems. It is particularly cost effective for industry and often more than adequate in determining the adhesion properties of coatings during commercial processing [72]. This test method uses a standard Rockwell-C hardness tester (maximum applied force $150 \mathrm{kgf}$ ) employing a Brale conical shape diamond indenter with a $120^{\circ}$ tip angle to facilitate its use in a production environment [73] (Fig 3.12). It is prescribed by the VDI 3198 norm and DIN CEN/TS 1071-8 standard $[74,75]$, as a destructive quality test for coated compounds. The indenter penetrates into the coating-substrate system, induces massive plastic deformation in the interface, and causes damage in the film, adjacent to the boundary of the indentation. The resulting fracture of the coating and delamination area are parameters used for evaluation of brittleness and adhesion of the film, respectively. The type and volume of the failure zone can be adequately examined by means of conventional optical microscopy. A more specific quality control can be conducted by scanning electron microscopy [76]. The explicit and comprehensive stress-strain field during indentation's loading/unloading process is of great importance, as it is intimately correlated to the 
failure modes of the coated systems. At low loads, elastic-plastic deformation generates circumferential tension, resulting in radial cracks in brittle materials. As indentation load is increased, shear stresses develop at the coating/substrate interface causing micro- and macrodelamination [77]. The set of parameters defining the overall performance of each specific coated assembly is broad: bulk mechanical properties of the component materials and their mismatch, film thickness, chemical affinity between the coating and the substrate, and many others. The elastoplastic indentation response can be examined using analytical methods, considering that this kind of problem is associated with three non-linear sub-aspects, i.e. plastic deformation of the substrate, anisotropic behavior of the compound and contact problem itself. Nevertheless, the test can be easily performed and evaluation of the results easily depicts the film brittleness and the interfacial adhesion.

Compared to the dynamic scratch test, the indentation technique imposes a static and less severe contact load. It was reported that indentation testing enables a more appropriate method for assessing of the intrinsic fracture resistance of the coating material and coating/substrate adhesion whereas the scratch testing, stimulating the sliding contact condition, is preferably used for evaluating the load carrying capacity of a coating/substrate composite [77].

Although the indentation technique has been widely used for investigate the influence of coating characteristics, i.e. chemical nature, layer architecture, deposition route, crystallographic and microstructural texture, etc. (e.g. Refs. [72,73,76,78-84]), literature information about substraterelated effects, in terms of either microstructure or surface finish, on the indentation response of coated hardmetals is scarce $[76,77,85]$. Larsson et al. [77] assessed the indentation response of TiN coated HSS, exhibiting five different substrate hardness levels. Radial crack initiated at a lower load for a softer HSS substrate than for a hard one, whereas adhesive failure occurred earlier on the coated compound with the harder substrate. They discussed the results on the basis that the compressive state built up in the coating, and the interfacial shear stress during indentation increase with the substrate yield strength (i.e. substrate hardness). Li et al. [85] reported indentation behavior of diamond coatings grown on laser-modified tungsten carbide hardmetal under different shots of laser irradiation. It was detected that diamond coatings with pulsed-UV-laser substrate pretreatment have much smaller cracking areas than those on substrates without any laser 
pretreatment. This phenomenon was related to the characteristic surface morphology produced by pulsed-UV-laser surface ablation, in terms of effective mechanical keying benefits, increased interface contact and altered chemical nature.

In this thesis, scratch of coated hardmetals with different substrate surface finishes are investigated. The failure mechanisms are systematically analyzed aiming to reveal the substrate surface finish role under such loading modes. In the case of static indentation test, in addition to distinct substrate surface finish, two microstructurally different substrates are also studied. 


\subsubsection{Contact Damage Resistance}

Many applications of cemented carbide tools involve complex service conditions. Among these, contact loading plays a significant role, as in wear components, hard body impacts, rollers, ball bearings, gears, etc. It induces irreversible deformation and small fissures, leading to structural integrity degradation. It is therefore essential to understand how the contact loading-induced damage initiates and evolves in these tool materials, because it affects directly not only performance but also reliability of hardmetal tools.

In order to study contact damage phenomena in hard materials, it is common practice to follow testing protocols based on spherical indentation (Hertzian contact). Here, a spherical indenter is implied to deliver concentrated stresses over a small area of specimen surface such that typical "blunt" service-like conditions are simulated. This enables one to follow the entire evolution of
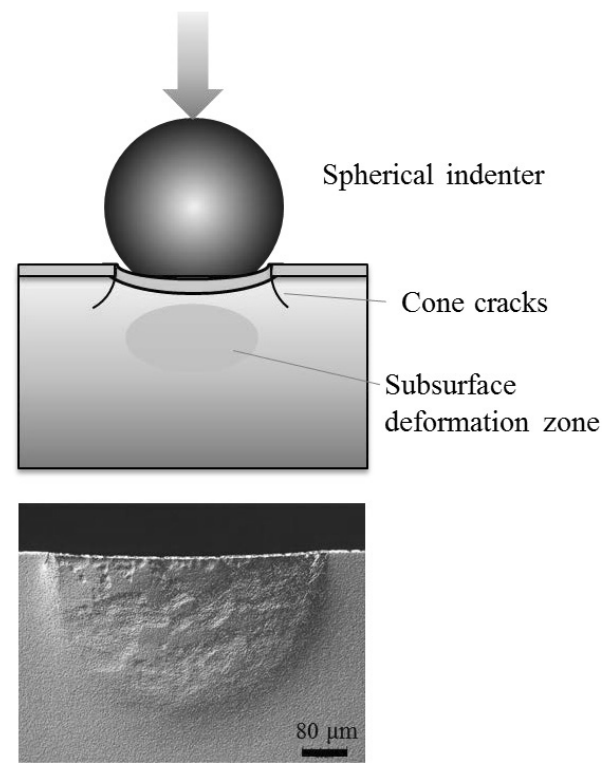

Fig. 3.13 Hertzian contact of sphere on coated specimen. Beyond elastic limit, contact initiates cone fracture ("brittle mode") or subsurface deformation zone ("quasi-plastic mode"). The bottom image shows the cross-section of a Hertzian indented imprint. 
damage modes, as a progressive transition from initial elasticity to full plasticity. It has been used extensively by the ceramic community, especially by Lawn and coworkers (for a review see Ref. [86]).

Considering the frictionless contact of a sphere on a flat continuum specimen, the stress field is initially elastic. As indentation load increases beyond a critical value, two types damage may emerge: as either a Hertzian cone crack ("brittle solid”) or a subsurface deformation zone (“plastic solid”) (Fig. 3.13). The basic Herztian elastic contact stress field has been well documented. The principle normal tensile stresses concentrate in a shallow surface region, with maximum value at the contact circle. The principle shear stresses are constrained beneath the contact, with widely spaced contours and maximum value along the contact axis. These two stress components are responsible for the two types of damages. The tensile stresses at the contact circle will generate a ring crack around the indentation imprint, extending shallow depth (usually a few micrometers) into the subsurface. As load increases, such crack propagates inside the material with a truncate angle to the surface, following the tensile stresses trajectories. This results in the well-known cone crack. The other quasi-plastic deformation damage can be developed by the shear stress at a depth below the surface, around half of the contact area radius. Macroscopically, this deformation region is analogous to the plastic zones that occurs in metals. Microscopically, this damage consists of an array of "closed" mode II cracks with internal sliding friction ("shear faults") at the weak planes within the microstructure. The type of damage that finally appears at the lowest load depends directly on the mechanical properties of the material under consideration. Brittle materials with low fracture toughness tend to exhibit cone cracks under spherical indentation. On the other hand, in tougher ones, quasi-plastic damage is more likely to occur. Meanwhile, a decrease of indenter radius (sharpening), implies an increasing applied stress and prominence to brittle cone crack formation [86,87]. Consequently structural integrity effects (e.g. strength lessening) are found to depend on the nature of the induced contact damage. Ideally brittle homogeneous materials experience abrupt strength losses once the critical load for cone crack initiation is reached. Meanwhile, for tough heterogeneous ceramics strength decrease is rather gradual and continuous, as microdamage cracking associated with a quasi-plastic response develops. 
In Paper 3, controlled damage (ring/cone cracks) is induced under a series of increasing loads, and the contact damage resistance is assessed on the basis of crack nucleation at the coating surface as well as its subsequent extension into the hardmetal substrate. This technique then allows to evaluate the influence of substrate surface integrity (microcracks, residual stresses, etc.), while keeping all other indentation and material variables unchanged, on contact damage response. 


\section{References}

[1] Klocke F, Brinksmeier E, Weinert K. Capability profile of hard cutting and grinding processes. CIRP Ann-Manuf Techn. 2005;54:22-45.

[2] Henriksen EK. Residual stresses in machined surfaces. Trans ASME. 1951;73:69-74.

[3] Colwell LV, Sinnot MJ, Tobin JC. The determination of residual stresses in hardened ground steel. Trans ASME. 1955;77:1099-105.

[4] Field M, Kahles JF. The surface integrity of machined-and ground high-strength steels. DMIC Report. 1964;210:54-77.

[5] Field M, Kahles JF. Review of surface integrity of machined components. CIRP Ann. 1971;20:153-62.

[6] Field M, Kahles JF, Cammett JT. A Review of measuring methods for surface integrity. CIRP Ann. 1972;21:219-38.

[7] Lucca DA, Brinksmeier E, Goch G. Progress in assessing surface and subsurface integrity. CIRP Ann-Manuf Techn. 1998;47:669-93.

[8] Withers PJ. Residual stress and its role in failure. Rep Prog Phys. 2007;70:2211.

[9] M'Saoubi R, Outeiro JC, Chandrasekaran H, Dillon Jr OW, Jawahir IS. A review of surface integrity in machining and its impact on functional performance and life of machined products. Int J Sustain Manuf. 2008;1:203-36.

[10] Ulutan D, Ozel T. Machining induced surface integrity in titanium and nickel alloys: A review. Int J Mach Tool Manu. 2011;51:250-80.

[11] Rech J, Hamdi H, Valette S. Workpiece Surface Integrity. In: Paulo Davim J (Eds.) Machining: Fundamentals and Recent Advances. London: Springer; 2008, p. 59-96.

[12] Astakhov VP. Surface Integrity - Definition and Importance in Functional Performance. In: Paulo Davim J (Eds.) Surface Integrity in Machining. London: Springer; 2010, p. 1-35.

[13] Grzesik W, Kruszynski B, Ruszaj A. Surface Integrity of Machined Surfaces. In: Davim JP (Eds.) Surface Integrity in Machining: Springer London; 2010, p. 143-79.

[14] Brinksmeier E, Cammett JT, König W, Leskovar P, Peters J, Tönshoff HK. Residual stresses — measurement and causes in machining processes. CIRP Ann-Manuf Techn. 1982;31:491510. 
[15] Griffiths B. Manufacturing surface technology: surface integrity and functional performance, London: Penton Press; 2001.

[16] Guo YB, Li W, Jawahir IS. Surface integrity characterization and prediction in machining of hardened and difficult-to-machine alloys: a state-of-art research review and analysis. Mach Sci Technol. 2009;13:437-70.

[17] Jawahir IS, Brinksmeier E, M'Saoubi R, Aspinwall DK, Outeiro JC, Meyer D, Umbrello D, Jayal AD. Surface integrity in material removal processes: Recent advances. CIRP AnnManuf Techn. 2011;60:603-26.

[18] Kahles JF, Field M. Surface integrity - new requirement for surfaces generated by materialremoval methods. Proc. I. Mech. E. 1967;182:31-45.

[19] Field M. Surface integrity - a new requirement for improving reliability of aerospace hardware. 18th Annual National SAMPE Symposium. Los Angeles, USA1973. p. 1-9.

[20] Sadat A. Surface integrity when machining metal matrix composites. In: Paulo Davim J (Eds.) Machining of metal matrix composites. London: Springer; 2012, p. 51-61.

[21] Byrne G, Dornfeld D, Denkena B. Advancing cutting technology. CIRP Ann-Manuf Techn. 2003;52:483-507.

[22] Malkin S, Guo C. Grinding technology: Theory and application of machining with abrasives. Second Edition, Industrial Press Inc. New York 2008.

[23] Marinescu ID, Tonshoff HK, Inaski I. Handbook of ceramic grinding and polishing, Noyes Publications/William Andrew Publishing, L.L.C New York 1998.

[24] Zhang B, Howes TD. Material-removal mechanisms in grinding ceramics. CIRP Ann-Manuf Techn. 1994;43:305-8.

[25] Swain MV. Microfracture about scratches in brittle solids. P Roy Soc A-Math Phy. 1979;366:575-97.

[26] Marshall DB, Evans AG, Khuri Yakub BT, Tien JW, Kino GS. The nature of machining damage in brittle materials. P Roy Soc A-Math Phy. 1983;385:461-75.

[27] Marshall DB. Failure from contact-induced surface flaws. In: Freiman SW, Hudson CM (Eds.) Methods for assessing the structural reliability of brittle materials. Philadelphia: American Society for Testing and Materials; 1984, p. 3-21.

[28] Kirchner HP. Damage penetration at elongated machining grooves in hot-pressed Si3N4. J Am Ceram Soc. 1984;67:127-32. 
[29] Malkin S, Hwang TW. Grinding mechanisms for ceramics. CIRP Ann-Manuf Techn. 1996;45:569-80.

[30] Quinn GD, Ives LK, Jahanmir S. On the fractographic analysis of machining cracks in ground ceramics: a case study on silicon nitride, NIST Spec Publ. 2003;996:1-106.

[31] Subhash G, Marszalek MA, Maiti S. Sensitivity of scratch resistance to grinding-induced damage anisotropy in silicon nitride. J Am Ceram Soc. 2006;89:2528-36.

[32] Li K, Warren Liao T. Surface/subsurface damage and the fracture strength of ground ceramics. J Mater Process Technol. 1996;57:207-20.

[33] Saljé E, Moehlen H. Material removal in grinding of advanced ceramics. 3rd International Grinding Conference. Dearborn, MI, USA SME Technical Paper MR88-498, Society of Manufacturing Engineers; 1988.

[34] Rice RW. Monolithic and composite ceramic machining flaw-microstructure-strength effects: model evaluation. J Eur Ceram Soc. 2002;22:1411-24.

[35] Johnson-Walls D, Evans AG, Marshall DB, James MR. Residual stresses in machined ceramic surfaces. J Am Ceram Soc. 1986;69:44-7.

[36] Samuel R, Chandrasekar S, Farris TN, Licht RH. Effect of residual stresses on the fracture of ground ceramics. J Am Ceram Soc. 1989;72:1960-6.

[37] Perry AJ, Geist DE, Narasimhan K, Treglio JR. On the state of stress in the surface of ground cemented carbide before and after metal ion implantation. Surf Coat Tech. 1996;86-87, Part 1:364-71.

[38] Hara A, Megata M, Yazu S. X-ray study of residual stresses in ground cemented carbides. Powder Metall Int. 1970;2:43-7.

[39] Takeyama H, Iijima N, Uno K. Surface integrity of cemented carbide tool and its brittle facture. CIRP Ann-Manuf Techn. 1982;31:59-63.

[40] Hegeman JBJW, De Hosson JTM, de With G. Grinding of WC-Co hardmetals. Wear. 2001;248:187-96.

[41] Jiang D, Anne G, Vleugels J, Vanmeensel K, Eeraerts W, Liu W, Lauwers B, Van der Biest O. Residual stresses in hardmetals caused by grinding and EDM machining and their influence on the flexural strength. 16th International Plansee Conference. Reutte, Austria 2005. p. 107585. 
[42] Merklein M, Andreas K, Engel U. Influence of machining process on residual stresses in the surface of cemented carbides. Procedia Eng. 2011;19:252-7.

[43] Anders A. Cathodic Arcs: From Fractal Spots to Energetic Condensation, Springer New York 2008.

[44] Martin PJ, McKenzie DR. Film growth. In: Boxman RL, Sanders DM, Martin PJ (Eds.) Handbook of Vacuum Arc Science and Technology. Park Ridge, NJ: William Andrew Publishing; 1996, p. 467-93.

[45] Anders A. A structure zone diagram including plasma-based deposition and ion etching. Thin Solid Films. 2010;518:4087-90.

[46] Windischmann H. Intrinsic stress in sputter-deposited thin films. Crit Rev Solid State. 1992;17:547-96.

[47] Ljungcrantz H, Hultman L, Sundgren JE, Karlsson L. Ion induced stress generation in arcevaporated TiN films. J Appl Phys. 1995;78:832-7.

[48] Erkens G, Vetter J, Müller J, Auf dem Brinke T, Fromme M, Mohnfeld A. Plasma-Assisted Surface Coating, Verlag Moderne Industrie Germany 2011.

[49] Bouzakis KD, Vidakis N, David K. The concept of an advanced impact tester supported by evaluation software for the fatigue strength characterization of hard layered media. Thin Solid Films. 1999;355-356:322-9.

[50] Fox V, Jones A, Renevier NM, Teer DG. Hard lubricating coatings for cutting and forming tools and mechanical components. Surf Coat Tech. 2000;125:347-53.

[51] Mitterer C, Holler F, Reitberger D, Badisch E, Stoiber M, Lugmair C, Nöbauer R, Müller T, Kullmer R. Industrial applications of PACVD hard coatings. Surf Coat Tech. 2003;163164:716-22.

[52] Podgornik B, Hogmark S, Pezdirnik J. Comparison between different test methods for evaluation of galling properties of surface engineered tool surfaces. Wear. 2004;257:843-51.

[53] Bouzakis KD, Michailidis N, Skordaris G, Bouzakis E, Biermann D, M'Saoubi R. Cutting with coated tools: coating technologies, characterization methods and performance optimization. CIRP Ann-Manuf Techn. 2012;61:703-23.

[54] Bromark M, Larsson M, Hedenqvist P, Olsson M, Hogmark S. Influence of substrate surface topography on the critical normal force in scratch adhesion testing of TiN-coated steels. Surf Coat Tech. 1992;52:195-203. 
[55] Knotek O, Löffler F, Krämer G. Substrate- and interface-related influences on the performance of arc-physical-vapour-deposition-coated cemented carbides in interrupted-cut machining. Surf Coat Tech. 1992;54-55, Part 2:476-81.

[56] Tönshoff HK, Karpuschewski B, Mohlfeld A, Seegers H. Influence of subsurface properties on the adhesion strength of sputtered hard coatings. Surf Coat Tech. 1999;116-119:524-9.

[57] Tönshoff HK, Seegers H. X-Ray diffraction characterization of pre-treated cemented carbides for optimizing adhesion strength of sputtered hard coatings. Surf Coat Tech. 2001;142144:1100-4.

[58] Carlsson P, Olsson M. PVD coatings for sheet metal forming processes-a tribological evaluation. Surf Coat Tech. 2006;200:4654-63.

[59] Denkena B, Breidenstein B. Influence of the residual stress state on cohesive damage of PVDcoated carbide cutting tools. Adv Eng Mater. 2008;10:613-6.

[60] Heinrichs J, Jacobson S. Laboratory test simulation of aluminium cold forming - influence from PVD tool coatings on the tendency to galling. Surf Coat Tech. 2010;204:3606-13.

[61] Denkena B, Breidenstein B. Residual stress distribution in PVD-coated carbide cutting tools: Origin of cohesive damage. Tribol Ind. 2012;34:158-65.

[62] Breidenstein B, Denkena B. Significance of residual stress in PVD-coated carbide cutting tools. CIRP Ann-Manuf Techn. 2013;62:67-70.

[63] Casas B, Lousa A, Calderón J, Anglada M, Esteve J, Llanes L. Mechanical strength improvement of electrical discharge machined cemented carbides through PVD (TiN, TiAlN) coatings. Thin Solid Films. 2004;447-448:258-63.

[64] Steinmann PA, Tardy Y, Hintermann HE. Adhesion testing by the scratch test method: The influence of intrinsic and extrinsic parameters on the critical load. Thin Solid Films. 1987;154:333-49.

[65] Shatov AV, Ponomarev SS, Firstov SA. 1.10 - Fracture and Strength of Hardmetals at Room Temperature. In: Sarin VK, Mari D, Llanes L (Eds.) Comprehensive Hard Materials. Oxford: Elsevier; 2014. Vol. 1, p. 301-43.

[66] Gurland J. New scientific approaches to development of tool materials. Int Mat Rev. 1988;33:151-66. 
[67] Casas B, Anglada M, Sarin VK, Llanes L. TiN coating on an electrical discharge machined WC-Co hardmetal: surface integrity effects on indentation adhesion response. J Mater Sci. 2006;41:5213-9.

[68] Sveen S, Andersson JM, M'Saoubi R, Olsson M. Scratch adhesion characteristics of PVD TiAlN deposited on high speed steel, cemented carbide and PCBN substrates. Wear. 2013;308:133-41.

[69] ASTM C 1624-05, Standard test method for adhesion strength and mechanical failure modes of ceramic coatings by quantitative single point scratch testing. West Conshohocken, PA: ASTM International; 2005.

[70] Bull SJ. Failure modes in scratch adhesion testing. Surf Coat Tech. 1991;50:25-32.

[71] Bull SJ. Failure mode maps in the thin film scratch adhesion test. Tribol Int. 1997;30:491-8.

[72] Heinke W, Leyland A, Matthews A, Berg G, Friedrich C, Broszeit E. Evaluation of PVD nitride coatings, using impact, scratch and Rockwell-C adhesion tests. Thin Solid Films. 1995;270:431-8.

[73] Mehrotra PK, Quinto DT. Techniques for evaluating mechanical properties of hard coatings. J Vac Sci Technol A. 1985;3:2401-5.

[74] Verein Deutscher Ingenieure Normen, VDI 3198. Dusseldorf, Germany: VDI-Verlag; 1991.

[75] DIN CEN/TS 1071-8 Advanced technical ceramics. Methods of test for ceramic coatings. Rockwell indentation test for evaluation of adhesion; German version. DIN CEN/TS 10718:2004.

[76] Vidakis N, Antoniadis A, Bilalis N. The VDI 3198 indentation test evaluation of a reliable qualitative control for layered compounds. J Mater Process Technol. 2003;143-144:481-5.

[77] Larsson M, Olsson M, Hedenqvist P, Hogmark S. Mechanisms of coating failure as demonstrated by scratch and indentation testing of TiN coated HSS. Surf Eng. 2000;16:43644.

[78] Jindal PC, Quinto DT, Wolfe GJ. Adhesion measurements of chemically vapor deposited and physically vapor deposited hard coatings on WC-Co substrates. Thin Solid Films. 1987;154:361-75.

[79] Diao DF, Kato K, Hokkirigawa K. Fracture mechanisms of ceramic coatings in indentation. J Tribol. 1994;116:860-9. 
[80] Ollendorf H, Schneider D. A comparative study of adhesion test methods for hard coatings. Surf Coat Tech. 1999;113:86-102.

[81] Hollstein F, Wiedemann R, Scholz J. Characteristics of PVD-coatings on AZ31hp magnesium alloys. Surf Coat Tech. 2003;162:261-8.

[82] Chen L, Du Y, Yin F, Li J. Mechanical properties of (Ti, Al)N monolayer and TiN/(Ti, Al)N multilayer coatings. Int J Refract Met Hard Mater. 2007;25:72-6.

[83] Horiuchi T, Yoshida K, Kano M, Kumagai M, Suzuki T. Evaluation of adhesion and wear resistance of DLC films deposited by various methods. Plasma Process Polym. 2009;6:410-6.

[84] Wang CT, Escudeiro A, Polcar T, Cavaleiro A, Wood RJK, Gao N, Langdon TG. Indentation and scratch testing of DLC-Zr coatings on ultrafine-grained titanium processed by highpressure torsion. Wear. 2013;306:304-10.

[85] Li T, Lou Q, Dong J, Wei Y, Zhou J, Liu J, Zhang Z, Sun F. Improved adhesion of diamond coating on cobalt-cemented tungsten carbide hardmetal by using pulsed-UV-laser substrate surface pretreatment. Appl Surf Sci. 2002;193:102-19.

[86] Lawn BR. Indentation of ceramics with spheres: a century after Hertz. J Am Ceram Soc. 1998;81:1977-94.

[87] Jiménez-Piqué E, Llanes L, Anglada M. 2.13 - Resistance to Contact Deformation and Damage of Hard Ceramics. In: Sarin VK, Mari D, Llanes L (Eds.) Comprehensive Hard Materials. Oxford: Elsevier; 2014, Vol.2, p. 367-83. 



\section{Materials and Characterization Techniques}

\subsection{Materials in This Study and Surface Finish Conditions}

The substrates studied here correspond to two commercial WC-Co hardmetal grades (supplied by SECO Tools AB) with similar fine grain size, but different binder content: 6 wt.\% and 13 wt.\%. They are here referred as $6 \mathrm{~F}$ and $13 \mathrm{~F}$ respectively. Nominal chemical composition, mean carbide grain size, as well as their basic bulk mechanical properties such as elastic modulus, hardness and fracture toughness values for the hardmetal grades investigated are listed in Table 4.1. Carbide grain size was determined by using an electron back scattered diffraction (EBSD) system manufactured by HKL using their Channel 5 software. Elastic modulus was measured by the method of the resonance frequency of the material. This procedure is simple and quickly implemented. It is performed on the basis given in ASTM E-1876 [1], which consists in measuring the natural frequency of vibration of the material from its transient response to slight mechanical impulse. Hardness was measured using a 30 kgf (294 N) Vickers pyramidal diamond indentation. Toughness measurement was conducted through three-point bending test of Chevron-notched specimens. Experimental details regarding microstructural, hardness and toughness characterization of the substrate materials are given in Ref. [2]. Fig. 4.1 shows the microstructural aspects for the two hardmetal grades studied.

Table 4.1. Mean and standard values for basic microstructural and mechanical parameters for the cemented carbides (WC-Co) studied [2].

\begin{tabular}{cccccc}
\hline $\begin{array}{c}\text { Hardmetal } \\
\text { grade }\end{array}$ & $\begin{array}{c}\text { Nominal } \\
\text { binder content } \\
(\text { wt.\% Co })\end{array}$ & $\begin{array}{c}\text { Mean WC } \\
\text { grain size } \\
(\mu \mathrm{m})\end{array}$ & $\begin{array}{c}\text { Elastic } \\
\text { modulus } \\
(\mathrm{GPa})\end{array}$ & $\begin{array}{c}\text { Hardness } \\
\text { HV30 }\end{array}$ & $\begin{array}{c}\text { Fracture } \\
\text { toughness } \\
(\mathrm{GPa})\end{array}$ \\
\hline $6 \mathrm{~F}$ & 6 & 0.70 & 678 & 17.8 & 9.4 \\
$13 \mathrm{~F}$ & 13 & 0.67 & 599 & 14.8 & 11.2 \\
\hline
\end{tabular}



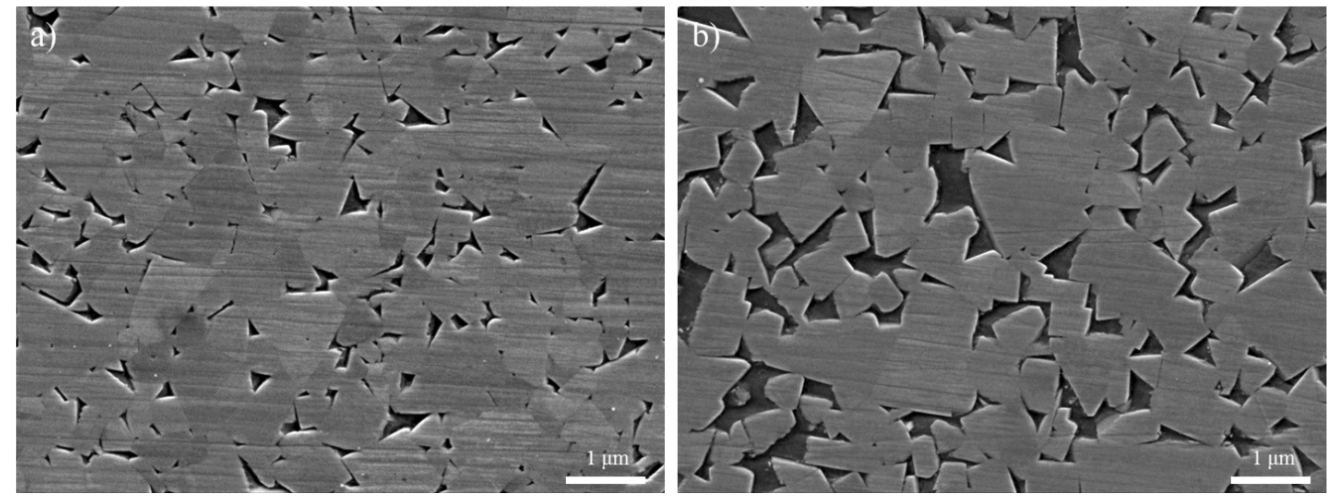

Fig. 4.1 Microstructural aspects of the two grades under consideration: (a) $6 \mathrm{~F}$ and (b) $13 \mathrm{~F}$.

Considering that bending strength will be a reference test procedure, the WC-Co grades investigated were provided in the form of rectangular bars of dimensions $4 \times 4 \times 50 \mathrm{~mm}$. Fig. 4.2 schematically outlines the surface preparation steps followed to obtain the different surface finish variants investigated. There are two different surface finish conditions directly received from SECO Tools AB: as-sintered without any machining process (condition AS), and ground (condition G). The grinding operation, using a diamond abrasive wheel and coolant, followed an industrial protocol. It is commonly implemented for inserts by SECO Tools AB. Additionally, a reference condition has been obtained at the laboratory, by means of conventional grinding and polishing (condition P) with diamond abrasive and silica colloidal. The referred surface preparation procedure consisted of grinding the samples with diamond disks $220 \#, 600 \#$ and 1200 \#, followed by polishing with diamond paste of 6 and $3 \mu \mathrm{m}$, and then finished with silica colloidal $(\leq 0.2 \mu \mathrm{m})$. Aiming to investigate a damaged-like ground condition without residual stresses, some of the originally ground specimens were heat-treated at $920^{\circ} \mathrm{C}$ for $1 \mathrm{~h}$ in vacuum. This ground and thermal treated condition is referred to as condition GTT.

The TiN coating was deposited by means of an industrial reactive cathodic arc evaporation system MZR323. Before deposition, the substrates were cleaned in ultrasonic baths of an alkali solution and alcohol. Subsequently, substrates with the four surface finish conditions were mounted at the 


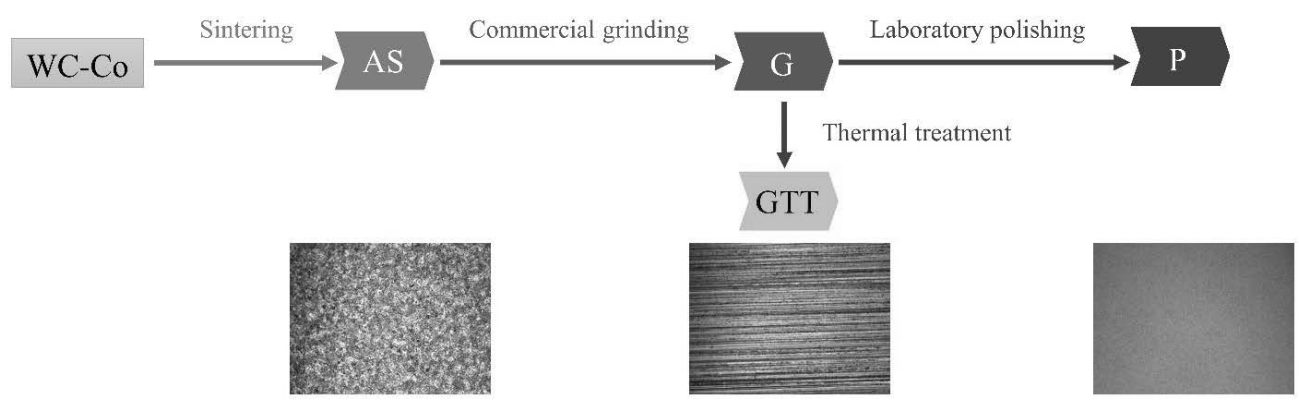

Fig. 4.2 Scheme of the process steps used to obtain the different surface finish variants investigated: AS, G, P and GTT. Images below are obtained by means of optical microscopy to illustrate surface conditions.

same height with respect to the cathodes on a rotating cylinder. The system was evacuated to a pressure of less than $2.0 \times 10^{-3} \mathrm{~Pa}$ such that the substrates were $\mathrm{Ar}$ ion etched with about $500 \mathrm{eV}$. After all those above steps, the deposition was performed from pure Ti cathodes in a $\mathrm{N}_{2}$ atmosphere at a pressure of $2 \mathrm{~Pa}$. A substrate bias of $-50 \mathrm{~V}$ was used to accelerate the Ti-ions towards the substrate and the temperature was maintained at $450{ }^{\circ} \mathrm{C}$.

\subsection{Surface Texture}

Surface roughness represents the shape and size of irregularities on a machined surface. It is one of the primary surface texture parameters used to describe the surface finish produced by machining processes. Roughness plays a significant role in understanding the nature of two contact surfaces, and has a major impact on controlling the performance of the end product regarding issues such as friction, durability, operating noise, energy consumption, and air-tightness.

Many parameters have been established to quantify surface irregularities, and they are categorized in terms of height, depth, and length interval. They are analyzed by a predetermined method and calculated according to measurement standards. In this thesis, $R_{a}$ and $R_{y}$ were selected to compare 
the different surface texture among the studied surface finish variants. Average roughness, $R_{a}$, is the most commonly specified parameter for surface finish measurements. It describes the arithmetic average deviation of a surface from a mean line, and provides a good general guide for part performance over a wide range of applications. Maximum peak to valley height value is represented by the $R_{y}$ parameter, and it can be measured to distinguish the profiles. Furthermore, $R_{y}$ is also utilized where extreme height of roughness profile is important, i.e. precision tolerance $[3]$.

Measurement techniques of surface texture may be broadly divided into two categories: contact and non-contact types. On the microscopic scale of surface measurement, a contact type stylus profiler (SP) using electronic amplification is the most popular. In SP technique, the stylus is loaded on the surface to be measured, and then moved across the surface at a constant velocity to obtain surface height variation [4] (Fig. 4.3). A stylus type, surface texture measuring system was employed in this thesis.

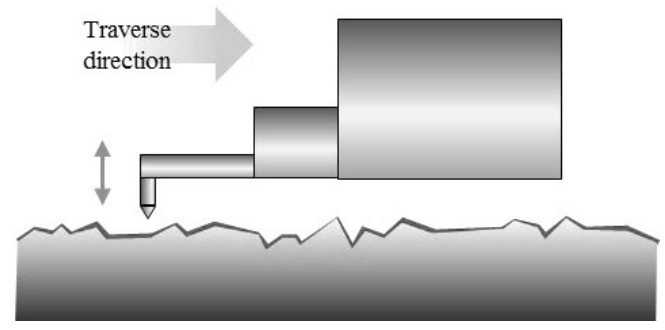

Fig. 4.3 Scheme of stylus-type roughness instrument. 


\subsection{X-ray Diffraction}

X-ray diffraction is a widely used method to measure residual stresses. It is nondestructive and requires no sample preparation. It measures the diffraction angle variation $\Delta \theta$, and this is translated into the plane spacing change $\Delta d$. As a consequence, the strain $\varepsilon$ can be calculated, and the stress $\sigma$ can be derived through elasticity theory.

\subsubsection{X-ray Scattering From Atomic Planes}

Fig. 4.4 shows a scheme of diffraction of x-rays by a crystal. When an x-ray beam with wave length $\lambda$ impinges on a crystal where the $(h k l)$ planes are parallel to the surface, the periodic distribution of atoms on planes cause constructive interference of the coherent component of the scattered radiation from the individual atoms, i.e. diffraction occurs when Bragg' law is satisfied:

$$
n \lambda=2 d_{h k l} \sin \theta
$$

where $n$ is an integral multiple, $d_{h k l}$ is plane spacing and $\theta$ is the angle of incidence and reflection. In the case of an actual three-dimensional crystal of finite dimensions, which contains a large number of atomic planes, several mutually reinforcing beams cause appreciable diffracted x-ray intensity at the correct angles. In a laboratory $\theta-2 \theta$ scan, plane spacing may be derived from equation 4.1, and crystal structure of the material can then be determined.

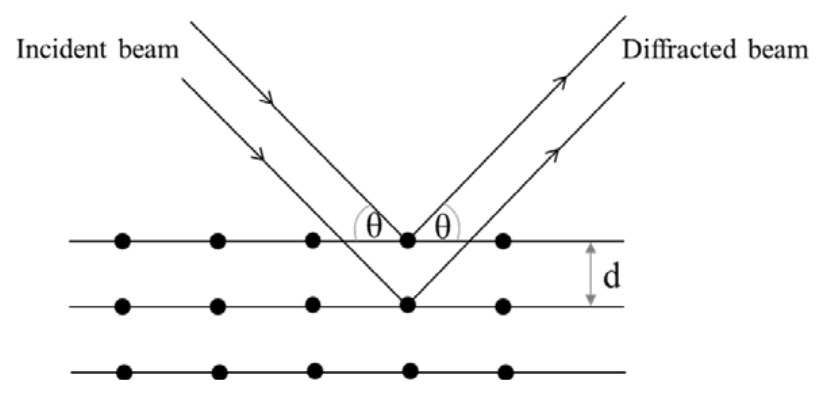

Fig. 4.4 Scheme of diffraction of x-rays by a crystal. 


\subsubsection{Elastic Stress-Strain Relations}

Consider stress tensors on the faces of a homogeneously loaded unit cube at static equilibrium within an isotropic material (Fig. 4.5). A normal stress $\sigma_{i i}$ will cause a tensile strain $\varepsilon_{i i}$ along the stress direction, and compressive strains $\varepsilon_{j j}$ along the transverse one, according to Hook's law in the form:

$$
\varepsilon_{i i}=\frac{1}{E} \sigma_{i i}, \quad \varepsilon_{j j}=-\frac{v}{E} \sigma_{i i}, \quad i \neq j
$$

The proportionality constants $E$ and $v$ are Young's modulus of elasticity and Poisson's ratio, respectively. Based on equation (4.2), the normal strain is the sum of the one produced by the stress in that direction, plus those caused by the stresses existing in the transverse direction, expressed as:

$$
\begin{aligned}
& \varepsilon_{11}=\frac{1}{E} \sigma_{11}-\frac{v}{E}\left(\sigma_{22}+\sigma_{33}\right) \\
& \varepsilon_{22}=\frac{1}{E} \sigma_{22}-\frac{v}{E}\left(\sigma_{11}+\sigma_{33}\right) \\
& \varepsilon_{33}=\frac{1}{E} \sigma_{33}-\frac{v}{E}\left(\sigma_{11}+\sigma_{22}\right)
\end{aligned}
$$

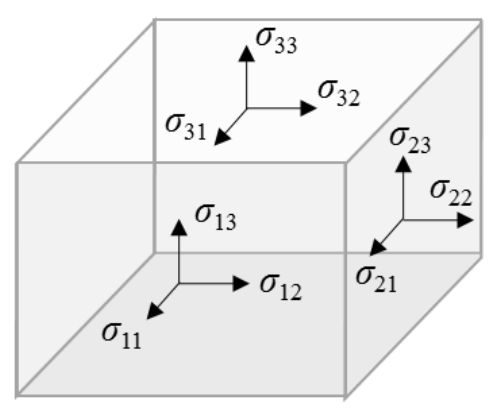

Fig. 4.5 Definition of sample-related stress tensor $\sigma_{i j}$. 
Shear strain exists when shear stain $\sigma_{i j}, i \neq j$ is applied and is given by:

$$
\varepsilon_{i j}=\frac{1}{2 \mu} \sigma_{i j}, \quad i \neq j
$$

Here, the proportionality constant $\mu$ is the shear modulus, and for isotropic materials, it is equal to $E / 2(1+v)$.

Combination of equations (4.3) and (4.4) yields the expression of each tensor component in one formula, as follow:

$$
\varepsilon_{i j}=\frac{1+v}{E} \sigma_{i j}-\delta_{i j} \frac{v}{E} \sigma_{k k}
$$

where $k$ is the dummy suffix and implies summation for all $k$; and $\delta_{i j}$ equals to 1 if $i=j$, otherwise it is zero. This is a generalization of Hook'law and constitutes the basis for derivation of strains and stresses. 


\subsubsection{Stress Determination From X-ray Diffraction Data}

The experimental geometry setup for stresses measurement in x-ray diffraction is schematically shown in Fig. 4.6. $S_{i}$ and $L_{i}$ represent two orthogonal coordinate systems. In the specimen system $S_{i}, S_{3}$ is normal to the sample surface, whereas $S_{1}$ and $S_{2}$ are in the sample surface. The laboratory system $L_{i}$ is defined such that $L_{3}$ is orthogonal to a family of x-ray diffracted $\{h k l\}$ planes. $L_{2}$ is in a plane parallel to the sample surface, and makes a rotation angle $\varphi$ with $S_{2}$. This rotation angle $\varphi$ measures the azimuth of the sample in the surface plane. The titling angle $\psi$ quantifies the amount of the tilting of the $S_{3}$ with respect to the scattering vector $L_{3}$. Once the lattice spacing $d_{\varphi \psi}$ of the reflection planes $\{h k l\}$ is determined through Equation (4.1), the strain $\varepsilon_{\varphi \psi}$ along $L_{3}$ will be defined as:

$$
\varepsilon_{\varphi \psi}=\frac{d_{\varphi \psi}-d_{0}}{d_{0}}
$$

where the $d_{0}$ is the lattice spacing in the unstressed plane.

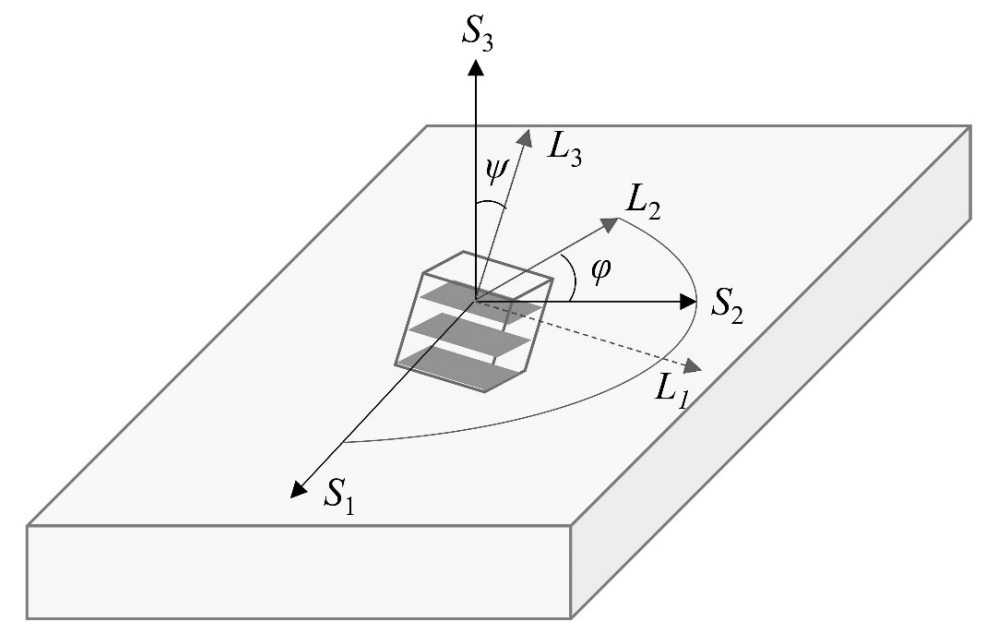

Fig. 4.6 Scheme of experimental geometry setup for stresses measurement in x-ray diffraction. Adapted from [5]. 
Alternatively, such strain measured in the laboratory system, can also be expressed in terms of the strains components $\varepsilon_{i j}$ in the sample reference frame $\left\{S_{i}\right\}$ by tensor transformation, according to [5]:

$$
\begin{aligned}
\varepsilon_{\varphi \psi}=\varepsilon_{11} \cos ^{2} \varphi \sin ^{2} \psi & +\varepsilon_{12} \sin 2 \varphi \sin ^{2} \psi \\
+\varepsilon_{22} \sin ^{2} \varphi \sin ^{2} \psi & +\varepsilon_{13} \cos \varphi \sin 2 \psi \\
& +\varepsilon_{33} \cos ^{2} \varphi
\end{aligned}
$$

In this general equation for x-ray strain determination, substituting the strain components $\varepsilon_{i j}$ and $\varepsilon_{\varphi \psi}$ using equations (4.5) and (4.6) yields:

$$
\begin{aligned}
\frac{d_{\varphi \Psi}-d_{0}}{d_{0}}= & \frac{1+v}{E}\left\{\sigma_{11} \cos ^{2} \varphi+\sigma_{12} \sin 2 \varphi+\sigma_{22} \sin ^{2} \varphi-\sigma_{33}\right\} \sin ^{2} \psi \\
& +\frac{1+v}{E} \sigma_{33}-\frac{v}{E}\left\{\sigma_{11}+\sigma_{22}+\sigma_{33}\right\} \\
& +\frac{1+v}{E}\left\{\sigma_{13} \cos \varphi+\sigma_{23} \sin \varphi\right\} \bullet \sin 2 \psi
\end{aligned}
$$

This is the so-called fundamental equation for $\mathrm{x}$-ray residual stress analysis. The biaxial stress model using a single in-plane stress component is sufficient to account for the full stress tensor for stress field measured in a thin layer, due to the fact that penetration depth of x-ray inside the WC material is approximately several micrometers.

This assumption can also be justified by the equilibrium conditions that the stress tensor has to obey [6]. In this case, the stress tensor is in the form of:

$$
\sigma_{i j}=\left(\begin{array}{ccc}
\sigma & 0 & 0 \\
0 & \sigma & 0 \\
0 & 0 & 0
\end{array}\right)
$$

which indicates that only in-plane components exist: $\sigma_{11}=\sigma_{22}=\sigma$. Accordingly, equation (4.8) is simplified to: 


$$
\frac{d_{\varphi \psi}-d_{0}}{d_{0}}=\frac{1+v}{E} \sigma \sin ^{2} \psi-\frac{2 v}{E} \sigma
$$

This becomes the well-known $d$ - $\sin ^{2} \psi$ method for measuring the residual stresses. $d_{\varphi \psi}$ against $\sin ^{2}$ $\psi$ plot will show a linear relationship, and the corresponding slope will be equal to $\frac{1+v}{E} \sigma$. Fig. 4.7 shows $d$ - $\sin ^{2} \psi$ plot measured for (220) peak of TiN film used in this work at eight different tilting angles. A least-squares line fitted to experimental data was drawn. To calculate the stress $\sigma$ from equation (4.10), three parameters need to be known: the unstressed plane spacing $d_{0}$, and the elastic constants $E$ and $v$, corresponding to the diffracted planes. $d_{0}$ can be measured from thermalannealed material powder in the same composition. However, in practice it may not be available; thus, it is commonly substituted by the lattice spacing assessed at $\psi=0$. Such substitution is validated by the fact that at most $0.1 \%$ difference in elastic strain between true $d_{0}$ and $d$ at any $\psi$ could be introduced. Furthermore, as $d_{0}$ is a multiplier factor for calculating stresses in equation (4.10), the total error yielded associated with this subsititution will be less than $0.1 \%$. It is negligible compared to the error caused by other sources. Elastic constants $E$ and $v$ may be obtained from the literature for a given material and its specific reflection plane. Otherwise, they can be measured experimentally or calculated from single crystal elastic constants using various approximations [5]. Elastic constants $E$ and $v$ used in this work for WC (211) peak and TiN (220) peak were obtained from reference [7].

From equation (4.10), it is derived that the measured stress is independent of the azimuth angle $\varphi$, under the assumption of a biaxial stress model. However, if the surface treatment/deposition process for thin film is asymmetric, off-diagonal stress factors may be introduced where $\sigma_{i j} \neq 0$, for $i \neq j$. In this case, it is evident from equation (4.8) that the measured results will be dependent on the azimuth angle $\varphi$. Off-diagonal stress factors are revealed such that peak position shifts with varied rotation angle $\varphi$. In order to elucidate this effect, the peak position can be measured for both positive and negative tilt angles, corresponding to $\varphi=0^{\circ}$ and $\varphi=180^{\circ}[6]$. 


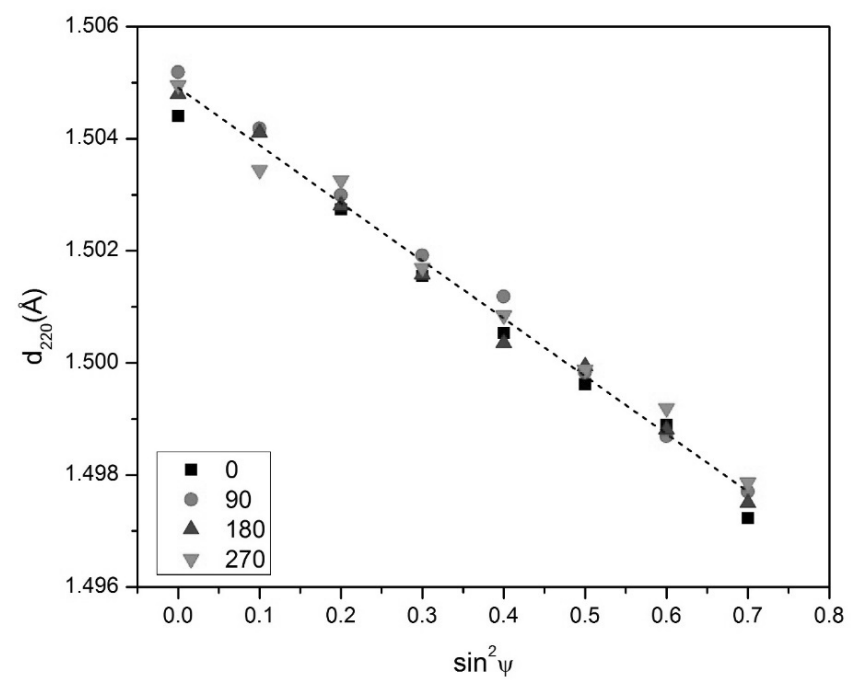

Fig. $4.7 d-\sin ^{2} \psi$ plot measured for (220) peak of TiN film. A set of tilt angles $\psi$ was selected such that $\sin ^{2} \psi$ yielded $0,0.1,0.2,0.3,0.4,0.5,0.6$, and 0.7 values. At each tilting angle $\psi$, four azimuth angles $-0^{\circ}, 90^{\circ}, 180^{\circ}, 270^{\circ}$ - were applied to rotate the sample.

\subsection{Microscopy}

Microscopy technique is a common approach in materials characterization to reveal metallography, structure, phases and composition. In this work, scanning and electron back scattered diffraction, together with transmission electron microscopy, were extensively utilized.

\subsubsection{Scanning Electron Microscopy}

Scanning electron microscopy (SEM) is intensively used in this work to characterize surface topography and cross-sectional structure, as well as fractography of the (coated) hardmetals. SEM permits the observation of a variety of materials from micrometer to nanometer scale. In SEM, a finely focused electron beam is swept in a raster across the target specimen to form images. The types of signals collected from the interaction of the electron beam and the sample surface include 
secondary electrons, backscattered electrons, characteristic x-rays, and other photons of various energies, coming from specific emission sample volume [8]. The two most interesting signals are the secondary and backscattered electrons. The former is very sensitive to the surface topography and provides contrast in the height variations. On the other hand, the latter reveals more contrast between different elemental compositions. The different images obtained from these two modes can be discerned from Fig. 2 in Paper 4.

\subsubsection{Electron Back Scattered Diffraction}

The electron back scattered diffraction (EBSD) technique is particularly implemented in this work to identify phase transformation phenomenon of the cobalt binder, considering its low content and relative small thickness between the carbides. EBSD is an accessory system attached to a SEM unit. It can provide quantitative microstructure information associated with grain size, grain boundary character, grain orientation, texture and phase identification. The spatial resolution can reach $20 \mathrm{~nm}$ with reasonable accuracy for a modern field emission SEM equipment (FE-SEM).

A typical arrangement including electron beam, sample stage and detector used in EBSD is schematically shown in Fig. 4.8 [9]. A stationary electron beam illuminates a flat sample surface which is steeply tilted (typically $70^{\circ}$ from the horizontal), in order to collect the maximum pattern

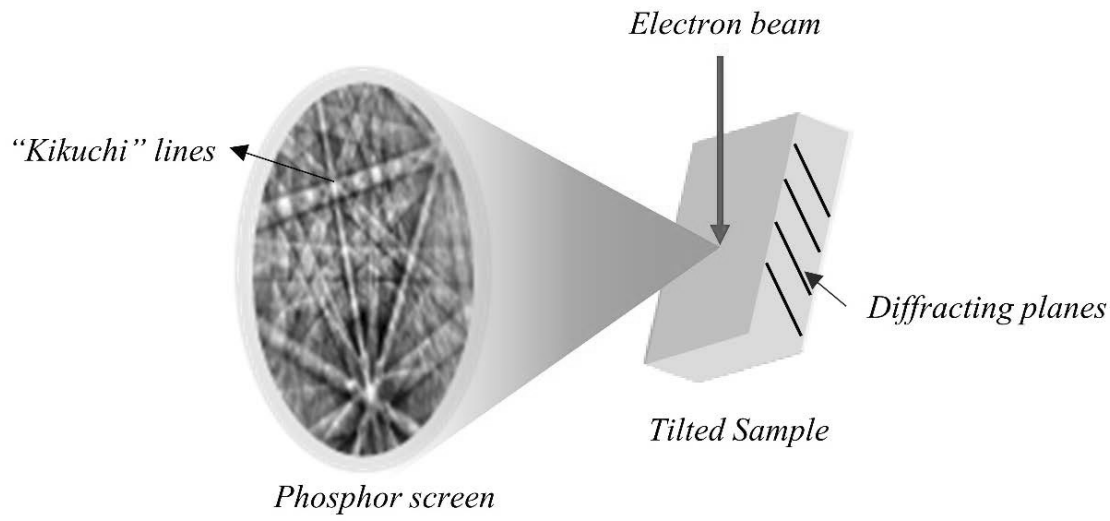

Fig. 4.8 Scheme of typical arrangement among electron beam, sample stage and detector using in EBSD. 
intensity. When the primary beam interacts with the crystal lattice of the sample, both diffraction and channeling of electrons induce the electrons to form very flat cones which intersect with a phosphor screen. As a final result, diffraction patterns are revealed. A typical EBSD pattern consists of a large number of parallel lines ("Kikuchi lines"). These lines contain unique crystallographic information, such that the line pairs represent planes within the crystal structure, and their intersecting point denotes the zone axes. These patterns are then indexed with specialized computer software (Channel 5 in this work). This is done by determining all possible orientations within each phase, and reporting the best fit as the identified phase and orientation.

EBSD maps are typically presented to interpret the specific issues of the material microstructure, such as crystal distribution of orientations, phases, grain boundaries and strain state, among others. They are comprised of “components”, based on the underlying data recorded. In this work, EBSD maps consisted of components including phases, pattern quality (band contrast) and orientation (inverse pole figure). Band contrast (BC) is a pattern quality factor related to brightness level of each diffraction band with respect to the overall background. It is affected by the diffraction intensity for a phase, dislocation/crystallographic defect density and orientation. BC maps are generally grey-scale images that appear similar to coarse SEM micrographs, showing the microstructure in a qualitative way. Grain boundaries are normally visible as poor BC quality and appear dark in the map [10]. In this work, the two allotropic structures of cobalt, fcc and hcp phases, were designated to two different colors. They were overlapped with the BC map, aiming to elucidate the phase transformation phenomena (see Fig. 3 in Paper 5 and Fig. A3.1 in Annex 3).

\subsubsection{Transmission Electron Microscopy}

Transmission electron microscopy (TEM) is an advanced characterization technique conventionally employed in materials research field for investigating microstructure (substructure) and deformation mechanisms, particularly within the submicron and nanometer length scales. These are in direct relation to the high spatial and analytical resolution of this technique, which can achieve $0.1 \mathrm{~nm}$. 
In its operation, a high voltage accelerated convergent electron beam is directed towards a very thin specimen (normally $\leq 200 \mathrm{~nm}$ ). The incident electrons interact with the specimen to form scattered (either elastic or inelastic) electrons, besides a direct transmitted beam. The wave of the electrons experiences changes in both amplitude and phase, resulting then in image contrast. Besides imaging the microstructure details, diffraction patterns (DPs) can be collected by using diffraction contrast, resulting from the difference of the diffracted beams in distinct regions of the specimen. These DPs contain direct crystallographic information in the select diffracted area. This capability is one of the most significant features of TEM, because it permits to relate crystallography features to attained images [11].

Precession electron diffraction (PED) is a new promising technique that has been developed in TEM analysis field recently. Fundamental basis behind it is that parallel incident electron beams are forced to precess rapidly on a cone surface, such that only a few reflections are simultaneously excited and dynamic effects are strongly reduced (Fig. 4.9). Hence, PED intensities are quasikinematical, likewise to x-rays, which permits “ab-initio” solving of crystalline structures $[12,13]$. The collected PED patterns can be solved through semi-automatic matching with theoretically generated templates, which is much less time-consuming than a conventional manual way. One interesting method applied with PED technique is the combined generation of the orientation/phase mapping through ultra-fast collection of precessed electron diffraction patterns, obtained on preselected area with a point spread nanoscale resolution. Indeed, the principle is analogous to the SEM based EBSD technique. However, such EBSD-like tool for TEM includes a much higher resolution (within the nanometer range), without the need of additional surface sample preparation.

In this work, PED - TEM analysis was utilized to characterize the microstructural alterations induced by grinding within the binder phase (see Fig. A3.2 - A3.4 in Annex 3). Appropriateness of using such technique was based on the consideration of the small area occupied by the cobalt phase and the severe deformation area just beneath the surface, which can be preserved by TEM lamella preparation using the focused ion beam approach. 


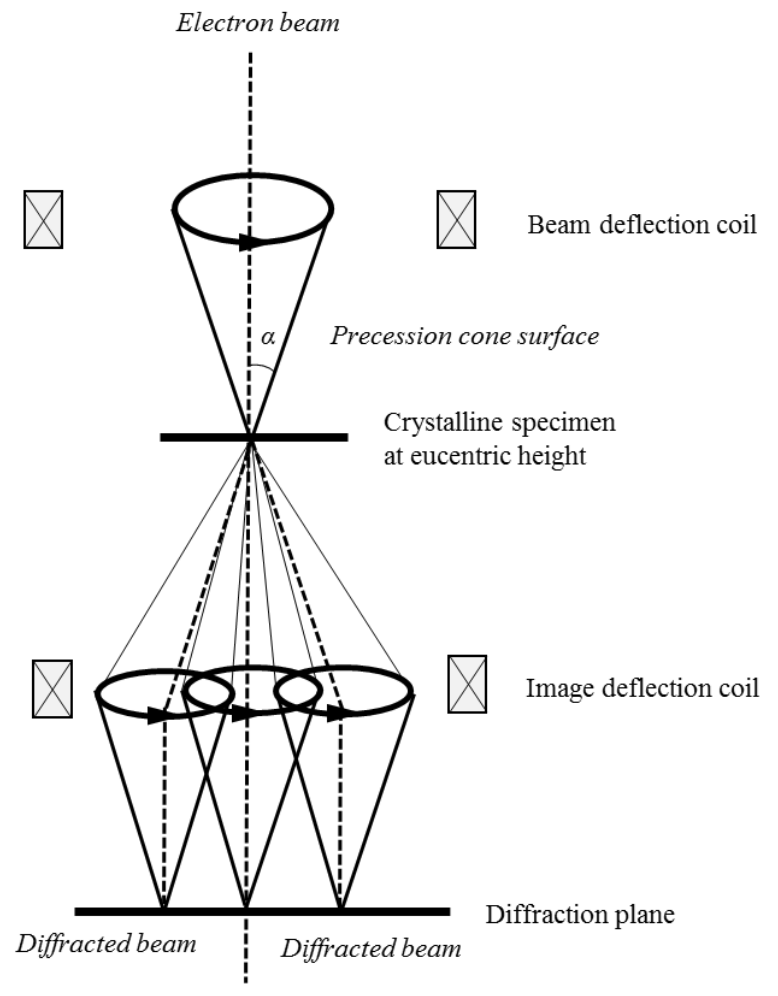

Transmitted beam

Fig. 4.9 Scheme of precession electron diffraction (PED) technique in TEM. The parallel incident electron beams are forced to precess rapidly on a cone surface.

\subsection{Focused Ion Beam and 3D Tomography}

Focused ion beam (FIB) and combined FIB/SEM dual systems are invaluable tools in materials analysis field. They can be used for in-situ observation of structural cross-sections, preparation of TEM lamella and atom probe specimens, generation of microstructural data in three dimensions, and nanofabrication of devices and prototypes [14,15]. In this work, FIB has been intensively utilized to characterize grinding and coatings effects on the subsurface features of the hardmetal 


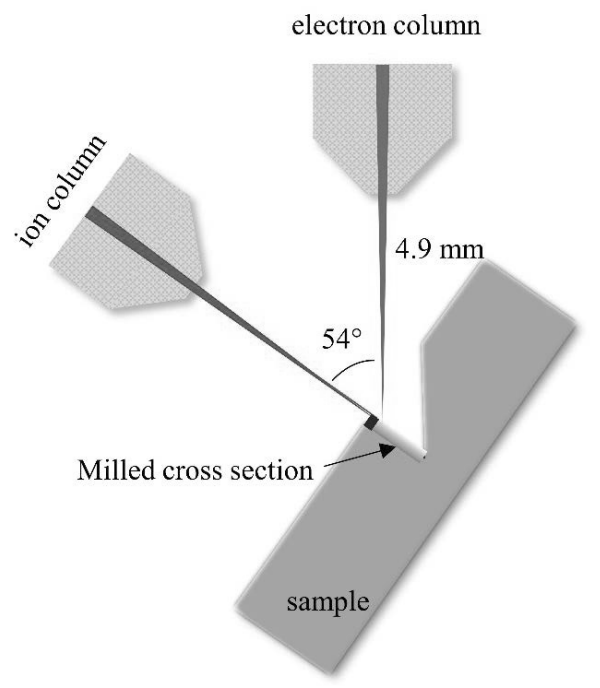

Fig. 4.10 Scheme of a dual FIB/SEM beam system configuration.

studied. Moreover, it has also been implemented for sequential image acquisition (i.e. data for 3D tomography) as well as preparation of TEM lamella.

Fundamentally, the FIB system produces and directs a stream of high-energy ionized atoms of relatively massive elements (usually $\mathrm{Ga}$ ), bombarding the target sample and sputtering atoms out of the target for etching or milling purpose [16]. In the case of a dual beam system configuration (Fig. 4.10), the electron column is mounted vertically inside the vacuum chamber, whereas the ion column aligns with the electron column at angle of $54^{\circ}$. The sample is arranged so that it lies in the coincidence point of the two beams, with a working distance of typically $4.9 \mathrm{~mm}$. In this configuration, the two beams are co-focused and the area of interest will be fixed when being tilted, as it lies in the eucentric plane. In practical operation, milling parameters are arranged under the ion beam mode, and during milling process in-situ cross-sections are directly observed using the electron beam. 


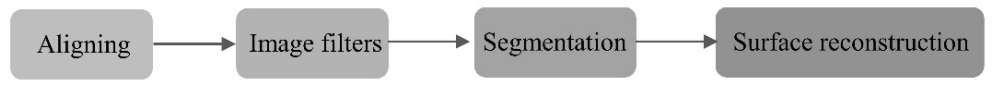

Fig. 4.11 A work flow scheme showing the 3D construction procedure in Avizo.

The dual beam system is extremely useful for generating 3-dimensional visualization of material microstructure. It is appropriated for characterizing microstructural features in the length-scale range from $\sim 100 \mathrm{~nm}$ to $10 \mu \mathrm{m}$, requires no sample preparation, and is ready to be applied to a wide range of materials. Sequential milling of layers using the ion beam and simultaneous examination of site-specific cross-sections using the electron beam, permits to gather a batch of 2D images, also called 2D tomos. Subsequently, these 2D tomos are loaded into a commercial software package (Avizo in this thesis) for 3D image reconstruction. It finally generates a 3D visualization of the volume examined. This software contains different modules that operate with data objects. A work flow scheme (Fig. 4.11) has been drawn to show the construction procedure in this work. As a first step, a data object containing all the raw data (2D tomos) is created. These images are aligned with respect to each other using an Align Slice module. Second, different filters module are applied to improve image quality, particularly in terms of reduction noise level caused by brightness variation, compensation for distortions arising from foreshortening of the images, and adjustment of grey level for a particular feature to ensure their consistency throughout the dataset. Third, different regions defined by grey ranges are segmented and assigned to a specific color. In this work, grinding-induced cracks are of particular interest. Accordingly, they are isolated out of the surrounding microstructure. In the situation when the automatic segmentation is not good enough to distinguish the cracks, manual segmentation is necessary. Finally, once all cracks in each tomo are well-defined, SurfaceGen module computes a mesh of total volume, forming a 3D view. Moreover, with some analysis modules equipped within Avizo software, it is possible to carry out some quantitative study. For example, MaterialStatistics module can be used to obtain volumetric information (volume of each region and volume per slice), and SurfaceArea module is helpful to study surface statistics of interfaces. 


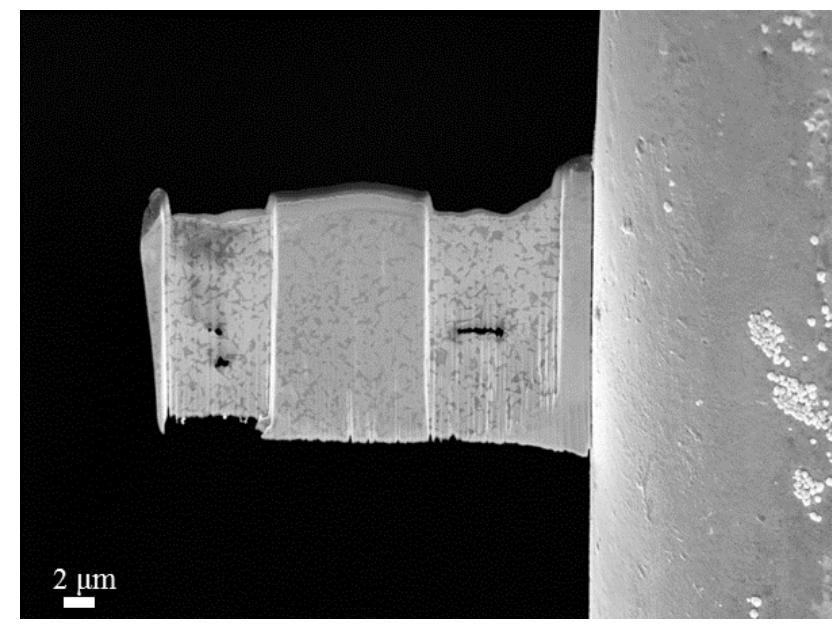

Fig. 4.12 TEM lamella prepared from the ground hardmetal sample using FIB milling approach.

Conventional method for preparing TEM lamella includes slicing and grinding of thin sections from bulk, followed by further profile thinning using ion milling or electron polishing. However, such a process could certainly alternate the ground superficial layer of the studied material, resulting in an undesirable loss of information. Moreover, because relative hardness difference between carbide and binder phases, non-uniform removal rates under mechanical polishing are usually discerned. On the contrary, FIB milling method is capable of being not only operated with extreme precision onto the area of interest, but also uniformly implemented in heterogeneous materials with a rapid processing time $[14,15]$. In this work, FIB is then employed to prepare the TEM lamella for the examination of grinding-induced microstructural changes in the subsurface layer.

The "lift-out" approach was used to prepare TEM specimens. The area of interest is selected and surface edge is protected by depositing of a Pt layer. Two trenches are milled at the front and at the back of the Pt layer to generate two sides of a membrane. A further series of mills are performed to thin this membrane. Sequentially, the membrane is removed from the milled trench using an insitu micromanipulator, and is attached to a $\mathrm{Cu}$ grid. Afterwards, this membrane is further polished 
on its two sides using very fine and gentle milling. Main objective is to leave it clean and electron transparent. Fig. 4.12 shows the TEM lamella prepared from the ground hardmetal sample and placed onto the $\mathrm{Cu}$ grid. Two regions have been milled for getting electron-transparent. However, the left one was found to be better prepared, and thus it is the one used for the TEM inspection in this work. 


\section{References}

[1] ASTM E1876-09, Standard test method for dynamic young's modulus, shear modulus, and poisson's ratio by impulse excitation of vibration. West Conshohocken, PA: ASTM International; 2009.

[2] Sheikh S, M'Saoubi R, Flasar P, Schwind M, Persson T, Yang J, Llanes L. Fracture toughness of cemented carbides: Testing method and microstructural effects. Int J Refract Met Hard Mater. 2015;49:153-60.

[3] Whitehouse DJ. Handbook of Surface Metrology, Bristol: Institute of physics publishing; 1994.

[4] Poon CY, Bhushan B. Comparison of surface roughness measurements by stylus profiler, AFM and non-contact optical profiler. Wear. 1995;190:76-88.

[5] Noyan IC, Cohen JB. Residual stress: measurement by diffraction and interpretation, Springer New York 2013.

[6] Birkholz M, Genzel C. Residual Stress Analysis. In: Birkholz M (Eds.) Thin Film Analysis by X-Ray Scattering. Weinheim: Wiley-VCH; 2006, p. 239-95.

[7] Eigenmann B, Macherauch E. Röntgenographische untersuchung von spannungszuständen in werkstoffen. Materialwissenschaft und Werkstofftechnik. 1996;27:11.

[8] Goldstein J. Scanning Electron Microscopy and X-ray Microanalysis: Third Edition, Springer US 2003.

[9] Schwartz AJ, Kumar M, Adams BL, Field DP. Electron Backscatter Diffraction in Materials Science, Springer US 2000.

[10] Maitland T, Sitzman S. Electron backscatter diffraction (EBSD) technique and materials characterization examples, Springer Berlin 2007.

[11] Williams DB, Carter CB. Transmission Electron Microscopy: A Textbook for Materials Science. New York: Springer; 1996.

[12] Rauch E, Veron M, Portillo J, Bultreys D, Maniette Y, Nicolopoulos S. Automatic crystal orientation and phase mapping in TEM by precession diffraction. Microsc Anal. 2008;22:S5S8. 
[13] Portillo J, Rauch EF, Nicolopoulos S, Gemmi M, Bultreys D. Precession electron diffraction assisted orientation mapping in the transmission electron microscope. Mater Sci Forum. 2010;644:1-7.

[14] Munroe PR. The application of focused ion beam microscopy in the material sciences. Mater Charact. 2009;60:2-13.

[15] Wirth R. Focused Ion Beam (FIB) combined with SEM and TEM: Advanced analytical tools for studies of chemical composition, microstructure and crystal structure in geomaterials on a nanometre scale. Chem Geol. 2009;261:217-29.

[16] Yao N. Focused ion beam systems: basics and applications, New York: Cambridge University Press; 2007. 



\section{Summary of The Results}

\subsection{Surface Integrity Resulting From Grinding and Subsequent}

\section{Coating}

Surface integrity becomes altered and evolves through the different process stages of hardmetal tools, i.e. from sintered state to coating of final piece. Within the manufacturing chain, substrate grinding and coating deposition represent key steps, as they are critical for defining the final performance and relative tool manufacturing cost. In this regard, this investigation addresses the influence of substrate surface integrity on different mechanical (flexural strength and contact damage resistance under spherical indentation) and tribological (scratch resistance as well as cracking and delamination response under Brale indentation) properties for a TiN-coated finegrained hardmetal grade (WC-13 wt.\%Co). In some particular case, the study is extended to another hardmetal grade with a lower binder content.

Results reported in Paper 1 indicate that grinding strongly affects surface integrity of the finegrained WC-13 wt.\%Co hardmetal studied. It is found that grinding yields roughness values one order of magnitude higher than those achieved for a reference mirror-like finish condition. At the subsurface level, it is discerned that a thin deformed/damaged layer, containing fragmented carbides and microcracks, is generated. From a stress state viewpoint, changes are also introduced in terms of relevant compressive residual stresses, with maximum levels close to -2 GPa at the surface and extending (although decreasing with depth) until subsurface levels of about $12 \mu \mathrm{m}$.

Grinding-induced surface integrity was further explored in Annex 2 and Annex 3. There, emphasis were placed on quantifying crack distribution using 3D FIB tomography and assessing cobalt phase deformation/transformation activity by means of EBSD/TEM, respectively. 3D image reconstruction reveals that: (1) a superficial tribolayer of approximately 200-400 nm in thickness, containing pulverized WC grains and smeared Co phase, is revealed; (2) microcracking beneath this superficial tribolayer is found to extend down to approximate $2.5 \mu \mathrm{m}$ depth into the bulk; and 
(3) crack distribution is highly anisotropic, with most of the cracks being lateral/near lateral ones running parallel to the ground surface. Concerning phase transformation within the binder phase, cross-section EBSD illustrates that grinding induces changes from the original fcc phase into the hcp one. It concentrates within a $5 \mu \mathrm{m}$ thick subsurface region, and decreases gradually with depth. Nevertheless, a few individual hcp grains can be observed until $10 \mu \mathrm{m}$ depth approximately. Such phase transformation can be related to distribution of the residual stresses along the specimen. Crystal orientation and phase maps for the binder phase, obtained by means of TEM using the PED technique, confirm fcc to hcp phase transformation of Co in the subsurface region. Grinding is also discerned to induce severe plastic deformation within the binder at the surface level. It leads to the formation of nanocrystalline and ultrafine grains. These experimental findings point then out the existence of a correlation between ultrafine microstructure and crack formation at the subsurface level.

In order to highlight the influence of residual stresses in ground hardmetals, a damage-like ground condition, but free of residual stresses, was generated by heat-treating some of the originally ground specimens. Surface integrity of this surface condition was also explored. Such annealing treatment may also be associated with practical implications, as hardmetals tools are usually exposed to high temperature during both processing (i.e. coating deposition) and effective operation. Results shown in Paper 1 prove that annealing at $920^{\circ} \mathrm{C}$ for $1 \mathrm{~h}$ effectively relieves the grinding-induced compressive residual stresses, leaving the undesirable damaged surface layer unchanged. Investigation presented in Paper 5, involving FIB/SEM and EBSD studies, indicates that thermal treatment also induces changes in the binder phase, as discerned by the emergence of an unexpected microporosity within the surface tribolayer together with metallurgical alterations: development of a recrystallized subgrain structure and reversal of the grinding-induced phase transformation.

Results reported in Paper 4 includes assessment of substrate microstructure by considering a second hardmetal degree with lower cobalt content (6F). First, surface integrity scenario for $6 \mathrm{~F}$ material was studied and found to be qualitatively alike to that discerned previously for 13F grade, regarding roughness, surface topography, subsurface damage and residual stresses. However, changes in roughness and altered subsurface layer seems to be less pronounced for the $6 \mathrm{~F}$ grade. 
Moreover, different from 13F material, damage in 6F grade is exclusively evidenced in terms of microcracking, running through either binder or carbides. It is suggested that differences observed between ground $6 \mathrm{~F}$ and $13 \mathrm{~F}$ samples should be related to the fact that material removal was done under same grinding conditions; and thus, less material becomes affected for the harder and more brittle grade.

After grinding, the following ion etching and coating process provides the final coated system a new surface condition. The corresponding surface integrity have been reported in Papers 2, 3, 4 and Annex 1. It may be summarized as follows: (1) as a consequence of the presence of microparticles in the TiN film (grown by cathodic arc evaporation), after coating deposition roughness values for $\mathrm{P}$ specimens rise up to levels similar to the ones assessed after grinding; (2) grinding-induced topography associated with unidirectional groove-like features is still clearly visible in the coated specimens; (3) despite ion etching (sputter cleaning process) relieves some material from the surface, grinding-induced damage was not completely removed from the substrate subsurface; (4) ion etching and coating deposition reduces the grinding-induced stresses by half degree (to -0.9 GPa level); (5) there is not any evidence of damage and/or residual stresses for both AS and P conditions, on either uncoated or coated ones; and (6) as expected for the GTT condition, residual stresses were not discerned at the substrate surface level in the coated specimens. Finally, it should be highlighted that intrinsic residual stresses of the TiN film deposited was measured as high as about -3.3 GPa, being independent of hardmetal substrate microstructure and surface finish.

\subsection{Grinding and Coating Effects on Fracture Strength}

The correlation existing among grinding, surface integrity and flexural strength is investigated in Paper 1. It is found that ground hardmetals exhibit a significant fracture strength enhancement, as compared to the reference polished condition. However, such beneficial effect may not be rationalized by superposition, at the shaped surface, of the grinding-induced residual and the externally imposed stresses. Such simple approach yields estimated fracture strength values much higher than the ones experimentally measured. Extensive fractography reveals that enhanced 
strength mainly stems from grinding-induced changes on effective location of strength controlling flaws, from the surface level into the subsurface one. On the other hand, strength improvement attained after grinding is lost after heat treating the ground specimens, as a direct consequence of the residual stress relief induced by annealing.

Coating deposition effects on mechanical strength of ground hardmetals were investigated In Annex 1. It is discerned that ion etching and subsequent film deposition processes diminish the relative strength differences among the various substrate surface finishes. On one hand, the grinding-induced strength rise is reduced because the compressive residual stresses are lessened. As a consequence, nature and location of failure initiation flaws are also changed, i.e. critical defects are now associated with grinding-induced damage at the surface level. On the other hand, strength of the coated GTT samples is increased, as compared to that determined for the corresponding uncoated ones. Such a change is postulated to occur because the large compressive residual stresses intrinsic to the deposited ceramic film.

\subsection{Influence of Grinding on Cracking and Delamination Response}

The influence of substrate surface finish on scratch resistance of coated hardmetals and associated failure mechanisms is investigated in Paper 2. The study addresses four different substrate surface finish conditions: AS, G, P and GTT. For G and GTT conditioned samples, scratch tests are conducted both parallel $(/ /)$ and perpendicular $(\perp)$ to the direction of the grinding grooves. Coated AS, G and P samples are found to exhibit similar critical loads, as related to initial substrate exposure, as well as alike failure modes (brittle - recovery spallation). However, differences are evidenced regarding failure scenario. On one hand, pronounced and continuous substrate exposure is discerned for AS and P conditions. On the other hand, G samples are characterized by rather discrete and quite localized damage features. Interfacial cracking discerned at the spallation site highlights the adhesive failure nature for coated AS, G and P surface finish conditions. Coated GTT samples shows a lower critical load and changes in failure modes: buckling cracks emerge for GTT- $\perp$ condition, and cohesive fracture through the substrate subsurface arise for GTT-// 
condition. Relative orientation between scratch and grinding direction affects the corresponding scratch response of ground and coated hardmetals. In this regard, substrate exposure tends to be more elongated and continuous as scratches are conducted parallel to the grinding groove direction. Furthermore, under these testing conditions, the probability of cohesive damage, through the substrate subsurface, increases.

Brale indentation technique is another simple and practical method widely applied for assessing adhesion of hard coated systems. In Paper 4, it is proposed and validated as an effective approach for evaluation of substrate microstructure ( $6 \mathrm{~F}$ and $13 \mathrm{~F}$ grades) and substrate surface finish ( $\mathrm{G}$ and $P$ variants) effects on the indentation response of the coated hardmetals. Aiming to understand the intrinsic influence of substrate brittleness/hardness on the indentation response of coated hardmetals, uncoated substrates were also indented under similar testing conditions. Deformation and fracture pattern evolution under the indentation is qualitatively similar in all the coated hardmetal systems studied. As load is increased, irreversible deformation, radial cracking, and finally spallation are sequentially evidenced. However, load levels at which cracking and delamination emerge, the type of cracking pattern developed, and how fracture mechanisms evolve with increasing load are clearly dependent on the substrate microstructure and substrate surface finish. As binder content decreases, polished and coated hardmetals exhibit more brittleness (radial cracking) and lower adhesion strength (coating delamination). Such microstructural effect is related to the brittleness/hardness of the substrate itself (as discerned under Brale indentation testing of uncoated substrates). Moreover, the direct relationship between substrate yield strength and effective shear stresses generated at the coating/substrate interface, during loading/unloading under elastic-plastic conditions, must be recalled for explaining the experimental findings. Concerning substrate surface finish, compared to the polished condition, grinding is found to inhibit radial cracking. However, it is accompanied by an easier delamination. Such a response is discussed on the basis of the interaction between elastic-plastic deformation during indentation and several grinding-induced effects: remnant compressive stress field, pronounced surface texture and existence of a thin microcracked subsurface region. As a final result, film delamination on ground and coated hardmetals seem to be the more effective mechanism for dissipating energy stored during elastic-plastic indentation. 


\subsection{Beneficial Grinding Effects on Contact Damage Resistance}

The contact damage resistance of coated hardmetals with different substrate surface finishes: $G, P$ and GTT is studied in Paper 3. It is done by means of spherical indentation under increasing monotonic loads. Contact response is assessed in terms of crack prevention (nucleation) and crack containment (extension). Substrate grinding is found to enhance contact damage resistance of coated hardmetals: crack emergence is delayed and its extension to the subsurface is particularly inhibited, as compared to the response exhibited with other substrate surface finishes. The discerned behavior is discussed on the basis of the grinding-induced compressive residual stresses remnant after ion-etching and coating deposition stages. This idea is supported by the finding of much deeper crack penetration on coated GTT specimens, where grinding-induced compressive residual stresses have been relieved by the heat treatment process. Moreover, the results point out that such remnant stress state overcomes the potential deleterious effect expected from surface texture (peak/valley stress raisers) or pre-existing grinding-induced damage.

Considering that crack path was observed to be less localized (and thus critical) for the G condition than for the $\mathrm{P}$ one, the interaction between grinding-induced surface integrity (especially as related to pre-existing distributed damage) and the propagating external contact-induced cracks was further analyzed. It was done by flexural testing of previously indented coated specimens. Although in both cases, it was found that ruptures were associated with indentation-induced damage, interaction between extrinsic damage and failure path were different. While rupture in the coated $\mathrm{P}$ system is characterized by going along previously identified surface ring, fracture for the coated $\mathrm{G}$ condition transverses the inner contact orthogonally (i.e., following grinding-induced grooves). As extrinsically induced damage is maximum (regarding depth and localization) in the contour periphery, these findings would point out a beneficial effect of grinding-induced changes with respect to effective damage tolerance of the coated hardmetals studied. 


\subsection{General Conclusions}

Grinding induces significant alterations in the surface integrity of the hardmetals studied. It results in high roughness and emergence of a topographic texture; anisotropic distribution of microcracks within a thin subsurface layer; severe deformation, microstructure refinement and phase transformation of binder regions; and large compressive residual stresses. Additional changes in surface integrity are induced during subsequent ion etching and coating deposition. In general, removal of material from the surface during sputter cleaning and heat treatment during film deposition resulted in a significant residual stresses decrease. However, damage induced by grinding was not completely removed, and some microcracks were still left on the substrate surface. On the other hand, high temperature annealing (GTT condition) resulted in a complete relief of the referred residual stresses, but without inducing any additional change in terms of existing microcracks and depth of damaged layer. This was not the case for the metallic binder phase where such treatment induced an unexpected microporosity, development of a recrystallized subgrain structure and reversion of grinding-induced phase transformation.

Strength of hardmetals was significantly enhanced by grinding, as compared to AS and P conditions. Such beneficial effect is partly lost during the subsequent ion etching and coating deposition stages. On the other hand, strength of coated GTT condition increases compared to that determined for the corresponding uncoated one. Systematic residual stress analysis combined with extensive fractographic inspection reveal that strength variations measured after individual manufacturing chain or heat treatment steps (grinding, ion-etching, coating and/or thermal annealing) may be rationalized on the basis of effective residual stress state and location, either at the surface or at the subsurface, of strength-controlling flaws.

Independent of substrate surface finish under consideration, coated AS, G and P samples exhibit similar critical load for initial substrate exposure as well as same predominant failure mode as they get scratched. However, clear differences in the failure scenario were evidenced. Scratch track for G samples exhibited discrete and localized substrate exposure, compared to the more pronounced and continuous exposure for AS and P ones. On the other hand, GTT samples showed lower critical 
load and changes in the mechanisms for the scratch-related failure; the latter depending on the relative orientation between scratch and grinding directions.

Coated hardmetals exhibit more brittleness and lower adhesion strength, under Brale indentation tsting conditions, with decreasing binder content. Grinding is discerned to promote delamination, compared to the polished condition, but also to strongly inhibit radial cracking. Such a response is analyzed on the basis of the interaction between elastic-plastic deformation imposed during indentation and several grinding-induced effects: remnant compressive stress field, pronounced surface texture and microcracking within a thin microcracked subsurface layer.

Contact damage resistance of coated hardmetals, subjected to spherical indentation, is enhanced by grinding of the substrate previous to coating stage. Such beneficial effects are discerned regarding both crack nucleation at the coating surface and subsequent propagation into the hardmetal substrate. The grinding-induced compressive residual stresses are pointed out as the main reason for the improved response against contact loading. Such statement is sustained by the lower damage resistance evidenced in coated GTT specimens. 


\section{Contributions and Future Work}

Main contributions of this thesis to the field, in the author's opinion, are the following:

- Specific surface integrity changes ascribed to each stage within the manufacturing chain of coated hardmetal tools are documented, analyzed and understood. Furthermore, investigation includes a systematic and comprehensive analysis of the influence of such surface integrity - manufacturing stage correlation on different mechanical and tribological properties. This information is critical for defining final performance and relative manufacturing costs of coated hardmetals in tool and component applications.

- Advanced characterization techniques have been successfully implemented on the characterization of surface integrity as well as on the evaluation of mechanical and tribological response of coated hardmetals. On the microstructural and damage characterization side, such techniques include 3D tomography and image reconstruction, FIB/FESEM, XRD, EBSD and TEM (including PED). On the other hand, nanoindentation, microscratch, conical and spherical indentation, fully-articulated (four-point) flexural testing, stress-relief thermal treatments, use of samples with artificial interfaces (BIT) are some of the protocols and techniques employed for assessment of mechanical and tribological parameters. They allowed to overcome relevant difficulties on the characterization of the studied materials, including binder-related features, cracking distribution, and failure micromechanisms, among others.

- Ground hardmetals are exposed to high temperatures during both processing (e.g. coating deposition) and effective application (e.g. as a cutting tool). From this perspective, surface integrity characterization of ground plus thermal treated (GTT) condition in this work, particularly regarding features associated with the metallic binder, provides novel knowledge on the synergic influence of service and manufacturing conditions on final performance. 
Future Possible ideas for future work may be summarized in the following three issues:

- Assessment of surface integrity - manufacturing - performance correlation on the basis of additional mechanical and tribological parameters. Within this context, fatigue response should be highlighted as cyclic loading is frequently involved in applications of coated hardmetals.

- Consideration of environmental effects as an additional variable. This could include either lubricants for reducing friction or corrosive media within the given application.

- Evaluation and analysis of the influence of secondary surface treatments, either mechanical or thermal, at both coating and substrate (previous to film deposition) levels, on the correlations here determined. 


\section{Papers}

The articles associated with this thesis have been removed for copyright reasons. For more details about these see:

http://urn.kb.se/resolve?urn=urn:nbn:se:liu:diva-127341 